\title{
CAN INCENTIVES TO INCREASE ELECTRICITY USE REDUCE THE COST OF INTEGRATING RENEWABLE RESOURCES
}

\author{
Laura Mørch Andersen \\ Lars Gårn Hansen \\ Carsten Lynge Jensen \\ Frank A. Wolak \\ Working Paper 25615 \\ http://www.nber.org/papers/w25615 \\ NATIONAL BUREAU OF ECONOMIC RESEARCH \\ 1050 Massachusetts Avenue \\ Cambridge, MA 02138 \\ February 2019
}

We are grateful to Innovation Fund Denmark, the University of Copenhagen, and the Program on Energy and Sustainable Development at Stanford University for supporting the research leading to this paper. The views expressed herein are those of the authors and do not necessarily reflect the views of the National Bureau of Economic Research.

NBER working papers are circulated for discussion and comment purposes. They have not been peerreviewed or been subject to the review by the NBER Board of Directors that accompanies official NBER publications.

(C) 2019 by Laura Mørch Andersen, Lars Gårn Hansen, Carsten Lynge Jensen, and Frank A. Wolak. All rights reserved. Short sections of text, not to exceed two paragraphs, may be quoted without explicit permission provided that full credit, including $\odot$ notice, is given to the source. 
Can Incentives to Increase Electricity Use Reduce the Cost of Integrating Renewable Resources Laura Mørch Andersen, Lars Gårn Hansen, Carsten Lynge Jensen, and Frank A. Wolak NBER Working Paper No. 25615

February 2019

JEL No. C93,L51,L94,Q41

\begin{abstract}
$\underline{\text { ABSTRACT }}$
We report results from a large field experiment that with a few hours prior notice provided Danish residential consumers with dynamic price and environmental signals aimed at causing them to shift their consumption either into or away from certain hours of the day. The same marginal price signal is found to cause substantially larger consumption shifts into target hours compared to consumption shifts away from target hours. Consumption is also reduced in the hours of the day before and after these into target hours and there is weaker evidence of increased consumption in the hours surrounding away target hours. The same into versus away results hold for the environmental signals, although the absolute size of the eects are smaller. Using detailed household-level demographic information for all customers invited to participate in the experiment, both models are re-estimated accounting for this decision. For both the price and environmental treatments, the same qualitative results are obtained, but with uniformly smaller quantitative magnitudes. These selection-corrected estimates are used to perform a counterfactual experiment where all of the retailer's residential customers are assumed to face these dynamic price signals. We find substantial wholesale energy cost savings for the retailer from declaring into events designed to shift consumption from high demand periods to low demand perio ds within the day, which suggests that such a pricing strategy could significantly reduce the cost of increasing the share of greenhouse gas free wind and solar electricity production in an electricity supply industry.
\end{abstract}

Laura Mørch Andersen

Institute of Food and Resource Economics

Rolighedsvej 23, DK-1958

Frederiksberg

Copenhagan

Denmark

lma@ifro.ku.dk

Lars Gårn Hansen

Institute of Food and Resource Economics

Rolighedsvej 23, DK-1958

Frederiksberg

Copenhagan

Denmark

lgh@ifro.ku.dk
Carsten Lynge Jensen

Institute of Food and Resource Economics

Rolighedsvej 23, DK-1958

Frederiksberg

Copenhagan

Denmark

clj@ifro.ku.dk

Frank A. Wolak

Department of Economics

Stanford University

Stanford, CA 94305-6072

and NBER

wolak@zia.stanford.edu 


\section{Introduction}

An increasing number of jurisdictions have implemented policies to increase significantly the share of renewable energy serving their electricity demand. These goals are being met primarily with wind and solar energy. Depending on availability of the underlying wind or solar resource, the amount of electricity produced by these generation units can change dramatically throughout the day. In contrast, the aggregate demand for electricity typically follows a smooth pattern throughout the day, starting at its lowest point in the early morning and steadily increasing during the daylight hours and eventually peaking during the late afternoon or early evening, depending on the season of the year. This difference between the pattern of aggregate demand and the pattern of renewable energy production throughout the day can create a substantial imbalance between the hourly supply and demand of electricity, particularly as the share of intermittent renewable generation capacity in a region increases.

This potential for significant positive and negative supply-demand imbalances substantially changes the role of active participation of consumers in wholesale electricity markets. Historically, the role of demand response in regions dominated by dispatchable thermal generation units was to reduce aggregate demand below the available supply of electricity. However, in regions with significant intermittent renewable generation capacity, there can be many hours when the amount of energy produced by these resources can exceed system demand. For example, if there is enough wind capacity that produces primarily during hours of the day when demand is low, some of the energy produced may need to be curtailed or exported outside the region in order to maintain system balance. Even a region that primarily relies on solar energy that produces during the high demand hours of the day, as appears to be the case in California, could face the same challenge if there is enough solar generation capacity. These reliability challenges imply a new role for active demand-side participation in shifting demand from hours with less renewable energy production to hours with more renewable energy production.

This paper presents the results of a field experiment aimed at exploring the economic potential of this new role for active participation of final consumers in wholesale electricity markets. We provided residential consumers from SE, a large Danish retailer, with dynamic price and environmental signals aimed at causing them to shift their consumption into certain hours of the day or away from certain hours of the day. Consumers were notified of these price and environmental signals through text messages to their cell phones. The amount of prior notification typically varied from 2 hours to 5 hours. For price signals, customers were offered rebates on their electricity bill that depended on the total amount of electricity they moved either into or away from the targeted hours. Specifically, customers could receive a 5 percent, 20 percent, or 50 percent rebate off of the price they paid for electricity for each $\mathrm{kWh}$ of energy they managed to either shift away from the target hours or shift into the target hours. For the purely environmental motivation signals, customers were told that SE would ensure greenhouse gas (GHG) emissions-free production of all electricity consumption that they shifted, but were not offered any financial compensation.

Although a random sample of SE's residential consumers were invited to participate in each of the experiment treatments, only those that accepted the invitation actually participated in the experiment. Consequently, we employ a version of the Ahn and Powell (1993) 
semiparametric estimator of the single index selection model to account for the joint determination of customer's decision to participate in the experiment and their willingness to shift their demand in response to text messages during the experiment period. We estimate a nonparametric conditional mean function for a customer's decision to participate in the experiment using household-level demographic data from Statistics Denmark and this conditional mean function enters nonparametrically in the customer's electricity consumption equation in order to recover selection-corrected estimates of the impact of into and away notifications during our experiment period.

For both the empirical analysis that conditions on participation in the experiment and the empirical analysis that accounts for self-selection into experiment, we find that the same marginal price signal produces a two to three times larger in absolute value estimated load shift into target hours relative to the absolute value of the estimated load shift away from target hours. We also find strong evidence that load shifts into a set of target hours significantly reduces consumption in the hours of the day before and after these target hours. For the away-from target hours, we find some evidence of slight increases in consumption in hours of the day that surround the target hours. The purely environmental signals produced qualitatively similar results. The absolute value of the shift-into effect is significantly larger in absolute value than the shift-away effect and there is stronger evidence that shifting consumption into a time interval reduced consumption in surrounding time periods than is the evidence that shifting consumption away from a time-interval increased consumption in the surrounding time periods. Accounting for the decision of each invited SE household to accept the invitation to participate in the experiment yields absolute magnitudes for each of the effects that are smaller in absolute value. This result is consistent with the logic that the households that accepted the invitation to participate in the experiment, are those among the population of invited households that expected to derive the greater economic or environmental benefits from participation in the experiment.

We perform a counterfactual analysis using our selection-corrected estimates to assess the wholesale energy purchase cost savings to the retailer from declaring an into or away event for all of its residential customers. We then take the estimated aggregate residential demand change for each hour impacted by the into or the away event and shift the aggregate hourly day-ahead market demand curve in the Nordpool wholesale electricity market by this amount and compute a counterfactual market price by intersecting it with the aggregate hourly offer curve in the day-ahead market in the Nordpool. We then compute the wholesale energy cost savings as the difference between the sum of the original day-ahead price times the utility's residential demand during each affected hour less the sum of the counterfactual market price times the counterfactual residential demand (both of which reflect our estimated demand response) during the same hours. We find that assuming the estimated demand changes for a 20 percent rebate into event, daily wholesale energy purchase cost saving can be as high as 100,000 Euros. Because the demand changes associated with away events are significantly smaller in absolute value, the potential daily wholesale energy cost savings from away events can be significantly smaller for the same day. These results emphasize the cost-effectiveness of into events in maintaining real-time system balance in regions with significant intermittent renewable generation units.

Finally, we present a simple model of household electricity demand under uncertainty that can 
explain the difference in the magnitude of the average consumption shift in response to into versus away events. This model exploits the "option to quit" identified in Wolak (2010) associated with rebate-based dynamic pricing plans relative to pure dynamic pricing plans. Specifically, under a rebate-based dynamic pricing plan if the customer is unable to reduce her consumption below the level necessary to receive a rebate during a shift-away period then she can pay for all of the electricity she consumes at the standard fixed retail price. In contrast, a customer on a traditional dynamic pricing plan pays the higher dynamic price for all consumption during a shift-away period and does not have the option to avoid paying this higher marginal price. This "option to quit" is far less relevant for into events, because customers are more likely to be able to exceed the level of consumption necessary to receive a rebate with some advance notice than they are to be able to reduce their consumption below the level necessary to receive a rebate during away events. As the model demonstrates, this "option-to-quit" can explain the larger in absolute value treatment effect for into events versus away events for both the price and environmental motivation treatments.

The remainder of the paper proceeds as follows. The next section presents two examples of the economic benefits of both into and away load-shifting in regions with significant renewable intermittent generation resources. Section 3 places the present paper in the context of the existing literature on dynamic pricing. Section 4 describes the experimental design and the data collection process for the experiment. Section 5 presents our econometric modeling framework and estimation results. Section 6 presents the results of our counterfactual analysis of the wholesale purchase cost savings from SE adopting these dynamic pricing plans for all of their residential customers. Section 7 presents our model of customer demand under uncertainty that rationalizes the difference in our empirical results for into versus away events. Section 8 discusses possible extensions and implications of these results for the active involvement of final demand in regions with significant intermittent renewable generation capacity.

\section{The Economics of Load-Shifting with Significant Renewable Generation Capacity}

This section motivates our experiment by describing two examples, one from Denmark and one from California, of how significant amounts of renewable generation capacity in a region increases the need for the load-shifting actions of electricity consumers both into and away from certain hours of the day. As we demonstrate in Section 6, different from the case of regions with only dispatchable thermal generation, increasing electricity consumption during certain hours of the day can reduce the cost of meeting a given renewable energy goal, particularly if this increase in consumption reduces consumption during other hours of the day, as is the case with our into events.

Figures 1(a) and 1(b) illustrate the challenges facing Denmark in managing a grid with more than 30 percent of the electricity coming from intermittent wind generation units. Figure 1(a) displays the pattern of wind generation and aggregate electricity consumption and Figure 1(b) the Danish wholesale price in Euros per megawatt-hour (MWh) for the period January 13 to 19, 2014, right before the start of our experiment. Figure 1(a) shows the smooth pattern of aggregate consumption throughout the day and across days of the week. In contrast, the total output of wind generation units is extremely irregular both within the day and across days of the week. There are hours when almost no wind energy is produced and hours when wind energy production exceeds Denmark's electricity consumption. 
Wholesale prices in Denmark are typically negatively correlated with the amount of wind energy produced. This relationship occurs because the difference between total consumption and renewable energy production must be met with dispatchable generation that is costly to operate, typically because it requires burning an input fossil fuel to produce electricity. This logic implies that increasingly expensive fossil fuel-fired generation units must operate the larger the difference is between system demand and renewable energy production. Therefore, shifting demand into hours with high levels of wind generation and away from hours with low wind generation has the potential to reduce wholesale energy purchase costs because customers would be buying more energy in low-priced hours and less energy in high-priced hours. Our counterfactual analysis reported in Section 6 finds that these actions can yield significant wholesale purchase cost savings for consumers and the retailer that serves them.

Volatility in the difference between total electricity consumption and total renewable energy production is not unique to Denmark. California has a renewables portfolio standard (RPS) that requires 33 percent of the state's electricity consumption to come from qualified renewable sources - primarily solar, wind, biomass, geothermal, and small hydro - by 2020. This share is required to increase to $50 \%$ by 2030 . Solar generation capacity is currently thought to be the primary technology that will be used to meet these renewable energy goals. There is currently more than 11,000 MW of grid-scale solar capacity in California and almost 8,000 MW of distributed solar capacity. ${ }^{2}$ This has given rise to Figure 2, which shows the expected net-of-renewables load curve-total system demand for the California Independent System Operator (ISO) control area less expected total renewable energy output in the California ISO control area for each hour of the day-for different amounts of solar generation capacity in California. This net-of-renewables load curve is called the "Duck Curve" because of its shape within the day. Both the morning ramp up and evening ramp down of solar production are increasingly steep as the amount of solar generation capacity in the state has increased over time.

The right panel of Figure 2 shows the magnitude of net load changes during four periods of the day. The net load changes in the 7 am to 10 am and $5 \mathrm{pm}$ to $8 \mathrm{pm}$ time periods have grown substantially as the amount of solar generation capacity in California has increased. This figure shows the increasing potential economic benefit from shifting consumption into the 10 am to $5 \mathrm{pm}$ time period as California continues to increase its solar generation capacity. Shifting consumption into the daylight hours and away from the evening and early nighttime hours can save consumers on their wholesale energy purchases, by the same logic as described above for Denmark. Hours with high renewable energy production typically have low wholesale prices and hours with low renewable energy production typically have higher wholesale prices.

In 2020 and beyond, during the hours when California's solar generation capacity is producing a substantial amount energy, there is a significant risk that total renewable energy production will exceed electricity consumption in the California ISO control area. When this happens, real-time prices are likely to be negative. Consequently, further wholesale energy cost savings are possible if consumers are able to shift their consumption into the hours of the day when this over-generation condition occurs. Consumers could even be paid to consume electricity during periods with

\footnotetext{
${ }^{2}$ California Energy Commission-Tracking Progress, December 2018, available at https://www.energy.ca.gov/ renewables/tracking_progress/documents/renewable.pdf
} 
negative prices.

Sustained periods of renewable energy production in excess of system demand are very likely to occur in California given its ambitious renewable energy goals. A simple rule of thumb is that if the RPS share exceeds the capacity factor of the renewable generation technology used to meet it, then there is a potential for an over-generation condition that could be addressed by customers shifting their demand into hours when renewable energy production is likely to be the highest. To illustrate this point suppose that demand in a region is $100 \mathrm{MWh}$ every hour of the year. Obtaining the mandated 33 percent annual renewable energy share from a technology with a 20 percent capacity factor will require at least $33 \mathrm{MW} / 0.20=165 \mathrm{MW}$ of solar PV capacity, assuming no curtailment of renewable energy production during the year. ${ }^{3}$ This means all hours in the year with an hourly capacity factor for all solar PV units over $0.606,100 \mathrm{MWh}=165 \mathrm{MWh}$ $\mathrm{x}$ 0.606, will produce more solar energy than system demand. The fleet-wide capacity factor for solar photovoltaic (PV) generation units in California is approximately 20 percent. This implies that if solar energy is the major renewable generation source used to meet the 33 percent RPS, then without significant investments in storage capacity there will be many hours of the year when total solar PV production exceeds total electricity demand in California. ${ }^{4}$

There are three major factors motivating our real-time pricing and information provision experiment to shift consumption with short notice via text messages. First, an increasing number of countries and regions have the ambitious renewable energy goals. Consequently, real-time pricing and information provision mechanisms to cause consumers to shift-their consumption both into certain hours of the day and away from other hours of the day are likely to be part of a cost-effective strategy for achieving these renewable energy goals. Second, because the amount of energy produced by wind and solar generation units can change with little advance notice, to be most effective at managing the supply and demand imbalances caused by intermittent renewable energy production, customers on dynamic pricing or other load-shifting plans must respond with short notice. Third, the popularity of rebate-based dynamic pricing plans with customers and regulators emphasizes the need to understand the relative effectiveness of different rebate-based dynamic pricing programs.

\section{Relation to Existing Research on Dynamic Pricing and Load-Shifting}

A number of studies have used randomized controlled experiments to investigate demand effects of various dynamic pricing schemes (e.g. Ito et al. (2018), Jessoe and Rapson (2014), Allcott (2011), Wolak (2010), Herter (2007), Lijesen (2007), Wolak (2006) and studies reviewed in Kessels et al. (2016) and Faruqui and Sergici (2010)). The main focus of this literature is on lowering peak load demand and the consensus is that critical peak pricing (CPP) schemes can effectively reduce demand in peak periods. There are five ways that we believe our experiment adds to this research.

\footnotetext{
${ }^{3}$ The annual capacity factor of generation unit is the ratio of annual MWh produced by the generation unit divided by the capacity of the unit multiplied by the number of hours in the year.

${ }^{4}$ California has significant interconnection capacity with the rest of the western United States, so it can export energy if in-state demand is less than in-state energy production up to the amount of this transmission capacity.
} 
First, most previous research studied day-ahead notifications of the need to reduce demand with Jessoe and Rapson (2014) being an exception where a 30-minute prior notice is tested. Our experiment uses text messages provided via a cell phone with short notice and so adds to the literature on short notice effects. Short notice effects are especially relevant for evaluating the potential of demand response to mitigate imbalances caused by variations in renewable energy production.

Second, we focus on explicit incentives to consume more electricity during certain time periods. Virtually all previous research on variable pricing schemes focuses on reducing demand during certain critical time periods. We are not aware of any other studies of incentives to increase electricity consumption during certain time periods. This approach to dynamic pricing and load-shifting is directly relevant to addressing periods of over-supply likely to occur because of large amounts of intermittent renewable generation capacity in a region.

Third, we study the question of how incentives to move electricity consumption into and away from target hours affects consumption in neighboring hours both between the time a customer is notified of an intervention and the target time period, as well as a period of time after the target period. This pre- and post-event load-shifting turns out to be important for calculating the overall benefits and costs of different approaches to managing renewable energy supply and system demand imbalances during the day.

Fourth, peak period rebate schemes are popular with consumers and utilities as an alternative to traditional dynamic pricing schemes, most likely because of the fear among regulators that dynamic pricing schemes can imply substantial wealth transfer among electricity consumers (Borenstein, 2007). Yet, only a few studies have investigated rebate schemes (e.g. Wolak (2006) and Wolak (2010)). Our experiment implements load-shifting (both increases and decreases) incentives using rebates.

Finally, we consider both financial incentive and environmental motivation interventions to move electricity consumption into and away from the target time intervals. We add to the literature where Ito et al. (2018) as far as we know is the only other study comparing the effects of financial incentives on electricity demand with the effects of pro-social motivation.

\section{Description of Experiment and Data Collected for Empirical Analysis}

The experiment was conducted in collaboration with the energy company $\mathrm{SE}^{5}$ one of the largest electricity retailers in Denmark. Participants were recruited through e-mails sent to customers that had given SE permission to contact them by e-mail ${ }^{6}$. In April 2015, an e-mail informed these customers of a new SE program called MOVEPOWER. In the e-mail a randomly selected set of customers were told that they could earn a rebate if they moved their energy consumption into or away from particular time slots and that information about the relevant time slots would be sent to them though a text to their cell phone (see an English translation of e-mail text in Appendix B-2).

\footnotetext{
${ }^{5} \mathrm{SE}$, https://www.se.dk/

${ }^{6}$ For this part of the experiment, e-mail invitations were sent to the 23,935 customers randomly selected from SE's database identified as residential households. This e-mail contact database contains 36,083 residential households out of SE's more than 247,000 residential customers in southern Denmark.
} 
The remaining randomly selected customers were told that SE would ensure GHG emissions-free production of the energy they moved in accordance with the text messages they received (see e-mail text in Appendix B-3).

The SE-customers contacted by e-mail were randomized across seven different treatments. The customers receiving the financial incentive e-mail were randomly offered a $5 \%, 20 \%$, or $50 \%$ rebate on all energy moved in accordance with the text messages (calculated based on SEs wholesale electricity price regardless of the price paid by the customer). Customers receiving the GHG emissions-free production e-mails, were randomly assigned to four types of messages promising that all energy moved in accordance with the text messages led to a commitment by SE to increase investments in GHG emissions-free energy production that matched the amount of energy moved. The four environmental motivation treatments only reflect slight differences in the wording of how this information was conveyed to the consumers. Consequently, which of the three rebate groups or the four environmental motivation treatments a customer is assigned to is the result of the initial invitation to participate in the experiment they were sent and their decision to accept or reject this invitation.

To participate in the experiment, customers were asked to click on a link in the e-mail to a dedicated SE-website where they were asked to inform SE of the cellphone number to which text messages should be sent and given additional information (see Appendix B-4 to B-6 for more details). Here they were also told that the program would be evaluated by researchers after the first year and that rebate payment and GHG-free energy investments for the first year would be made at that time. In total, 735 customers signed up for the rebate-based program and 1,061 customers signed up for the GHG emissions-free energy program.

The first text messages were sent on the June 4, 2015 and the experiment was terminated on February 7, 2016. ${ }^{7}$ Customers were prompted via text messages to their cell phones a few hours in advance on the same day they were supposed to move energy. Customers were notified an average of 1.2 times per week of the three-hour time slots in which a rebate could be earned. The text message notified them of the target time slot and whether they should move energy into or away from the target time slot that day in order to earn the rebate or ensure GHG emissions-free electricity production. The text message also reminded them of the rebate percent on the standard rate that they would earn or the GHG emissions-free energy production they would ensure by moving energy in accordance with the text message (see the Appendix C. for English translations of sample text messages).

The target time slots for into and away from events for each participating customer varied randomly across the days of the week, between different 3 hour time slots (10 am to $1 \mathrm{pm} ; 3 \mathrm{pm}$ to $6 \mathrm{pm} ; 6 \mathrm{pm}$ to $9 \mathrm{pm} ; 9 \mathrm{pm}$ to $12 \mathrm{am}$, and 12 am to $3 \mathrm{am}$ ). The amount of prior notification typically varied from 2 hours to 5 hours in advance of the target 3-hour time slot. All peaks were randomly assigned to require moving consumption into or moving consumption away from the target 3-hour time slot. All consumers had interval meters that recorded their hourly consumption each day,

\footnotetext{
${ }^{7}$ The part of the experiment we report results for here was terminated at this date and the dataset used in our empirical analysis ends on this date. After this date some participants were subject to other interventions before the overall experiment was terminated in May of 2016.
} 
making it possible to calculate their consumption during the relevant into and away time slots.

Each month customers received an e-mail with feedback comparing their performance at moving their consumption with that of other participants (see Appendix D). However, it was not possible for customers to deduce how much energy they had actually moved during a given month from this relative feedback. Customers were not informed of their actual rebate earnings nor of the actual quantity of energy moved prior to February 7, 2016. They were also not informed about precisely how SE would calculate how much energy they had moved or how much rebate they had earned $^{8}$.

After the experiment was terminated, rebates were calculated and the amount of $\mathrm{kWhs}$ of GHG emissions-free energy production due each customer. Rebates were then paid to costumers and earned GHG emissions-free $\mathrm{kWh}$ reported. We estimated energy movement for each customer using a variant of the model estimates described below. However, because these estimates for individual households were based on a statistical model, we rounded up rebate refunds and credited GHG emissions-free $\mathrm{kWh}$ so that most people were actually paid or credited GHG emissions-free energy in excess of what they rationally would have expected. However, this (positive surprise) was not announced to them before or during the experiment and so it could not have affected the participant's behavior during the experiment. All communication with customers from the initial recruitment e-mail to text messages and feedback was done by SE through their mail server and text message service using their letterhead and logo. ${ }^{9}$ At the end of the experiment customers were informed that the MOVEPOWER program would not be continued.

Table 1 presents summary statistics on the number of households participating in the three rebate treatments and the average number of treatment and non-treatment days for each of three different rebate level treatment groups. ${ }^{10}$ Table 2 presents the same summary statistics for the four environmental motivation treatment groups ${ }^{11}$. As shown in Appendices B-5 and B-6, these groups differ only slightly in wording of the supplementary information provided just after the initial invitation, whereas all of the initial e-mail invitations were identical for the groups 31, 34, 35 , and 36.

\section{Estimation Procedure and Empirical Results}

In this section we estimate a number of average treatment effects for each of the three rebate groups and the four environmental motivation groups. We first estimate the average treatment effect for the population of customers that decided to participate in our experiment. We then

\footnotetext{
${ }^{8}$ Customers could contact SE's help desk who had dedicated service personal who had been instructed about the experiment who registered all questions and answers. No one contacted the help desk about the size of their earned rebates or GHG-free energy production or how these magnitudes were calculated.

${ }^{9}$ All communications with SE's costumers were approved by the marketing division of SE. Customers with questions could contact SE's help desk, which had dedicated customer service personal who were familiar with the experiment. As noted above, customers were informed that the scheme would be evaluated by researchers and possibly discontinued after the first year.

${ }^{10}$ The number of participants in these treatments-624-is lower than the 735 who signed up because we randomly selected some of these customers for other interventions.

${ }^{11}$ The number of participants in these treatments-792-is lower then the 1,061 who signed up because we randomly assigned some of these customers to other interventions.
} 
examine the extent to which our results change when we account for the self-selection of SE customers to participate in the experiment using the semimparametric Ahn and Powell (1993) estimator. We estimate both models separately for the sample of rebate customers and the sample of environmental motivation customers.

The average treatment effect for the populations of customers that decided to participate in our experiment can be recovered from a difference-in-difference estimator because customers in each of the three rebate treatment groups are randomly assigned to receive treatments (via text messages) across and within days and customers in each of the four environmental motivation treatment groups are randomly assigned to receive treatment (via text messages) across and within days. This implies that customers in each of the two samples not experiencing a treatment event in that time interval or day are serving as the "control" group used to estimate the treatment effect for that day. This logic implies that these difference-in-difference estimation procedures are recovering the average treatment effect for customers receiving rebates and the average treatment effect for customers receiving the environmental motivation intervention for the population of customers that participated in the two experiments.

To estimate the selection-corrected estimates of the treatment effects for the population of SE residential customers for an into or away event for the rebate and environmental treatment groups we estimate a flexible model for the conditional mean of the binary decision of an invited household to participate in the experiment as a function of a variety of household-level demographic characteristics compiled by Statistics Denmark. Following the procedure outlined by Ahn and Powell (1993), we use the fitted value of this conditional mean function and the assumption of continuity of the underlying selection function in this conditional mean of the decision to participate in the experiment to estimate six into and away coefficients nonparametrically controlling for the selection mechanism. As discussed in the following section, the six coefficients are the away and into effects and the before and after effects for both away and into events.

\subsection{Treatment Effects for Rebate Experiment Population}

Because we are interested in quantifying whether into events cause reduced consumption in periods that surround a treatment period and whether away events cause increased consumption in periods that surround a treatment period, for each rebate group we define six indicators, three for the into-treatment and three for the away-treatment. The first variable, $A w a y_{\text {ritd }}$, is equal to 1 for rebate level $r$ ( $r=5$ percent, 20 percent and 50 percent), if customer $i$ in time period t, of day $d$ received an away notification for that time period and day, and the variable is equal to zero for all other time periods in the sample. The second variable, BeforeAway ${ }_{\text {ritd }}$, is equal to 1 for all time periods after an away notification was sent to consumer $i$ with rebate level $r$ and before the actual away time period occurred for this customer and is equal to zero for all other time periods in the sample. The third variable, AfterAway ${ }_{\text {ritd }}$, is equal to 1 for as many hours after the away

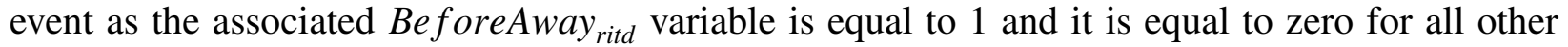
time periods in the sample. The idea of including the BeforeAway ritd and AfterAway ritd $_{\text {variables }}$ in the regression is to determine if shifting energy consumption away from a given time period during an away event within the day leads to higher or lower consumption immediately after being notified of the event up to the event time period and after the away event for a time period equal to 
the same length of time as the amount of advance notice the customer received for this away event.

Three analogous variables are defined for the into events. The variable, Into ritd $_{\text {is }}$ equal to 1 for rebate level $r$ if customer $i$ in time period $t$ of day $d$ received an into notification for that time period and day and equal to zero for all other time periods in the sample. Be fore Into $o_{\text {ritd }}$ is equal to 1 for all time periods after an into notification was sent to consumer $i$ with rebate level $r$ and before the actual into time period occurred for this customer and is equal to zero for all other time periods in

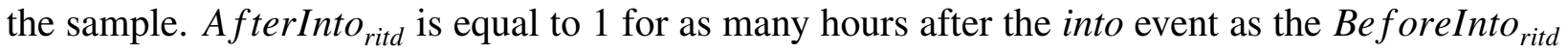
variable was equal to 1 for the same into event and is equal to zero for all other time periods in the sample. Again, these variables are included to determine if shifting energy into a given time period leads to lower or higher consumption immediately after being notified of the event up to the event time and after the into event for a period of time equal to amount of advance notice the customer received for this into event.

For the purposes of the experiment, the day is divided into 9 time periods, $t=1,2, \ldots, 9$. They are: 3 am to 6 am, 6 am to 7 am, 7 am to 10 am, 10 am to 1 pm, 1 pm to 3 pm, 3 pm to 6 pm, 6 pm to $9 \mathrm{pm}, 9 \mathrm{pm}$ to $12 \mathrm{am}$, and $12 \mathrm{am} 3 \mathrm{am}$. Treatment events for both the rebate and environmental motivation samples were only declared during the 10 am to $1 \mathrm{pm}$ period and the last four 3-hour time periods.

Let $y_{i t d}$ equal the natural logarithm of electricity consumption in kilowatt-hours $(\mathrm{kWh})$ by customer $i$ during period $t$ of day $\mathrm{d}$. In terms of this notation, we estimate the following regression for each of the three samples of rebate customers, $r=5 \%, 20 \%$, and $50 \%$ :

$$
\begin{aligned}
y_{i t d} & =\mu_{t}+v_{i}+\eta_{d}+\beta_{1} \text { BeforeInto }_{\text {ritd }}+\beta_{2} \text { Into }_{\text {ritd }}+\beta_{3} \text { AfterInto }_{\text {ritd }} \\
& +\alpha_{1} \text { BeforeAway }_{\text {ritd }}+\alpha_{2} \text { Away }_{\text {ritd }}+\alpha_{3} \text { AfterAway } \\
\text { ritd } & +\varepsilon_{\text {itd }}
\end{aligned}
$$

where the $\mu_{t}(\mathrm{t}=1,2, \ldots, 9)$ are period-of-day fixed effects, the $v_{i}(\mathrm{i}=1,2, \ldots, \mathrm{I})$ are customer fixed effects, the $\eta_{d}(\mathrm{~d}=1,2, . ., \mathrm{D})$ are day-of-sample fixed effects, and the $\varepsilon_{i t d}$ are mean zero regression disturbances that are independently distributed of the randomly assigned regressors, BeforeInto $_{\text {ritd }}$, Into $_{\text {ritd }}$, A fterInto fitd $_{\text {, BeforeAway }}$ ritd, Away ritd, and AfterAway ritd because both away and into events are draw randomly both across customers and over time.

The first column of numbers in Table 3 presents the estimates of $\left(\beta_{1}, \beta_{2}, \beta_{3}, \alpha_{1}, \alpha_{2}, \alpha_{3}\right)$ ' for the 5 percent rebate level intervention. The second column presents the 20 percent rebate level estimates and the third column presents the estimates for the 50 percent rebate sample. To account for arbitrary forms of autocorrelation in the $\varepsilon_{i t d}$ across time periods and days in the sample for a customer and the possibility that this pattern of autocorrelation could differ across customers, we report the Arellano (1987) standard errors that are robust to this form of heteroscedasticity and autocorrelation in the values of $\varepsilon_{i t d}$. The bottom row of each column lists the total number of combined time period, day, and customer observations used to estimate each regression.

The first result of note is the uniformly two to three times larger in absolute value coefficient on Into $_{\text {ritd }}$ versus $A$ way $_{\text {ritd }}$. The into average treatment effect ranges from a 8.5 percent to 13.5 percent increase in consumption during the treatment period, and is significantly larger for the 50 percent 
rebate level relative to the 5 percent and 20 percent rebate level. The away average treatment effect is between 3.2 and 4.4 percent for all rebate levels, with the highest percentage reduction occurring for the 20 percent rebate level. A second result is the fact that both before and after an into event, consumption is significantly lower relative to the control group. These two results are very encouraging for using into treatments to achieve targeted demand reductions as well as a targeted demand increases. For the 5 percent rebate sample, there appears to be some evidence that before and after an away event demand increases. The imprecisely estimated coefficients on BeforeAway $_{\text {ritd }}$ and AfterAway fitd $_{\text {for }}$ for 20 percent and 50 percent rebate samples could be the result of the significantly smaller samples sizes available for these regressions relative to the 5 percent rebate sample.

To investigate whether the results for the BeforeAway ${ }_{\text {ritd }}$ and AfterAway ritd $_{\text {for }}$ fore different rebate levels is due to the sample size differences shown in Table 3, we also estimate a pooled version of the model which imposes the restriction that all three rebate groups have the same time-period-in-the-day fixed effects and the same day-of-sample fixed effects. Specifically, we estimate the following pooled regression across the three rebate groups:

$$
\begin{aligned}
y_{\text {itd }}=\mu_{t}+v_{i}+\eta_{d} & +\sum_{r=5,20,50}\left[\beta_{1 r} \text { BeforeInto }_{\text {ritd }}+\beta_{2 r} \text { Into }_{\text {ritd }}+\beta_{3 r} \text { AfterInto }_{\text {ritd }}\right. \\
& \left.+\alpha_{1 r} \text { BeforeAway } \text { fritd }_{\text {for }}+\alpha_{2 r} \text { Away } \text { ritd }+\alpha_{3 r} \text { AfterAway } \text { ritd }_{\text {ritd }}\right]+\varepsilon_{i t d}
\end{aligned}
$$

Table 4 reports the results of estimating this regression along with Arellano (1987) standard error estimates. The major change in the results from rebate-level-specific regressions is the larger in absolute value coefficients on Into $_{\text {ritd }}$ for the 20 and 50 percent rebate levels and the smaller in absolute value coefficient on $A w a y_{\text {ritd }}$ for the 50 percent rebate level. Otherwise, the same qualitative conclusions from the results in Table 3 hold for Table 4. For the same rebate percentage, the absolute value of the treatment effects for the into interventions are significantly larger than the corresponding value for the away interventions. A significant fraction of the energy that shifts into a treatment period comes from reductions in consumption during periods after the customer is notified and the into treatment periods occurs, as well as immediately after the into period. To lesser extent, the energy that is shifted away from the away period results in increased consumption during periods after the customer has been notified and the away treatment period occurs. There is evidence of increased consumption after the away event only for the 5 percent rebate group.

We now turn to the environmental motivation treatment sample. We first estimate a pooled version of the model that allows for different values of $\left(\beta_{1}, \beta_{2}, \beta_{3}, \alpha_{1}, \alpha_{2}, \alpha_{3}\right)$ ' for each of the four treatments. ${ }^{12}$ These results are given in Table 5 along with the Arellano (1987) standard error estimates. The same qualitative results appear to hold for environmental motivation treatments as for rebates. The absolute value of the estimated impact of an into environmental motivation treatment is significantly larger than the estimated impact of an away event. In addition, there is stronger evidence that shifting consumption into a time period leads to lower consumption in

\footnotetext{
${ }^{12}$ In this case $" r "$ in the definition of BeforeInto ritd , Into ritd $_{1}$, AfterInto ritd $_{\text {, BeforeAway }}$ ritd, Away ritd $_{\text {, and }}$

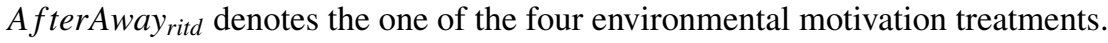


the time periods that surround that period than there is evidence that shifting consumption away from a time period leads to higher consumption in the surrounding periods. However, because many of the coefficients in Table 5 are not very large relative to their standard errors and the point estimates for the same element of $\left(\beta_{1}, \beta_{2}, \beta_{3}, \alpha_{1}, \alpha_{2}, \alpha_{3}\right)$ ' are not significantly different across the four environmental motivation treatments, in Table 6 we present estimates of this regression that impose the restriction that the elements $\left(\beta_{1}, \beta_{2}, \beta_{3}, \alpha_{1}, \alpha_{2}, \alpha_{3}\right)^{\prime}$ are the same across the four environmental motivation treatments.

The estimation results in Table 6 confirm the qualitative results in Table 5 with significantly more statistical precision. The absolute value of the into treatment effect is 6.73 percent, whereas the absolute value of the away treatment effect is less than half that magnitude at 2.66 percent. The

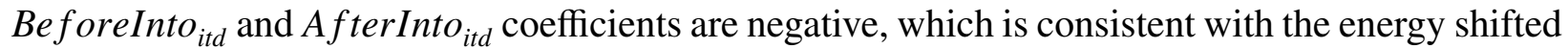
to the into period coming from these periods. Although the point estimates of the BeforeAway ${ }_{i t d}$ and Afterway ${ }_{i t d}$ coefficients are positive, which is consistent with the energy shifting away going to these periods, these coefficients are not nearly as precisely estimated or as large in absolute value as the coefficients on Before Into ritd $_{\text {and AwayInto }}$ ritd .

We now report the results of several placebo regressions to investigate whether our into and away interventions actually caused the consumption changes presented in Tables 3 to 6 . We create the following two indicator variables, both covering periods which were NOT treated, and therefore should have no effect: Into $P_{i t d}$ equals 1 in time period $t$ of day $d$ if this time period is immediately before notification of an into event given to customer $i$ with any rebate level and zero in all other time periods and (2) Away $P_{i t d}$ equals 1 in time period $t$ of day if this time period is immediately before an away notification is presented to customer $i$ with any rebate level and zero in all other time periods.

For each rebate level sample and the pooled rebate sample, we estimate the following regression:

$$
y_{i t d}=\mu_{t}+v_{i}+\eta_{d}+\beta \operatorname{IntoP} P_{i t d}+\alpha A w a y P_{i t d}+\varepsilon_{i t d}
$$

For each regression we would not expect either $\alpha$ or $\beta$ to be nonzero because customers have no economic or environmental incentive to shift their consumption into or away from time periods when either IntroP $P_{i t d}$ or $A w a y P_{i t d}$ is equal to 1 . Table 7 reports these results with Arellano (1987) standard error estimates. In all cases, as expected, the null hypothesis $\alpha=0$ and $\beta=0$ cannot be rejected. The last column of Table 7 presents estimates of these coefficients that pool the data for all of the rebate levels. In this case as well, the null hypothesis that $\alpha=0$ and $\beta=0$ cannot be rejected. These results are consistent with our into and away events actually causing the consumption changes that we estimate before, during, and after these events.

Table 8 reports the results of estimating this same regression for the pooled environmental motivation intervention sample with Arellano (1987) standard estimates. The variable Into $P_{i t d}$ now equals 1 in time period $t$ of day $d$ if this time period is immediately before notification of an into event is given to customer $i$ for any environmental motivation treatment and zero in all other time periods and $A w a y P_{i t d}$ equals 1 in time period $t$ of day if this time period is immediately before an away intervention is given to customer $i$ for any environmental motivation treatment and zero in 
all other time periods. In this case as well, the null hypothesis $\alpha=0$ and $\beta=0$ cannot be rejected.

The results in Tables 7 and 8 are consistent with the into and away consumption shifting estimates presented in the previous section being caused by our rebate and environmental motivation treatments.

\subsection{Selection Corrected Estimates of Experimental Results}

This section presents estimates of the models in Tables 3 to 8 that correct for the decision of SE households to participate in the experiment. The first step in computing selection-corrected estimates is to estimate the conditional probability of participating in the experiment as a function of characteristics of the invitation sent to the customer and demographics and home characteristics for the customer obtained from Statistics Denmark. The next step takes the value of this conditional probability of participating in the experiment for each customer and uses it to construct a nonparametric (in the sense described below) selection-corrected estimate of the parameters of the models presented in Tables 3 to $8 .^{13}$

The first-step in estimating the semiparametric selection model is an estimate of the conditional mean of the decision of a customer to participate in the experiment. To do this, we first match each SE customer that was invited to participate in our experiment to the set of demographic and home characteristics from Statistics Denmark. Out of the 23,935 customers invited, 23,089 could be matched with data from Statistics Denmark, which implies our estimation sample size is 23,089.

Empirical evidence that selection may be an issue can be obtained from comparing the mean characteristics of the invitation for those that participated in the experiment and those that did not. Table 9 gives these sample means, the difference between these sample means, and the estimated standard error of the difference. ${ }^{14}$ Appendix B-1 gives the variable definitions for each variable in Table 9. For the majority of the variables, the means are statistically different between customers that did and did not participate in the experiment. For instance, customers offered higher rebates were more likely to participate in the experiment. We also performed a multivariate difference of means test for the joint null hypothesis that all nine means are equal and obtained a test statistic equal to 151.6, which is substantially larger than the critical value for virtually any nonzero size test of this null hypothesis. ${ }^{15}$

Table 10 reports the same four magnitudes for each of the customer demographic and home

\footnotetext{
${ }^{13}$ For these models, there are 611 individuals from the experiment in the rebate sample and 784 in the environmental motivation sample. Experiment participants were removed from each of these samples because they could not be matched with the household-level demographic data from Statistics Denmark necessary to compute our selection-corrected estimates. This explains the smaller number of observations in Tables 11 to 16 relative to Tables 3 to 8 .

${ }^{14}$ The estimated standard error of the difference in means is equal to $\mathrm{SE}(\mathrm{Diff})=\sqrt{\frac{\left(s_{\text {Participate }}\right)^{2}}{N_{\text {Participate }}}+\frac{\left(s_{\text {Not Participate }}\right)^{2}}{N_{\text {Not Participate }}}}$, where $\left(s_{k}\right)^{2}$ is the sample variance of the variable and $N_{k}$ is the number of observations used to compute this sample variance for group $k=$ Participate or Not Participate.

${ }^{15}$ The test statistic is equal to $\left(\bar{X}_{\text {Participate }}-\bar{X}_{\text {Not Participate }}\right)^{\prime}\left[\frac{\hat{\Sigma}_{\text {Participate }}}{N_{\text {Participate }}}+\frac{\hat{\Sigma}_{\text {Not Participate }}}{N_{\text {Not Participate }}}\right]^{-1}\left(\bar{X}_{\text {Participate }}-\bar{X}_{\text {Not Participate }}\right)$, where $\bar{X}_{k}$ is the sample mean and $\hat{\Sigma}_{k}$ is the sample covariance matrix of the vector $X$ for group $k=$ Participate or Not Participate. This statistic is asymptotically distributed as a $\chi_{j}^{2}$, where $j$ is the dimension of $X$, under the null hypothesis.
} 
characteristics variables for customers that participated in the experiment and those that did not. Appendix B-1 gives the variable definitions for each variable listed in Table 10. For virtually all of the variables, the mean for those who participated is statistically different from mean of those who did not participate. A joint test that all 31 means are equal yields a test statistic equal to 554.6, which is much larger than the critical value for virtually any nonzero size test of the null hypothesis. A joint test that the means of all 40 invitation and customer demographic and home characteristics are jointly equal yields a test statistic 713.0, which is larger than the critical value for virtually any size test of the null hypothesis. The results in Tables 9 and 10 provide strong evidence that selection into the experiment was not independent of the values of invitation variables and demographic and home characteristics variables.

Let $g_{i}$ equal $E\left(D_{i}=1 \mid w_{i}\right)$ where $D_{i}=1$ if customer $i$ chose to participate in the experiment and $w_{i}$ is a $K$-dimensional vector of invitation and customer and home characteristics for customer $i$ listed in Tables 9 and 10. Although we focus on rebates for energy moved and green energy investment commitments for energy moved during into and away events, our conditional mean of participation estimation procedure accounts for all possible inducements. We employ a multivariate kernel regression to estimate $g_{i}$ :

$$
E\left(D_{i}=1 \mid w_{i}\right)=g_{i}=\frac{\sum_{i=1}^{N} y_{i} \mathbf{k}_{H}\left(w-w_{i}\right)}{\sum_{i=1}^{N} \mathbf{k}_{H}\left(w-w_{i}\right)}
$$

where $\mathbf{k}_{H}(s)$ is the multivariate normal kernel $\mathbf{k}_{H}(s)=(2 \pi)^{-K / 2}|H|^{-1 / 2} \exp \left(-\frac{1}{2} s^{\prime} H^{-1} t\right)$ for $s \in \mathbb{R}^{K}$ and $H$ is a $(K \times K)$ diagonal matrix of smoothing parameters that we estimate using cross-validation. Let $\hat{g}_{i}$ equal the estimated value of this conditional mean from our kernel regression estimation for the cross-validated value of $H$. Figure 3 plots the histogram of values $\hat{g}_{i}$ for $y_{i}=1$ and $y_{i}=0$. There is some overlap in the supports of the histograms of the $\hat{g}_{i}$ for $y_{i}=1$ and $y_{i}=0$. As a robustness check of our kernel regression procedure, we also estimated a flexible probit including $w_{i}$ and squares and interactions of the elements of $w_{i}$ and obtained histograms of $\hat{g}_{i}$ for $y_{i}=1$ and $y_{i}=0$ with more support in common, although the estimation results reported in this section did not change significantly if we used this estimate of $\hat{g}_{i}$ instead of the one obtained from our kernel regression.

The Ahn and Powell (1993) estimator relies on continuity of the selection function $\lambda(\cdot)$ in the conditional mean function, $g_{i}$, to effectively difference out the unknown selection function in the regression equation. Selection-corrected estimates of the coefficients of the original model are obtained from a regression involving all pairwise differences of observations.

To operationalize this intuition consider the following observation for time period $t$ of day $d$ of the selection-corrected equation for our rebate sample:

$$
y_{i t d}=\mu_{t}+v_{i}+\eta_{d}+X_{i t d}^{\prime} \Gamma+\lambda_{t d}\left(g_{i}\right)+u_{i t d}
$$

where $X_{\text {itd }}$ contains the six into and away regressors. The vector $\Gamma$ is the associated vector regression coefficients. The function is $\lambda_{t d}(\cdot)$ is unknown, but is assumed to be continuous in its argument. Note that this function is allowed to vary across both time periods, $t$, and days in the sample, $d$, to account for the fact that the dependence between a customer's decision to participate 
in the experiment and their consumption during the experiment can differ across time periods and days.

To account for the presence of customer specific fixed-effects we compute the mean of each variable over all time periods and days in the sample to obtain:

$$
\bar{y}_{i}=\bar{\mu}+v_{i}+\bar{\eta}+\bar{X}_{i}^{\prime} \Gamma+\overline{\lambda\left(g_{i}\right)}+\bar{u}_{i}
$$

where $\bar{Z} \equiv \frac{1}{9 D} \sum_{d=1}^{D} \sum_{t=1}^{9} Z_{t d}$ for any variable $Z_{t d}$ to account for the fact that there are $D$ days in our sample and 9 consumption periods in each day. Subtracting equation (2) from (1) yields:

$$
\left(y_{i t d}-\bar{y}_{i}\right)=\left(\mu_{t}-\bar{\mu}\right)+\left(\eta_{d}-\bar{\eta}\right)+\left(X_{i t d}-\bar{X}_{i}\right)^{\prime} \Gamma+\left(\lambda_{t d}\left(g_{i}\right)-\overline{\lambda\left(g_{i}\right)}\right)+\left(u_{i t d}-\bar{u}_{i}\right)
$$

Define $y_{i t d}^{*} \equiv\left(y_{i t d}-\bar{y}_{i}\right)$. Equation (3) can be re-written in this notation as:

$$
y_{i t d}^{*}=\mu_{t}^{*}+\eta_{d}^{*}+X_{i t d}^{*^{\prime}} \Gamma+\lambda_{t d}\left(g_{i}\right)^{*}+u_{i t d}^{*}
$$

Taking the difference between the observations of equation (4) for the same day and period of the day for customer $i$ and customer $j$, for individuals with $g_{i} \approx g_{j}$ yields:

$$
\begin{gathered}
y_{i t d}^{*}-y_{j t d}^{*}=\left(X_{i t d}^{*^{\prime}}-X_{j t d}^{*^{\prime}}\right) \Gamma+\left[\lambda_{t d}\left(g_{i}\right)^{*}-\lambda_{t d}\left(g_{j}\right)^{*}\right]+\left[u_{i t d}^{*}-u_{j t d}^{*}\right] \\
\approx\left(X_{i t d}^{*}-X_{j t d}^{*}\right)^{\prime} \Gamma+\left[u_{i t d}^{*}-u_{j t d}^{*}\right]
\end{gathered}
$$

The second $\approx$ follows from the fact that the $\lambda_{t d}(g)$ are assumed to be continuous in $g$, that if $g_{i}=g_{j}$ then $\lambda_{t d}\left(g_{i}\right)^{*}=\lambda_{t d}\left(g_{j}\right)^{*}$ for all $t$ and $d$. As discussed by Ahn and Powell (1993), this result is also the reason that the estimator provides a nonparametric selection correction, because the functional form for $\lambda_{t d}$ does not need to be specified, in order to obtain a consistent estimate of $\Gamma$.

The estimator of the elements of $\Gamma$ assigns weights to each pair of observations in the sample that participated in the experiment, with a smaller weight given to pairs of observations with larger values of $\left|\hat{g}_{i r}-\hat{g}_{j r}\right|$. Let the weight assigned to the $(i, j)$ pair of observations equal

$$
\hat{\omega}_{i j} \equiv \frac{1}{h_{S}} K\left(\frac{\hat{g}_{i}-\hat{g}_{j}}{h_{S}}\right) D_{i} D_{j}
$$

where $K(s)=\frac{3}{4}\left(1-s^{2}\right)$ for $|s| \leq 1$ is the Epanechnikov kernel, and $h_{S}>0$ is a smoothing parameter. The smoothing parameter, $h_{S}$, is chosen to be consistent with the rate restrictions in Assumption 3.6 in Ahn and Powell (1987) as ten percent of $\sigma_{\hat{g}}$, the sample standard deviation of the $\hat{g}_{i \cdot}{ }^{16}$

Our estimate of $\Gamma$ is equal to:

$$
\hat{\Gamma}=\left[\hat{S}_{x x}\right]^{-1} \hat{S}_{x y},
$$

where the $(6 \times 6)$ matrix

$$
\hat{S}_{x x}=\frac{1}{9 D} \sum_{d=1}^{D} \sum_{t=1}^{9} \hat{S}_{x x}(t, d)
$$

\footnotetext{
$\Gamma$.

${ }^{16}$ We experimented with values as large at fifty percent of $\sigma_{\hat{g}}$ for $h_{S}$ and obtained similar estimates of the elements
} 
and the $(6 \times 1)$ vector

$$
\hat{S}_{x y}=\frac{1}{T} \sum_{d=1}^{D} \sum_{t=1}^{9} \hat{S}_{x y}(t, d) .
$$

These these components of $\hat{\Gamma}$ depend on:

$$
\begin{aligned}
& \hat{S}_{x x}(t, d)=\left(\begin{array}{c}
n_{t d} \\
2
\end{array}\right)^{-1} \sum_{i=1}^{n_{t d}-1} \sum_{j=i+1}^{n_{t d}} \hat{\omega}_{i j}\left(X_{i t d}^{*}-X_{j t d}^{*}\right)\left(X_{i t d}^{*}-X_{j t d}^{*}\right)^{\prime} \\
& \hat{S}_{x y}(t, d)=\left(\begin{array}{c}
n_{t d} \\
2
\end{array}\right)^{-1} \sum_{i=1}^{n_{t d}-1} \sum_{j=i+1}^{n_{t d}} \hat{\omega}_{i j}\left(X_{i t d}^{*}-X_{j t d}^{*}\right)\left(y_{i t d}^{*}-y_{j t d}^{*}\right),
\end{aligned}
$$

where $n_{t d}$ is the total number of customers in our sample during time period $t$ of day $d$. Following the logic of Ahn and Powell (1993), we can prove that $\sqrt{n}(\hat{\Gamma}-\Gamma)$ converges in distribution to a $N\left(0, \Sigma_{x x}^{-1} \Omega_{x x}\left[\Sigma_{x x}^{-1}\right]^{\prime}\right)$ random variable where $n=\sum_{d=1}^{D} \sum_{t=1}^{9} n_{t d}$, the total number of observations in our sample. Appendix A derives expressions for consistent estimates of $\Sigma_{x x}$ and $\Omega_{x x}$ for our setting that are used to construct our standard error estimates.

We estimate the models in Tables 3 to 8 using this estimator and the values of $\hat{g}_{i}$ from our kernel regression estimate of $E\left(D_{i}=1 \mid w_{i}\right)=g\left(w_{i}\right)$.

A consistent result across all of the selection-corrected estimates in Tables 11 to 14 is a smaller in absolute value coefficient estimate for the three Into coefficients and the three Away coefficients relative to the corresponding coefficients in Tables 3 to 6 . This result is consistent with the logic that those customers invited to participate in the experiment that accepted are those best able to benefit from it. There is also a remarkable degree of agreement between our original results and the selection-corrected results for both the three rebate level and four environmental motivation treatments both in terms of the relative magnitude and precision of the three Into parameter estimates relative to the Away parameter estimates. The Into coefficient estimates for both the price and environmental treatments are at least two to three times the absolute value of the Away coefficient estimates for the same rebate level or environmental incentive. For both treatments, the BeforeInto and AfterInto coefficient estimates are significantly larger in absolute value and more precisely estimated than the BeforeAway and AfterAway coefficient estimates.

Our selection-corrected placebo estimates using the variables IntoP and AwayP are also not statistically different from zero for all rebate samples and the pooled rebate sample shown in Table 15. The same is true for the environmental sample in Table 16.

\section{Customer-Level and Firm-Level Benefits of into versus away Events}

This section first assesses the net impacts of into and away events for our selection-corrected estimates in Table 11. We compute net impact of each type of intervention as well the decomposition of this net impact into the Before, During, and After periods. These results reveal that for most customers and rebate levels, both into and away events imply net increases in daily electricity consumption, although during all away events there is a reduction in consumption during the specified target period. The sum of the increases in consumption before and after the away 
events, can be larger than the reduction in consumption during the away event. For the case of into events, both the "Before" and "After" periods imply significant reductions in consumption, which suggests that with careful timing, the declaration of into events can save SE significant wholesale energy costs in serving its customers.

We investigate this hypothesis using our selection-corrected parameter estimates to compute the potential wholesale energy cost savings to SE from implementing coordinated away and into events for all of its residential customers. Using hourly prices from the Nordpool, the wholesale electricity market operating in the Nordic countries, we select days when SE declaring an into event or away event for all of its residential customers could significantly reduce its cost of purchasing the wholesale energy necessary to serve these customers.

We find that the daily wholesale energy cost savings to SE of more than 100,000 Euros can be obtained from careful timing of away and into events. It would be relatively straightforward for SE to declare these events based on day-ahead forecasts of renewable energy production and load in the Nordpool. The expected change in the demand each hour of the day associated with an into or away event could be offered into the day-ahead market in the same manner that we do in our counterfactual analysis. SE would face the residual risk that the actual demand reduction does not equal what the reduction it offered in. However, given the magnitude of the wholesale purchase cost savings that we find, there is little risk that SE would not realize significant cost savings from these actions. We close this section with a discussion of why we believe these results are likely to carry over to places like California because of the pattern of net load shown in Figure 2.

\subsection{Net Impacts of into versus away Events}

To estimate the net impacts of the into and away treatments, we compute the following. For the net impact of into treatments, compute

$$
\begin{gathered}
\phi_{1 i d}=\sum_{t \in \text { BeforeInto }}\left(1-\exp \left(-\gamma_{\text {BeforeInto }}\right)\right) C_{i t d} \\
\phi_{2 i d}=\sum_{t \in \text { Into }}\left(1-\exp \left(-\gamma_{\text {Into }}\right)\right) C_{i t d} \\
\phi_{3 i d}=\sum_{t \in \text { AfterInto }}\left(1-\exp \left(-\gamma_{\text {AfterInto }}\right)\right) C_{i t d}
\end{gathered}
$$

for each consumer $i$ where $C_{i t d}$ is customer's $i$ 's actual consumption during time period $t$ of day $d$. $\gamma_{x}$ is the coefficient on the regressor $x$, estimated in the censored selection models described above. Note that although summations over time periods in Before and After an event can be over multiple periods, depending on the length of these time periods, Into is for a single time period in the day. For each customer, $i$, the net impact of an Into event at day $d$ is then $\phi_{2 i d}+\left(\phi_{1 i d}+\phi_{3 i d}\right)$.

For the net impact of the away treatments, we compute

$$
\psi_{1 i d}=\sum_{h \in \text { BeforeAway }}\left(1-\exp \left(-\gamma_{\text {BeforeAway }}\right)\right) C_{i t d}
$$




$$
\begin{gathered}
\psi_{2 i d}=\sum_{h \in \text { Away }}\left(1-\exp \left(-\gamma_{\text {Away }}\right)\right) C_{i t d} \\
\psi_{3 i d}=\sum_{h \in \text { AfterAway }}\left(1-\exp \left(-\gamma_{\text {AfterAway }}\right)\right) C_{i t d}
\end{gathered}
$$

for each consumer $i$. The net impact for each $i$ is then $\psi_{2 i d}+\left(\psi_{1 i d}+\psi_{3 i d}\right)$.

Figure 4 plots the average hourly consumption in kilowatt-hours for each of the nine daily time periods. Figures 5 to 7 plot the kilowatt-hour net impacts for into and away treatments for samples with a 5\%,20\%, and 50\% rebate, respectively. Figures 8 to 10 plot the histogram of kilowatt-hour impacts for Before these events for a 5\%, 20\%, and 50\% rebate, respectively. Figures 11 to 13 plot the histogram of kilowatt-hour During impacts for a 5\%, 20\%, and 50\% rebate, respectively. Figures 14 to 16 plot the histogram of kilowatt-hour impacts for After an event for a 5\%, 20\%, and $50 \%$ rebate, respectively. In all cases, the support of Into kilowatt-hour changes is significantly larger than the support for Away kilowatt-hour changes. Consistent with the coefficients in Table 11, the absolute values of the kilowatt-hour changes for Into events many times larger than the absolute of the kilowatt-hour changes for Away events.

\subsection{Potential Wholesale Cost Savings of into versus away Events}

Using the estimates of the impact of into and away events from the cesored selection model in Table 11, we can estimate what would happen to aggregate hourly demand if the SE population of residential customers all received an into or away signal. Plugging this estimated aggregate demand reduction (or increase) into a model for setting wholesale prices in the Nordpool each impacted hour, we re-compute the hourly price for each hour that is impacted by the event. The total wholesale energy cost savings associated with this price reduction is equal to:

$$
\sum_{h=1}^{H(E)} P W(\text { actual }, h) \times C_{S E}(\text { actual }, h)-P W(\text { new }, h) \times C_{S E}(n e w, h)-\text { Rebate Paid }
$$

where $C_{S E}($ actual,$h)$ is SE's residential consumption in hour $h$ and $C_{S E}(n e w, h)$ is SE's residential consumption with the impact of the into or away event accounted for, $P W($ actual, $h)$ is the Nordpool wholesale price during hour $h$ and $P W(n e w, h)$ is the Nordpool price during hour $h$ accounting for the impact of the into or away event during that hour, and $H(E)$ is the number of hours impacted by the into over away event. ${ }^{17}$

The rebate is paid per kWh of energy moved for into and away events based on the average residential price of 27.35 Euro cents per kWh. For example, a 5\% rebate would pay 1.37 Euro cents per $\mathrm{kWh}$ moved, $20 \%$ rebate would pay 5.47 Euro cents per $\mathrm{kWh}$ moved and finally a $50 \%$ rebate would pay 13.68 Euro cents per $\mathrm{kWh}$. Note that the payment is made only for the amount moved into the designated period for an into event and the amount moved away from the designated period for an away event.

\footnotetext{
${ }^{17}$ For example, if notification occurs five hours before an into or away event that occurs within a three hour period, the total number of hours of the day impacted is 13: 5 hours before the event, 3 hours during the event, and 5 hours after the event.
} 
For the into simulations, a notification is assumed to be sent at 8:00 am asking all customers to shift usage shift into the hours of 13:00 to $15: 00$ for a 5\%, 20\%, or 50\% rebate. The five hours preceding that window constitute the "Before" period, and the five hours following it constitute the "After" period. We chose this time period for our into event based on the pattern of average daily demand in Figure 4 and the pattern daily average hourly wholesale prices in Figure 17. The time period 13:00 to 15:00 has the lowest average demand relative to the surrounding periods and the average wholesale prices are lower than the periods that surround this time period. This means that consuming more during 13:00 to 15:00 time is unlikely to significantly increase wholesale prices, but consuming less during the 5 hours before and after this into period should reduce wholesale prices in these periods and the quantity of energy demanded, resulting in a net reduction in wholesale energy purchase costs for SE.

Our assumed away events are also based on the pattern of average daily demand in Figure 4 and the pattern of daily average hourly wholesale prices in Figure 17. We chose the time period 8:00 to 10:00 for away events because it has the highest average demand relative to the surrounding periods and average wholesale prices are higher in that period. In this case, we also assumed the event was called 5 hours before at 3 am. ${ }^{18}$ Our parameter estimates imply more consumption during the 3:00 to 8:00 period and less during the 8:00 to 10:00 period. We also examined the period 17:00 to 19:00 for an away event because of high average demand and high average prices in this period. The event was assumed to be called 5 hours in advance at $12 \mathrm{pm}$. Declaring away events during these high demand and high price periods will lower SE's demand and the Nordpool price during these hours and increase SE's demand 5 hours before and after this time period and increase the Nordpool prices during these hours as well.

Table 17 shows wholesale energy purchase cost saving from the one into event and the two away events for several days during 2014 with high day-ahead prices in the Nordpool for a 5 percent rebate event. Table 18 repeats these calculations for a 20 percent rebate event and Table 19 repeats them for a 50 percent rebate event.

Are the wholesale energy cost savings associated with into events in Tables 17, 18, and 19 unique to Denmark? The "Duck Curve" graph in Figure 2 provides strong evidence they are not. In fact, the approximately 19,000 MW of grid-scale and distributed solar generation capacity in California suggests that the pattern of net demand (system demand less the production of intermittent wind and solar generation) during the day yields wholesale prices that are lower during the middle of the day when the solar facilities in California are producing significant amounts of energy and higher in the early morning hours and late evening when there is no solar energy being produced. This result implies that declaring into events for customers in California during the middle of the day is likely to yield wholesale purchase cost saving similar to those that were found for Denmark. Moreover, the increasing amount of solar capacity being built in California should only increase the financial viability of declaring into events during the middle of the day in California.

\footnotetext{
${ }^{18}$ Assuming that that a household would respond to text message send at 3 am to reduce consumption may be unrealistic, but we wanted to give away events the best chance of having the largest possible wholesale energy cost savings to SE.
} 
The declaration of into events in California need not require an net increase in electricity production from thermal generation units if there is a sufficient amount of storage capacity within the state. During the into event these units could be storing energy to be used during and after the into event or the following day.

\section{Explaining Results Using A Model of Household-Level Demand under Uncertainty}

This section presents a simple model of household-level demand under uncertainty that rationalizes our empirical results. The model builds on the "option-to-quit" property of rebate schemes versus dynamic pricing schemes discussed in Wolak (2010). Under an away rebate scheme, such as the one used in our experiment, if a household does not consume below the level necessary to receive a rebate, that customer only pays the usual fixed price for its consumption during the event. The same logic applies for the into scheme. If the household does not consume more than the level necessary to receive a rebate, the household pays for consumption at the usual fixed price.

Figure 18 considers the behavior of a household that has received an into signal. However, at the time the into signal occurs, the household does not know if their demand for electricity will be low $\left(D_{L}(p)\right)$ or high $\left(D_{H}(p)\right)$ during the coming into event. By assumption $D_{L}(p)<D_{H}(p)$ for all prices, $p$ and $\operatorname{Prob}_{L}$ is the probability that $D_{L}(p)$ occurs and $\operatorname{Prob}_{H}$ is the probability that $D_{H}(p)$ occurs. Figures 18(a)-(c) shows the reference level relative to which a rebate is issued as $Q_{R}$. Figure 18(a) shows the customer's demand if it faces, $P_{N}$, the normal fixed retail price, and $P_{N}-r$, the price less the rebate amount. In this case $D_{L}\left(P_{N}\right)<Q_{R}$, but $D_{L}\left(P_{N}-r\right)>Q_{R}$, so the household would receive a rebate in the low demand state for consuming more than $Q_{R}$.

Figure 18(b) repeats Figure 18(a), for $D_{H}(p)$. In this case the household would also receive a rebate because $D_{H}\left(P_{N}-r\right)>Q_{R}$, Figure 18(c) presents the average treatment effect for the customer by computing the difference between the household's consumption in the low demand state if an into event has been declared less the household's consumption if an into event has not been declared times the probability of the low demand state plus the same difference for the high demand state times the probability of the high demand state. In this case,

$$
A T E_{\text {into }}=\operatorname{Prob}_{L}\left(D_{L}\left(P_{N}-r\right)-D_{L}\left(P_{N}\right)\right)+\operatorname{Prob}_{H}\left(D_{H}\left(P_{N}-r\right)-D_{H}\left(P_{N}\right)\right) .
$$

Figure 19 repeats Figure 18 for the case of an away event. Figure 19(a) shows that the customer will receive a rebate under the low demand state, because $D_{L}\left(P_{N}+r\right)<Q_{R}$. However, the customer will not receive a rebate under the high demand state at the price, $\left(P_{N}+r\right)$, because $D_{H}\left(P_{N}+r\right)>Q_{R}$ in Figure 19(b). Here is where the option to quit comes into play. The customer can obtain a higher level of utility in the high demand state by continuing the consume at $P_{N}$ and purchase $D_{H}\left(P_{N}\right)$. Figure 19(c) shows what this utility-maximizing action under the rebate scheme does to the average treatment effect of an away event. It becomes,

$A T E_{\text {away }}=\operatorname{Prob}_{L}\left(D_{L}\left(P_{N}\right)-D_{L}\left(P_{N}+r\right)\right)+\operatorname{Prob}_{H}\left(D_{H}\left(P_{N}\right)-D_{H}\left(P_{N}\right)\right)=\operatorname{Prob}_{L}\left(D_{L}\left(P_{N}\right)-D_{L}\left(P_{N}+r\right)\right)$,

Figure 20(a) compares the into and away average treatment effects in Figures 18 and 19 and shows that because of the option to quit being exercised in the high demand state under the away event, the absolute value of the ATE under the away event is significantly smaller than the absolute value 
of the ATE for the into event. Figure 20(b) shows that if the reference level is increased, this result could be ambiguous because the customer will not get a rebate during an away event in the low demand state and will therefore find it utility-maximizing to consume $D_{L}\left(P_{N}\right)$ under the low demand state, so that the away average treatment effect becomes,

$$
A T E_{\text {away }}=\operatorname{Prob}_{H}\left(D_{H}\left(P_{N}-r\right)-D_{H}\left(P_{N}\right)\right) .
$$

However, because the away event ATE in Figure 20(b) is based on the change in demand in the low demand state under $P_{N}$ versus $P_{N}+r$, and the into ATE in Figure 20(b) is based on the change in demand in the high demand state under $P_{N}-r$ and $P_{N}$, it seems very likely that the absolute value of the ATE for the into event will still be higher than the ATE for the away event. Consequently, the differential impact of the option to quit under the into rebate dynamic pricing plan versus the away dynamic pricing plan rationalizes the significantly smaller in absolute value average treatment effect for away versus into interventions that we find in our empirical work.

\section{Conclusions}

The results of this experiment suggest an alternative more cost-effective mechanism for active participation of the final consumers in managing the real-time supply and demand balance in regions with significant intermittent renewable generation. For the same rebate percentage, load-shifting into a time period induced a two to three times larger percent increase in demand than that rebate percent induced for load-shifting away from that time period. A significant amount of the energy that shifted into the time period also resulted in reductions in consumption during time periods before and after the event period. The evidence for load-shifting away from the period finds mixed evidence that this led to increased consumption in neighboring time periods.

The purely environmental motivation interventions produced analogous results: Significantly larger in absolute value average load-shifting into time periods relative to shifting away from time periods and evidence that load-shifting into a time period led to lower consumption during neighboring time periods, but load-shifting away from a time period did not consistently lead to increases in consumption in neighboring periods.

Both sets of qualitative results continue to hold for the into and away treatment effect estimates that account for the decision of customers to participate in the experiment, although the quantitative magnitude of all of these coefficient estimates is significantly smaller in absolute value than the corresponding estimates from just the sample of experiment participants. This result is consistent with the logic that the SE customers that selected to participate in the experiment are those that expected to benefit the most from their participation.

A counterfactual experiment with these selection-corrected estimates shows that substantial daily wholesale energy purchase cost savings are possible from declaring into events designed to shift consumption from high to low demand periods and that the overall wholesale energy cost savings can be larger than for an away event during the same day. Given popularity of rebate-based dynamic pricing programs with consumers and regulators, a more cost-effective approach to implementing these programs may be to use into rather than away rebate schemes, particularly in regions with significant intermittent renewable generation capacity shares such as 
California. Thus giving incentives to increase electricity use in certain time periods is a pricing strategy that could reduce the cost of - and therefor help increase the share of - greenhouse gas emissions-free wind and solar electricity production. 


\section{References}

Arellano, M. (1987) "Computing Robust Standards Errors for Within-Groups Estimators," Oxford Bulletin of Economics and Statistics, 49(4):431-34.

Ahn, Hyungtaik, and James L. Powell. "Semiparametric estimation of censored selection models with a nonparametric selection mechanism," Journal of Econometrics 58, no. 1-2 (1993): 3-29.

Allcott, H. (2011) "Rethinking real-time electricity pricing," Resource and Energy Economics 33: $820-842$

Borenstein, S. (2007) "Wealth Transfers among Large Customers from Implementing Real-Time Retail Electricity Pricing,” Energy Journal 28 (2): 131

Faruqui, A., and S. Sergici. 2010. "Household Response to Dynamic Pricing of Electricity: A Survey of 15 Experiments," Journal of Regulatory Economics 38 (2): 193-225.

Herter, K. (2007) "Residential implementation of critical-peak pricing of electricity," Energy Policy 35: $2121-2130$

Ito, K. (2015) "Asymmetric Incentives in Subsidies: Evidence from a Large-Scale Electricity Rebate Program,” American Economic Journal: Economic Policy, 7(3): 209-237

Ito, K.,T. Ida, M. Tanaka. (2018) "Moral Suasion and Economic Incentives: Field Experimental Evidence from Energy Demand," American Economic Journal: Economic Policy, 10(1) 240-67.

Jessoe, Katrina and David Rapson (2014). "Knowledge is (Less) Power: Experimental Evidence from Residential Energy Use," American Economic Review, 104(4): 1417-1438

Kessels, K., C. Kraan, L. Krag, S. Maggiore, P. Valkering, and E. Laes. 2016. "Fostering Residential Demand Response through Dynamic Pricing Schemes: A Behavioural Review of Smart Grid Pilots in Europe.” Sustainability (Switzerland) 8 (9), 1-21.

Lijesen, M.G. (2007) "The real-time price elasticity of electricity," Energy Economics 29(2): 249-258

Wolak, Frank A., (2006) "Residential customer response to real-time pricing: The Anaheim critical peak pricing experiment," available at http://www.stanford.edu/ wolak

Wolak, Frank A. (2010) "An Experimental Comparison of Critical Peak and Hourly Pricing: The PowerCentsDC Program," available at http://www.stanford.edu/ wolak 
Table 1. Summary Statistics for Rebate Participants.

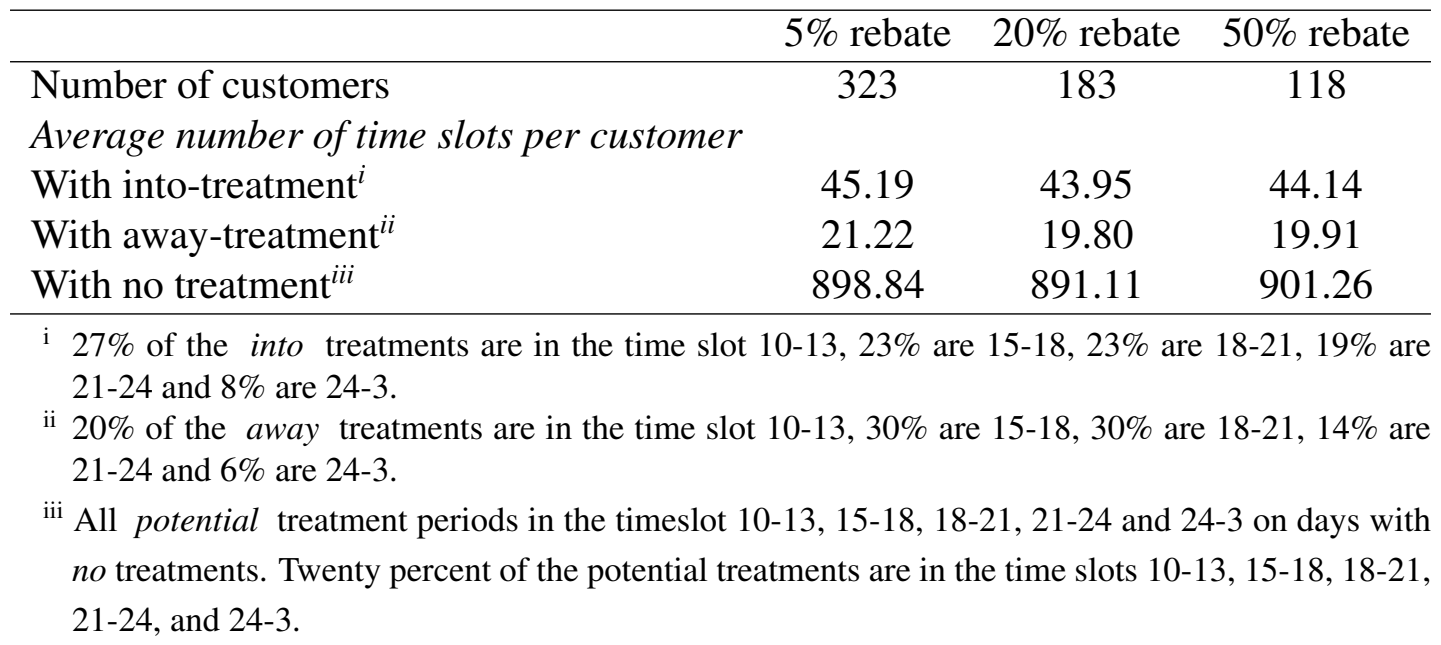

Table 2. Summary Statistics for Zero-GHG Emissions Energy Participants

\begin{tabular}{|c|c|c|c|c|}
\hline & $\begin{array}{l}\text { Group: } \\
\quad 31\end{array}$ & $\begin{array}{l}\text { Group: } \\
\quad 34\end{array}$ & $\begin{array}{l}\text { Group: } \\
\quad 35\end{array}$ & $\begin{array}{l}\text { Group: } \\
\quad 36\end{array}$ \\
\hline Number of customers & 319 & 256 & 133 & 84 \\
\hline \multicolumn{5}{|l|}{ Average number of time slots per customer } \\
\hline With into-treatment ${ }^{a}$ & 45.07 & 45.73 & 44.56 & 44.76 \\
\hline With away-treatment ${ }^{b}$ & 20.68 & 21.36 & 20.93 & 20.32 \\
\hline With no treatm & 904.80 & 901.39 & 911.05 & 882.14 \\
\hline \multicolumn{5}{|c|}{$\begin{array}{l}\text { a } 27 \% \text { of the into treatments are in the time slot } 10-13,23 \% \text { are } 15-18,23 \% \text { are } 18-21,19 \% \text { are } \\
21-24 \text { and } 8 \% \text { are } 24-3 \text {. } \\
\text { b } 20 \% \text { of the away treatments are in the time slot } 10-13,30 \% \text { are } 15-18,30 \% \text { are } 18-21,14 \% \text { are } \\
21-24 \text { and } 6 \% \text { are } 24-3 \text {. }\end{array}$} \\
\hline \multicolumn{5}{|c|}{$\begin{array}{l}\text { c All potential treatment periods in the timeslot } 10-13,15-18,18-21,21-24 \text { and } 24-3 \text { on days } \\
\text { with no treatments. }\end{array}$} \\
\hline
\end{tabular}


Table 3: Separate Estimation Results for 5 Percent, 20 Percent and 50 Percent Rebate Levels

\begin{tabular}{|c|c|c|c|}
\hline \multicolumn{4}{|c|}{ Dependent Variable is Natural Logarithm of Customer $i$ 's Consumption in Time Period $t$} \\
\hline \multicolumn{4}{|l|}{ Regressor } \\
\hline \multirow[t]{2}{*}{ BeforeInto } & -0.0259 & -0.0154 & -0.0178 \\
\hline & $(0.0056)$ & $(0.0080)$ & $(0.0107)$ \\
\hline \multirow[t]{2}{*}{ Into } & 0.0849 & 0.0916 & 0.1354 \\
\hline & $(0.0084)$ & $(0.0115)$ & $(0.0180)$ \\
\hline \multirow[t]{2}{*}{ AfterInto } & -0.0106 & -0.0085 & -0.0006 \\
\hline & $(0.0042)$ & $(0.0070)$ & $(0.0071)$ \\
\hline \multirow[t]{2}{*}{ BeforeAway } & 0.0141 & 0.0002 & 0.0250 \\
\hline & $(0.0080)$ & $(0.0111)$ & $(0.0127)$ \\
\hline \multirow[t]{2}{*}{ Away } & -0.0374 & -0.0444 & -0.0323 \\
\hline & $(0.0084)$ & $(0.0107)$ & $(0.0137)$ \\
\hline \multirow[t]{2}{*}{ AfterAway } & 0.0080 & -0.0112 & 0.0093 \\
\hline & $(0.0062)$ & $(0.0087)$ & $(0.0114)$ \\
\hline Number of Observations & 705,792 & 389,672 & 258,313 \\
\hline
\end{tabular}

Table 4: Pooled Estimation results for 5 percent, 20 percent and 50 percent rebate levels

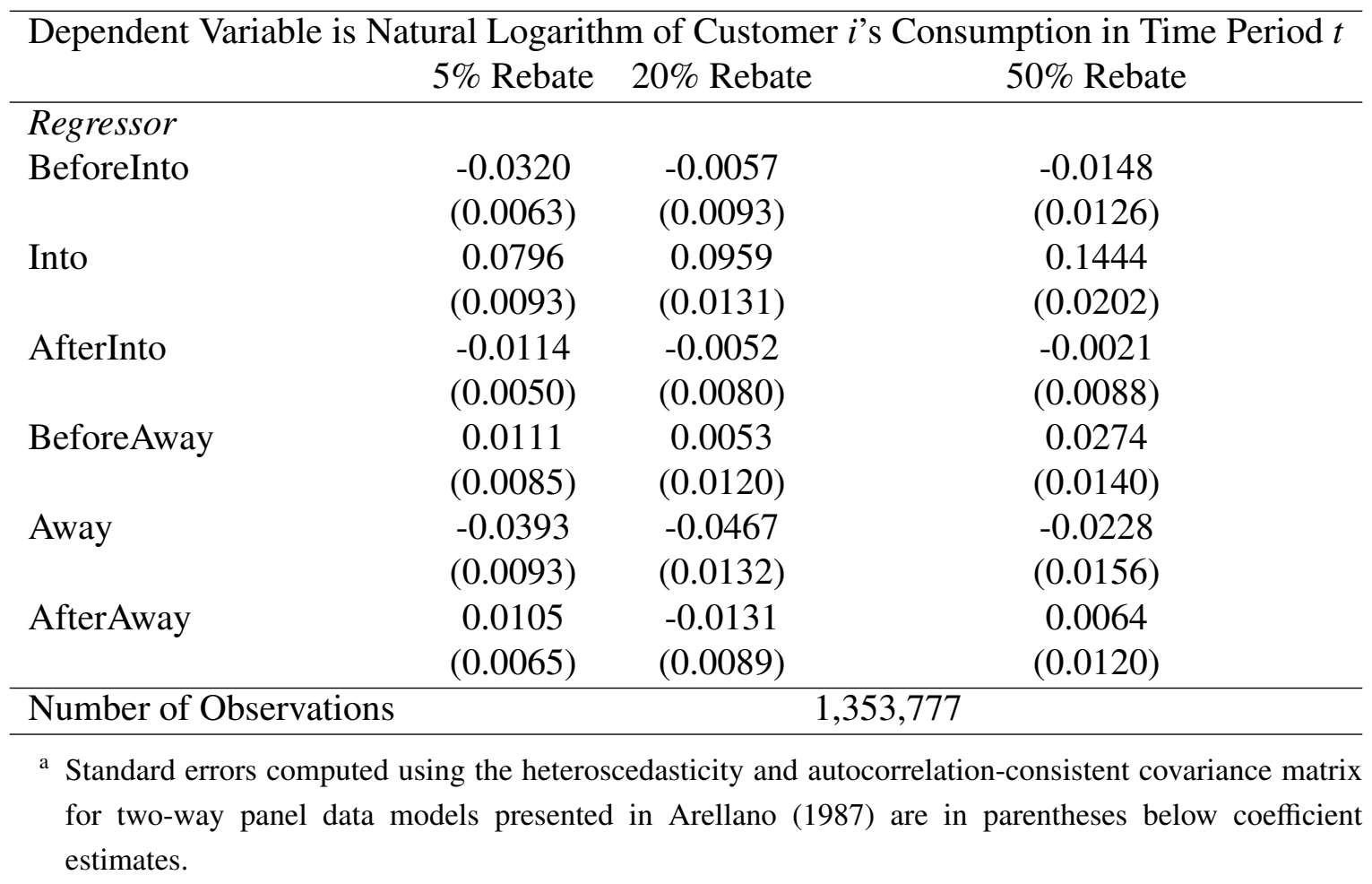


Table 5: Separate Estimates of Impact of Four Environmental Motivation Treatments

\begin{tabular}{lcccc}
\hline \multicolumn{5}{l}{ Dependent Variable is Natural Logarithm of Customer $i$ 's Consumption in Time Period $t$} \\
\hline Regressor & Group 31 & Group 34 & Group 35 & Group 36 \\
BeforeInto & -0.0199 & -0.0196 & -0.0107 & -0.0116 \\
\multirow{2}{*}{ Into } & $(0.0073)$ & $(0.0087)$ & $(0.0112)$ & $(0.0129)$ \\
& 0.0664 & 0.0589 & 0.0771 & 0.0815 \\
AfterInto & $(0.0095)$ & $(0.0097)$ & $(0.0157)$ & $(0.0192)$ \\
& -0.0042 & -0.0029 & -0.0054 & -0.0078 \\
BeforeAway & $(0.0061)$ & $(0.0064)$ & $(0.0079)$ & $(0.0115)$ \\
& 0.0024 & 0.0040 & -0.0037 & 0.0040 \\
Away & $(0.0081)$ & $(0.0097)$ & $(0.0130)$ & $(0.0161)$ \\
& -0.0298 & -0.0220 & -0.0203 & -0.0388 \\
AfterAway & $(0.0098)$ & $(0.0117)$ & $(0.0164)$ & $(0.0183)$ \\
& -0.0010 & 0.0108 & 0.0090 & 0.0020 \\
Number of Observations & $(0.0067)$ & $(0.0088)$ & $(0.0116)$ & $(0.0128)$
\end{tabular}

a Standard errors computed using the heteroscedasticity and autocorrelation-consistent covariance matrix for two-way panel data models presented in Arellano (1987) are in parentheses below coefficient estimates.

Table 6: Pooled Estimates of Impact of Environmental Motivational Treatments

\begin{tabular}{lc}
\hline Dependent Variable is Natural Logarithm of Customer $i$ 's Consumption in Time Period $t$ \\
\hline Regressor & -0.0174 \\
BeforeInto & $(0.0039)$ \\
& 0.0673 \\
Into & $(0.0052)$ \\
& -0.0043 \\
AfterInto & $(0.0031)$ \\
& 0.0021 \\
BeforeAway & $(0.0047)$ \\
& -0.0266 \\
Away & $(0.0054)$ \\
& 0.0049 \\
AfterAway & $(0.0043)$ \\
& $1,732,391$ \\
\hline Number of Observations & $(1987)$ are in parentheses below coefficient \\
\hline a Standard errors computed using the heteroscedasticity and autocorrelation-consistent covariance matrix \\
for two-way panel data models presented in Arellano \\
estimates.
\end{tabular}


Table 7: Placebo Estimates of Impact of Rebate Treatments

\begin{tabular}{lcccc}
\multicolumn{4}{l}{ Dependent Variable is Natural Logarithm of Customer $i$ 's Consumption in Time Period $t$} \\
& 5\% Rebate & 20\% Rebate & 50\% Rebate & Pooled Sample \\
\hline $\begin{array}{l}\text { Regressor } \\
\text { IntoP }\end{array}$ & -0.0146 & -0.0189 & 0.0020 & -0.0126 \\
& $(0.0083)$ & $(0.0120)$ & $(0.0161)$ & $(0.0073)$ \\
AwayP & 0.0091 & -0.0032 & -0.0270 & -0.0013 \\
& $(0.0112)$ & $(0.0143)$ & $(0.0158)$ & $(0.0078)$ \\
\hline Number of Obs & 708,688 & 391,291 & 259,366 & $1,359,345$ \\
\hline
\end{tabular}

a Standard errors computed using the heteroscedasticity and autocorrelation-consistent covariance matrix for two-way panel data models presented in Arellano (1987) are in parentheses below coefficient estimates.

Table 8: Placebo Estimates of Impact of Environmental Motivation Treatments

\begin{tabular}{|c|c|c|c|c|}
\hline \multicolumn{5}{|c|}{ Dependent Variable is Natural Logarithm of Customer $i$ 's Consumption in Time Period $t$} \\
\hline \multicolumn{5}{|l|}{ Regressor } \\
\hline \multirow[t]{2}{*}{ IntoP } & \multicolumn{4}{|c|}{-0.0094} \\
\hline & \multicolumn{4}{|c|}{$(0.0059)$} \\
\hline \multirow[t]{2}{*}{ AwayP } & \multicolumn{4}{|c|}{-0.0008} \\
\hline & \multicolumn{4}{|c|}{$(0.0071)$} \\
\hline Number of Observations & \multicolumn{4}{|c|}{$1,739,476$} \\
\hline \multicolumn{5}{|c|}{$\begin{array}{l}\text { a Standard errors computed using the heteroscedasticity and autocorrelation-consistent covariance matrix } \\
\text { for two-way panel data models presented in Arellano (1987) are in parentheses below coefficient } \\
\text { estimates. }\end{array}$} \\
\hline \multicolumn{5}{|c|}{ Table 9: Summary Stats for Invitation Variables } \\
\hline & Mean $($ Participate $=0)$ & Mean $($ Participate $=1)$ & Diff. & Std. Error \\
\hline Second Wave & 0.5028 & 0.4506 & 0.0522 & 0.0123 \\
\hline $5 \%$ Rebate & 0.1714 & 0.2391 & -0.0676 & 0.0104 \\
\hline $20 \%$ Rebate & 0.0758 & 0.1027 & -0.0269 & 0.0074 \\
\hline $50 \%$ Rebate & 0.0408 & 0.0662 & -0.0254 & 0.0060 \\
\hline Foot in the Door with Price Motive & 0.1423 & 0.2155 & -0.0732 & 0.0100 \\
\hline Foot in the Door with Envi Motive & 0.3550 & 0.3008 & 0.0542 & 0.0114 \\
\hline Offered Device & 0.3296 & 0.3300 & -0.0004 & 0.0116 \\
\hline
\end{tabular}

There are 1,782 observations who participated, and 21,307 who did not. 
Table 10: Summary Stats for Demographic and Home Variables

\begin{tabular}{|c|c|c|c|c|}
\hline & Mean $($ Participate $=0)$ & Mean $($ Participate $=1)$ & Diff. & Std. Error \\
\hline$\#$ of men $21+$ in house & 0.8964 & 0.8743 & 0.0221 & 0.0102 \\
\hline$\#$ of men $21+$ in house, sq & 0.9875 & 0.9349 & 0.0526 & 0.0165 \\
\hline \# of women $21+$ in house & 0.8707 & 0.8984 & -0.0277 & 0.0091 \\
\hline$\#$ of women $21+$ in house, sq & 0.9105 & 0.9411 & -0.0306 & 0.0138 \\
\hline \# of kids $15-20$ & 0.2015 & 0.1706 & 0.0309 & 0.0115 \\
\hline \# of kids 7-14 & 0.2709 & 0.1863 & 0.0846 & 0.0131 \\
\hline \# of kids 0-6 & 0.2096 & 0.1195 & 0.0901 & 0.0110 \\
\hline$\#$ of kids $15-20, \mathrm{sq}$ & 0.2890 & 0.2447 & 0.0443 & 0.0217 \\
\hline$\#$ of kids $7-14$, sq & 0.4630 & 0.3075 & 0.1555 & 0.0270 \\
\hline \# of kids $0-6$, sq & 0.3521 & 0.2026 & 0.1496 & 0.0229 \\
\hline Household disposable income & 7.7540 & 7.5653 & 0.1888 & 0.0907 \\
\hline Household disposable income squared & 78.0228 & 70.3972 & 7.6255 & 2.4678 \\
\hline Income $<0$ & 0.0013 & 0.0006 & 0.0008 & 0.0006 \\
\hline Income $\in[0,50,000)$ & 0.0036 & 0.0022 & 0.0013 & 0.0012 \\
\hline Income $\in[50,000,150,000)$ & 0.0589 & 0.0432 & 0.0157 & 0.0051 \\
\hline Income $\in[150,000,250,000)$ & 0.2022 & 0.2043 & -0.0021 & 0.0099 \\
\hline Income $\in[250,000,350,000)$ & 0.2052 & 0.2329 & -0.0277 & 0.0104 \\
\hline Income $\in[350,000,450,000)$ & 0.1943 & 0.2183 & -0.0239 & 0.0102 \\
\hline Income $\in[450,000,550,000)$ & 0.1605 & 0.1543 & 0.0062 & 0.0089 \\
\hline farmhouse & 0.0405 & 0.0387 & 0.0018 & 0.0048 \\
\hline terraced_or_double_house & 0.1188 & 0.1296 & -0.0108 & 0.0083 \\
\hline storey_bld & 0.1412 & 0.0763 & 0.0649 & 0.0067 \\
\hline single_fam_house & 0.6976 & 0.7536 & -0.0561 & 0.0107 \\
\hline \# of rooms & 4.5180 & 4.5999 & -0.0819 & 0.0368 \\
\hline Total area of home & 135.0484 & 137.9972 & -2.9488 & 1.1594 \\
\hline Construction Year & 1954.1063 & 1955.9641 & -1.8578 & 1.1080 \\
\hline district_heat & 0.5579 & 0.5224 & 0.0354 & 0.0123 \\
\hline Central heating & 0.3374 & 0.3333 & 0.0040 & 0.0116 \\
\hline Electric oven & 0.0626 & 0.0898 & -0.0272 & 0.0070 \\
\hline Heating pump & 0.0278 & 0.0426 & -0.0149 & 0.0049 \\
\hline Individual Owns Home & 0.7051 & 0.7755 & -0.0704 & 0.0104 \\
\hline num_employed & 1.0980 & 0.9293 & 0.1687 & 0.0220 \\
\hline hh_unemployed & 0.3137 & 0.4108 & -0.0971 & 0.0121 \\
\hline \# of Retired in $\mathrm{HH}$ & 0.4319 & 0.6235 & -0.1915 & 0.0191 \\
\hline \# of High-skill employees & 0.1635 & 0.1409 & 0.0226 & 0.0099 \\
\hline \# of Mid-skill employees & 0.2160 & 0.1835 & 0.0325 & 0.0105 \\
\hline \# of low-skill employees & 0.4539 & 0.3760 & 0.0779 & 0.0150 \\
\hline $\mathrm{HH}$ state scholarship funds & 4787.8427 & 2719.4484 & 2068.3943 & 344.9879 \\
\hline HH pension income & 95841.6083 & 145206.3681 & -49364.7599 & 4213.0859 \\
\hline Married couple in $\mathrm{HH}$ & 0.5626 & 0.6156 & -0.0530 & 0.0120 \\
\hline$\#$ of immigrants in $\mathrm{HH}$ & 0.1495 & 0.1027 & 0.0468 & 0.0115 \\
\hline
\end{tabular}

There are 1,782 observations who participated, and 21,307 who did not. 
Table 11: Replication of Table 3 Using Censored Selection Method

\begin{tabular}{c|ccc}
\hline & $(1)$ & $(2)$ & $(3)$ \\
& $\log (\mathrm{kwh} / \mathrm{hr})$ & $\log (\mathrm{kwh} / \mathrm{hr})$ & $\log (\mathrm{kwh} / \mathrm{hr})$ \\
\hline Regressor & & & \\
BeforeInto & -0.0076 & -0.0111 & -0.0091 \\
& $(0.0010)$ & $(0.0017)$ & $(0.0018)$ \\
Into & 0.0306 & 0.0289 & 0.0505 \\
& $(0.0025)$ & $(0.0021)$ & $(0.0053)$ \\
AfterInto & -0.0027 & -0.0028 & 0.0004 \\
BeforeAway & $(0.0011)$ & $(0.0011)$ & $(0.0017)$ \\
& 0.0042 & -0.0007 & 0.0026 \\
Away & $(0.0015)$ & $(0.0019)$ & $(0.0024)$ \\
& -0.0108 & -0.0106 & -0.0055 \\
AfterAway & $(0.0016)$ & $(0.0022)$ & $(0.0031)$ \\
& 0.0015 & -0.0037 & -0.0024 \\
& $(0.0013)$ & $(0.0019)$ & $(0.0033)$ \\
\hline $\mathrm{N}$ & 704,484 & 388,269 & 252,153
\end{tabular}

Columns 1, 2, and 3 are results for 5\%, 20\%, and 50\% rebates, respectively

Table 12: Replication of Table 4 Using Censored Selection Method

\begin{tabular}{c|ccc}
\hline & $(1)$ & $(2)$ & $(3)$ \\
& $\log (\mathrm{kWh} / \mathrm{hr})$ & $\log (\mathrm{kWh} / \mathrm{hr})$ & $\log (\mathrm{kWh} / \mathrm{hr})$ \\
\hline Regressor & & & -0.0072 \\
BeforeInto & -0.0094 & -0.0087 & $(0.0024)$ \\
& $(0.0013)$ & $(0.0029)$ & 0.0560 \\
Into & 0.0288 & 0.0295 & $(0.0082)$ \\
& $(0.0024)$ & $(0.0025)$ & -0.0018 \\
AfterInto & -0.0025 & -0.0021 & $(0.0021)$ \\
& $(0.0010)$ & $(0.0016)$ & 0.0061 \\
BeforeAway & 0.0026 & 0.0004 & $(0.0028)$ \\
& $(0.0018)$ & $(0.0023)$ & 0.0034 \\
Away & -0.0124 & -0.0118 & $(0.0043)$ \\
& $(0.0019)$ & $(0.0027)$ & -0.0041 \\
AfterAway & 0.0019 & -0.0041 & $(0.0030)$ \\
& $(0.0012)$ & $(0.0022)$ & \\
\hline
\end{tabular}

Columns 1, 2, and 3 are results for 5\%,20\%, and 50\% rebates, respectively 
Table 13: Replication of Table 5 Using Censored Selection Method

\begin{tabular}{c|cccc}
\hline & $\begin{array}{c}\log (\mathrm{kWh} / \mathrm{hr}) \\
\text { Group 31 }\end{array}$ & $\begin{array}{c}\log (\mathrm{kWh} / \mathrm{hr}) \\
\text { Group 34 }\end{array}$ & $\begin{array}{c}\log (\mathrm{kWh} / \mathrm{hr}) \\
\text { Group 35 }\end{array}$ & $\begin{array}{c}\log (\mathrm{kWh} / \mathrm{hr}) \\
\text { Group 36 }\end{array}$ \\
\hline Regressor & & -0.0049 & -0.0038 & -0.0059 \\
BeforeInto & -0.0054 & $(0.0019)$ & $(0.0029)$ & $(0.0025)$ \\
& $(0.0019)$ & 0.0182 & 0.0200 & 0.0304 \\
Into & 0.0250 & $(0.0030)$ & $(0.0034)$ & $(0.0036)$ \\
& $(0.0033)$ & 0.0034 & 0.0003 & -0.0002 \\
AfterInto & 0.0001 & $(0.0019)$ & $(0.0017)$ & $(0.0021)$ \\
& $(0.0020)$ & -0.0011 & -0.0013 & 0.0058 \\
BeforeAway & 0.0018 & $(0.0024)$ & $(0.0028)$ & $(0.0033)$ \\
& $(0.0022)$ & -0.0037 & -0.0069 & -0.0033 \\
Away & -0.0032 & $(0.0022)$ & $(0.0031)$ & $(0.0019)$ \\
& $(0.0029)$ & 0.0045 & 0.0033 & 0.0028 \\
AfterAway & 0.0008 & $(0.0017)$ & $(0.0019)$ & $(0.0023)$ \\
\hline \multirow{5}{*}{$\mathrm{N}$} & $(0.0029)$ & $1,736,111$ & \\
\hline
\end{tabular}

Heteroscedasticity consistent standard errors

Table 14: Replication of Table 6 Using Censored Selection Method (npregress)

\begin{tabular}{c|c}
\hline & $\log (\mathrm{kWh} / \mathrm{hr})$ \\
\hline Regressor & \\
BeforeInto & -0.0051 \\
& $(0.0007)$ \\
Into & 0.0227 \\
& $(0.0021)$ \\
AfterInto & 0.0011 \\
& $(0.0007)$ \\
BeforeAway & 0.0008 \\
& $(0.0015)$ \\
Away & -0.0040 \\
& $(0.0016)$ \\
AfterAway & 0.0026 \\
& $(0.0014)$ \\
\hline $\mathrm{N}$ & $1,736,111$ \\
\hline
\end{tabular}


Table 15: Replication of Table 7 Using Censored Selection Method

\begin{tabular}{c|cccc}
\hline & $\log (\mathrm{kWh} / \mathrm{hr})$ & $\log (\mathrm{kWh} / \mathrm{hr})$ & $\log (\mathrm{kWh} / \mathrm{hr})$ & $\log (\mathrm{kWh} / \mathrm{hr})$ \\
& 5\% Rebate & 20\% Rebate & 50\% Rebate & Pooled Sample \\
\hline Regressor & & & & \\
IntoP & -0.0030 & -0.0043 & 0.0035 & -0.0023 \\
& $(0.0017)$ & $(0.0027)$ & $(0.0025)$ & $(0.0016)$ \\
AwayP & -0.0011 & 0.0023 & -0.0039 & -0.0005 \\
& $(0.0019)$ & $(0.0025)$ & $(0.0028)$ & $(0.0014)$ \\
\hline $\mathrm{N}$ & 707,346 & 389,880 & 253,179 & $1,350,405$ \\
\hline
\end{tabular}

Table 16: Replication of Table 8 Using Censored Selection Method

\begin{tabular}{c|c}
\hline & $\log (\mathrm{kWh} / \mathrm{hr})$ \\
\hline Regressor & \\
IntoP & 0.0009 \\
& $(0.0014)$ \\
AwayP & 0.0014 \\
& $(0.0019)$ \\
\hline $\mathrm{N}$ & $1,743,167$ \\
\hline
\end{tabular}

Table 17: Total Wholesale Cost Savings (EUR); 5\% rebate

\begin{tabular}{c|ccc}
\hline Day & $\begin{array}{c}\text { Into Signal } \\
(13: 00)\end{array}$ & $\begin{array}{c}\text { Away Signal } \\
(8: 00)\end{array}$ & $\begin{array}{c}\text { Away Signal } \\
(17: 00)\end{array}$ \\
\hline \hline January 14, 2014 & $18,902.16$ & $52,668.70$ & $-6,068.05$ \\
January 15, 2014 & $39,084.92$ & $72,125.45$ & $12,171.64$ \\
January 21, 2014 & $28,280.46$ & $55,660.59$ & $19,415.90$ \\
January 22, 2014 & $41,059.58$ & $80,610.57$ & $-20,918.28$ \\
January 23, 2014 & $3,416.99$ & $12,716.84$ & -465.48 \\
January 24, 2014 & $75,079.54$ & $83,449.95$ & $5,219.41$ \\
January 31, 2014 & $1,452.31$ & 824.10 & $6,899.82$ \\
April 1, 2014 & $-3,474.61$ & $-2,233.61$ & $-1,253.00$ \\
April 2, 2014 & $17,614.12$ & $15,967.71$ & $-1,107.94$ \\
\hline
\end{tabular}


Table 18: Total Wholesale Cost Savings (EUR); 20\% rebate

\begin{tabular}{c|ccc}
\hline Day & $\begin{array}{c}\text { Into Signal } \\
(13: 00)\end{array}$ & $\begin{array}{c}\text { Away Signal } \\
(8: 00)\end{array}$ & $\begin{array}{c}\text { Away Signal } \\
(17: 00)\end{array}$ \\
\hline \hline January 14, 2014 & $44,652.41$ & $73,126.01$ & $11,890.53$ \\
January 15, 2014 & $66,778.13$ & $91,417.40$ & $26,250.35$ \\
January 21, 2014 & $100,440.30$ & $88,190.25$ & $35,655.95$ \\
January 22, 2014 & $87,448.47$ & $102,736.94$ & $31,788.63$ \\
January 23, 2014 & $14,855.12$ & $32,045.77$ & $19,818.83$ \\
January 24, 2014 & $104,055.05$ & $105,787.09$ & $21,124.51$ \\
January 31, 2014 & $3,505.74$ & $8,858.92$ & $12,788.63$ \\
April 1, 2014 & $-1,173.19$ & $7,926.95$ & $6,040.92$ \\
April 2, 2014 & $27,265.75$ & $31,137.76$ & $5,015.49$ \\
\hline
\end{tabular}

Table 19: Total Wholesale Cost Savings (EUR); 50\% rebate

\begin{tabular}{c|ccc}
\hline Day & $\begin{array}{c}\text { Into Signal } \\
(13: 00)\end{array}$ & $\begin{array}{c}\text { Away Signal } \\
(8: 00)\end{array}$ & $\begin{array}{c}\text { Away Signal } \\
(17: 00)\end{array}$ \\
\hline \hline January 14, 2014 & $-26,465.11$ & $37,752.47$ & -2433.37 \\
January 15, 2014 & $-8,339.11$ & $56,859.14$ & $6,396.53$ \\
January 21, 2014 & $-4,808.20$ & $22,263.77$ & $4,156.47$ \\
January 22, 2014 & $-9,540.09$ & $28,766.65$ & $-1,993.5$ \\
January 23, 2014 & $-63,627.44$ & $16,550.52$ & $1,350.93$ \\
January 24, 2014 & $28,516.81$ & $62,497.95$ & $3,046.81$ \\
January 31, 2014 & $-28,545.33$ & 566.18 & $4,206.86$ \\
April 1, 2014 & $-31,696.24$ & $2,142.64$ & $4,210.74$ \\
April 2, 2014 & $-36,62.47$ & $9,609.89$ & 768.90 \\
\hline
\end{tabular}


Figure 1. Danish Electricity Consumption, Wind Energy Production, and Short-term Prices

Figure 1(a)

Consumption and wind/solar production

Sum of DK-West and DK-East Markets

Monday 13 to Sunday 19 January 2014
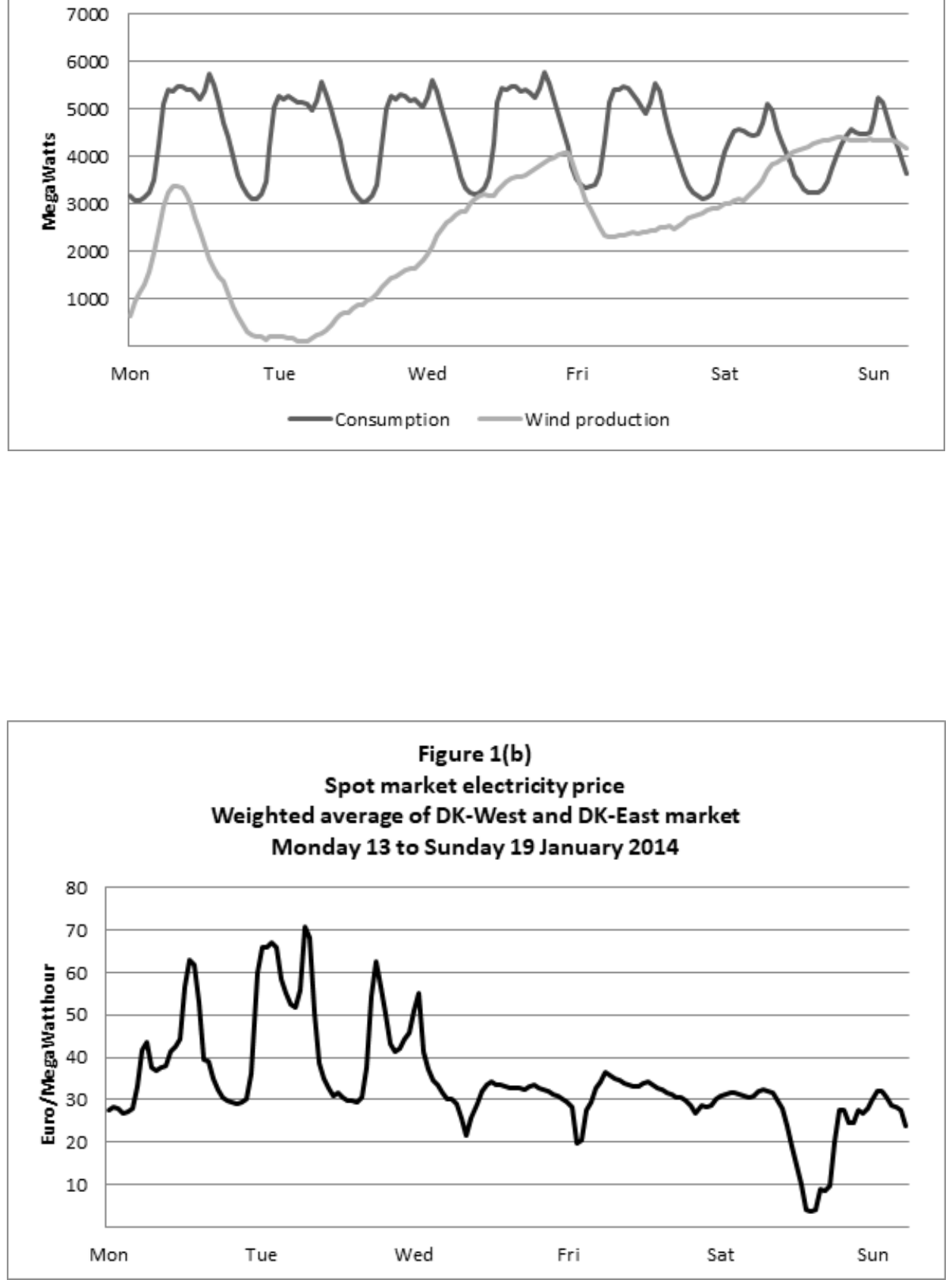
Figure 2: The Impact of Solar Generation Deployment on Net Load in California

California ISO average net electric load last week of March

gigawatts

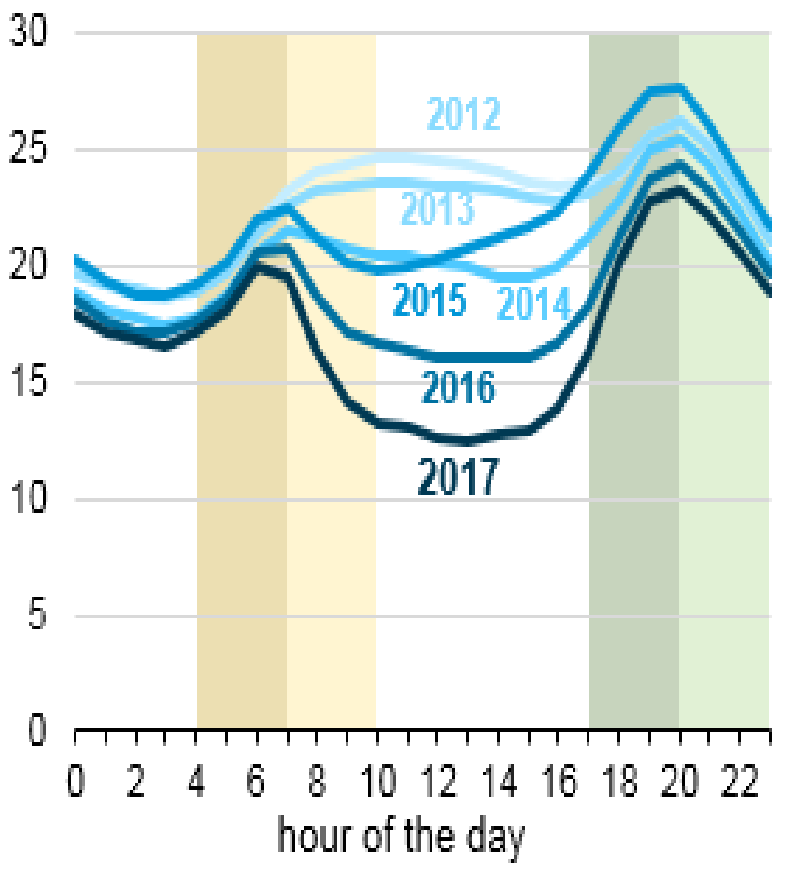

Net load change during ramping periods last week of March gigawatts

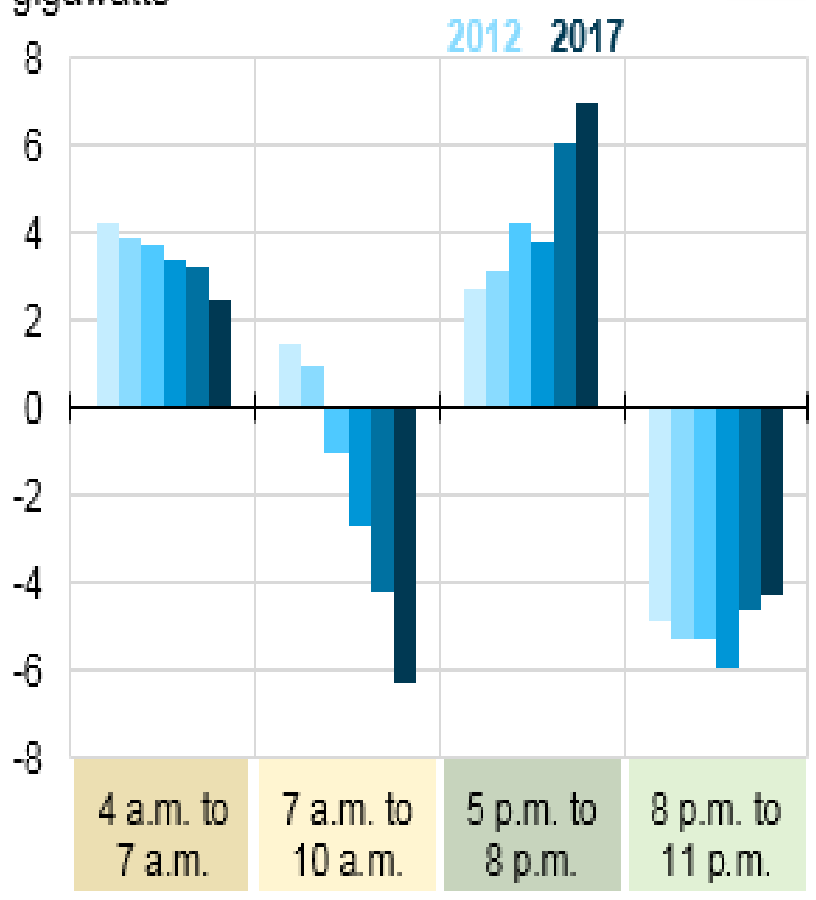


Figure 3: Histogram of Propensity Scores by Participation

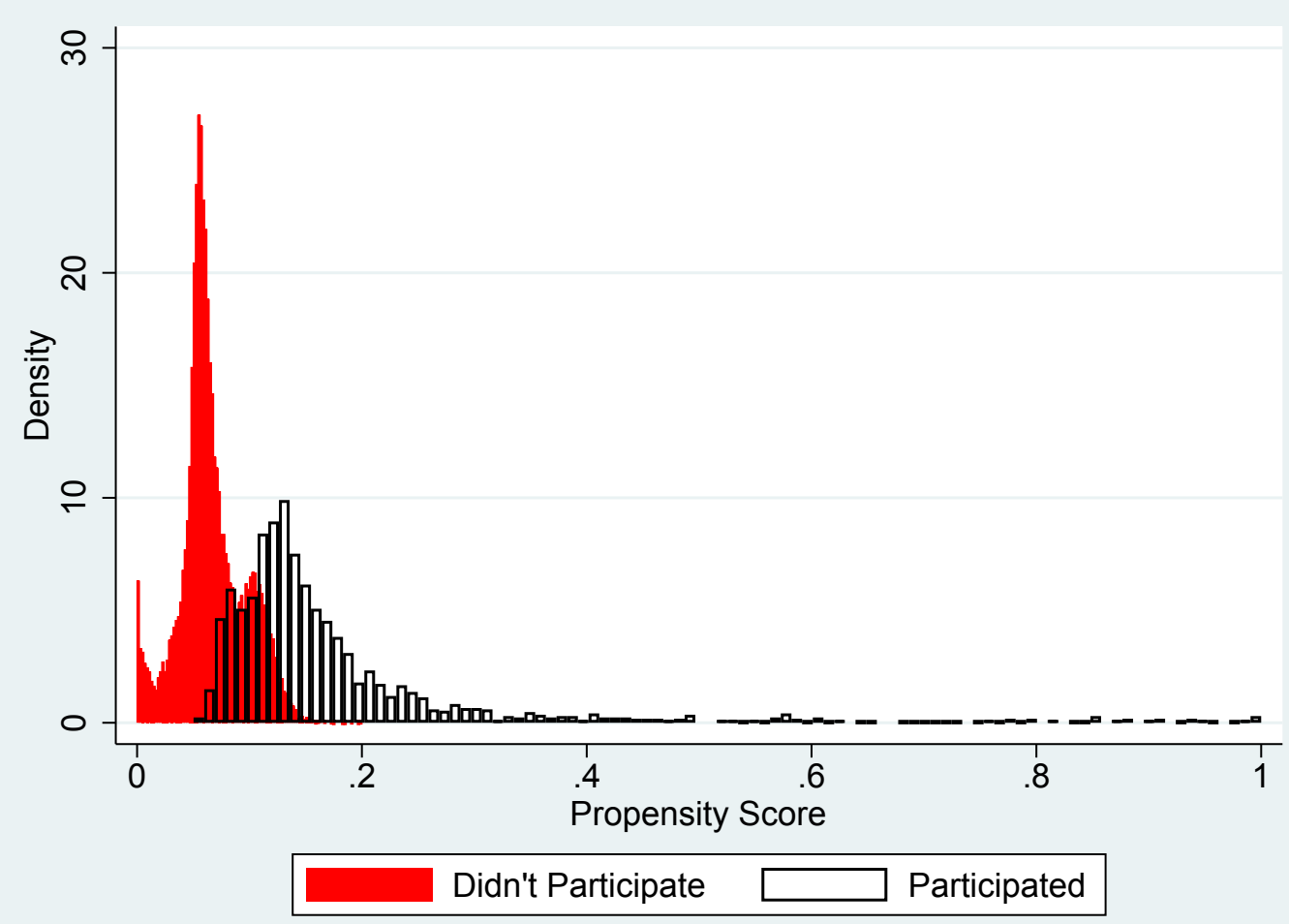


Figure 4: Average Hourly Energy Consumption (kWh per Hour)

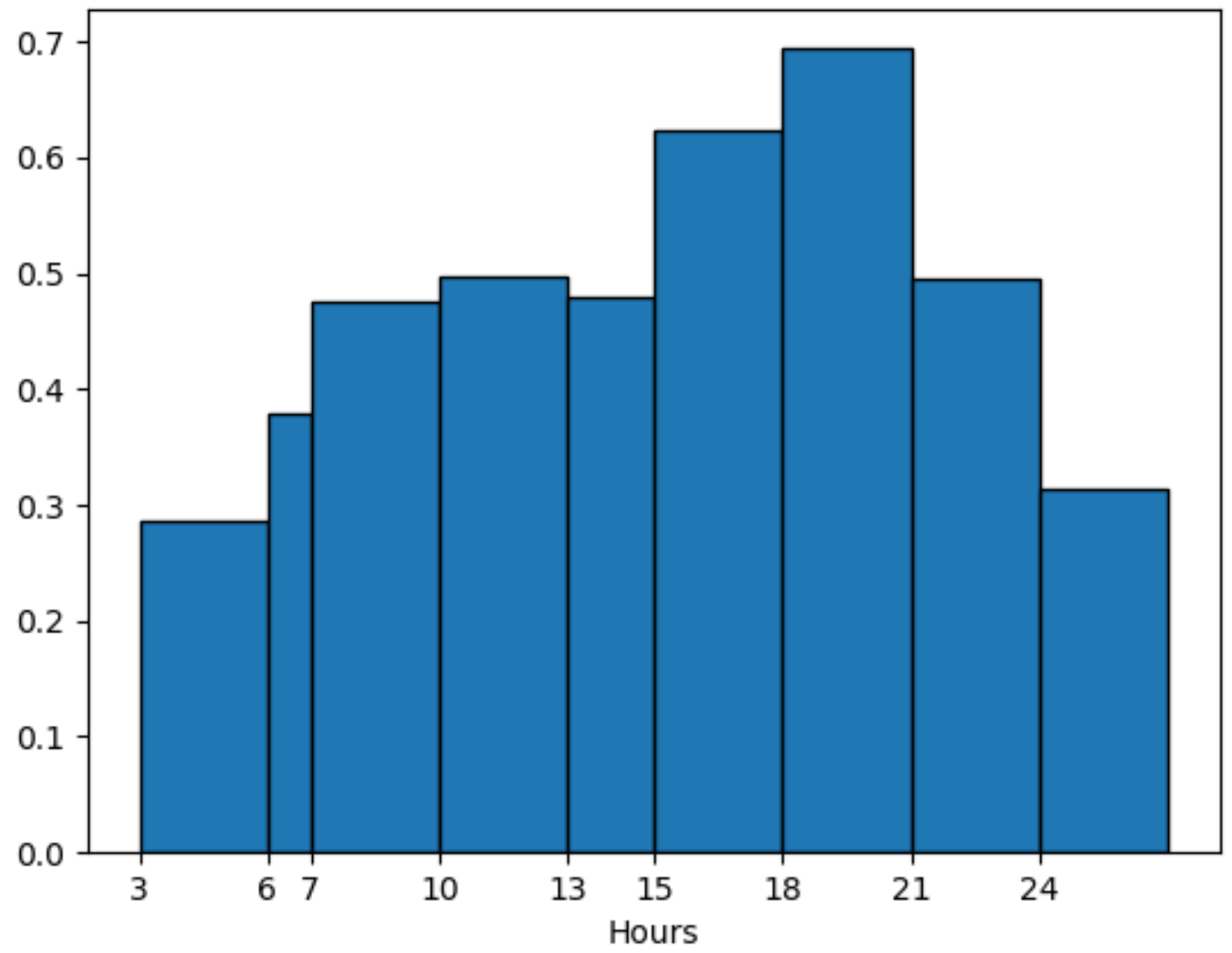

Figure 5: Net Impact using Coefficients from Table 3 (with censored selection) and a 5\% rebate

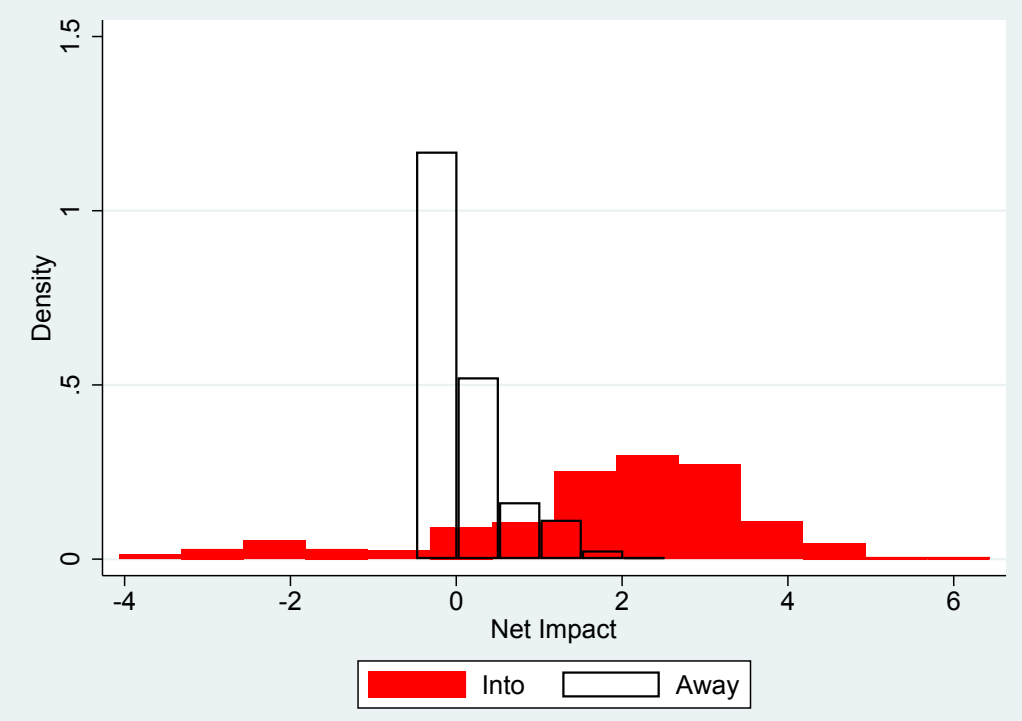


Figure 6: Net Impact using Coefficients from Table 3 (with censored selection) and a 20\% rebate

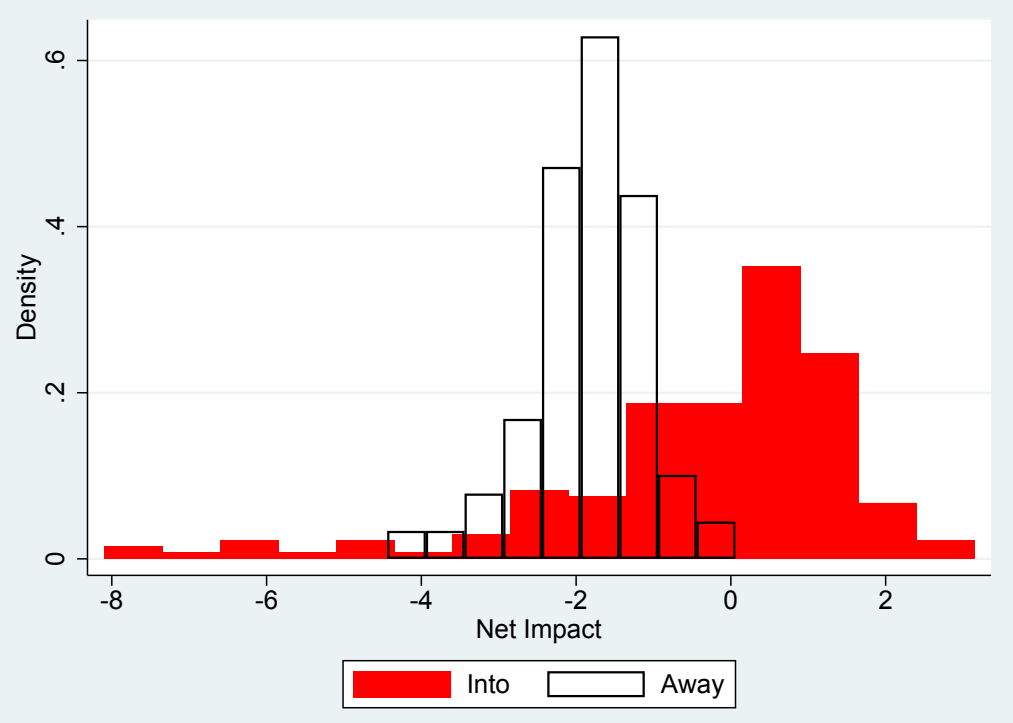

Figure 7: Net Impact using Coefficients from Table 3 (with censored selection) and a 50\% rebate

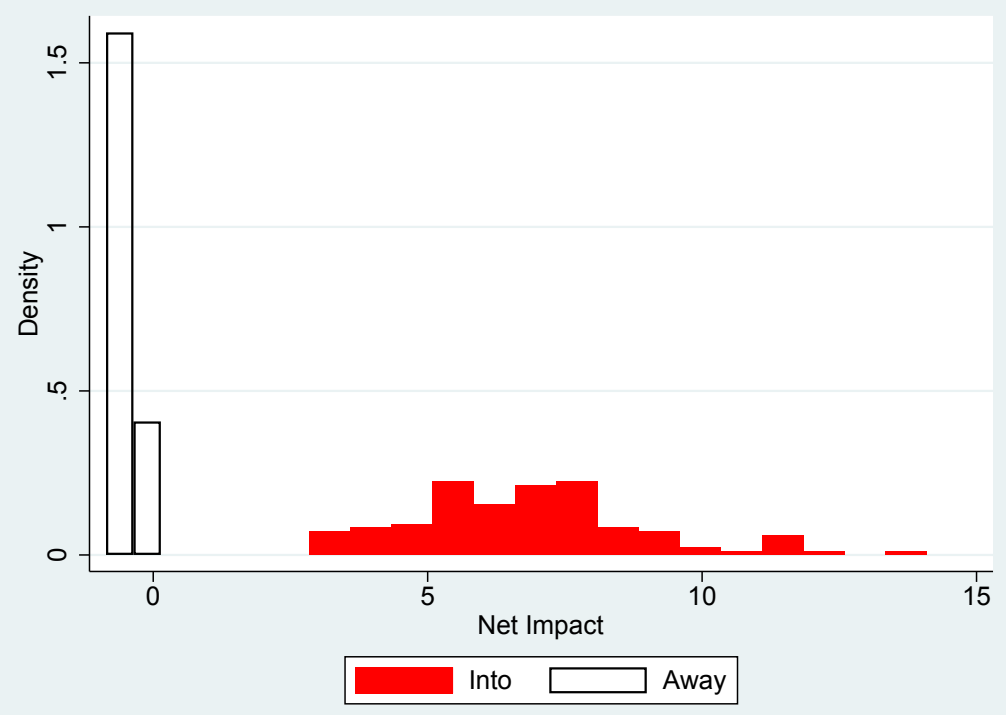


Figure 8: $\phi_{1}$ and $\psi_{1}$ using Coefficients from Table 3 (with censored selection) and a 5\% rebate

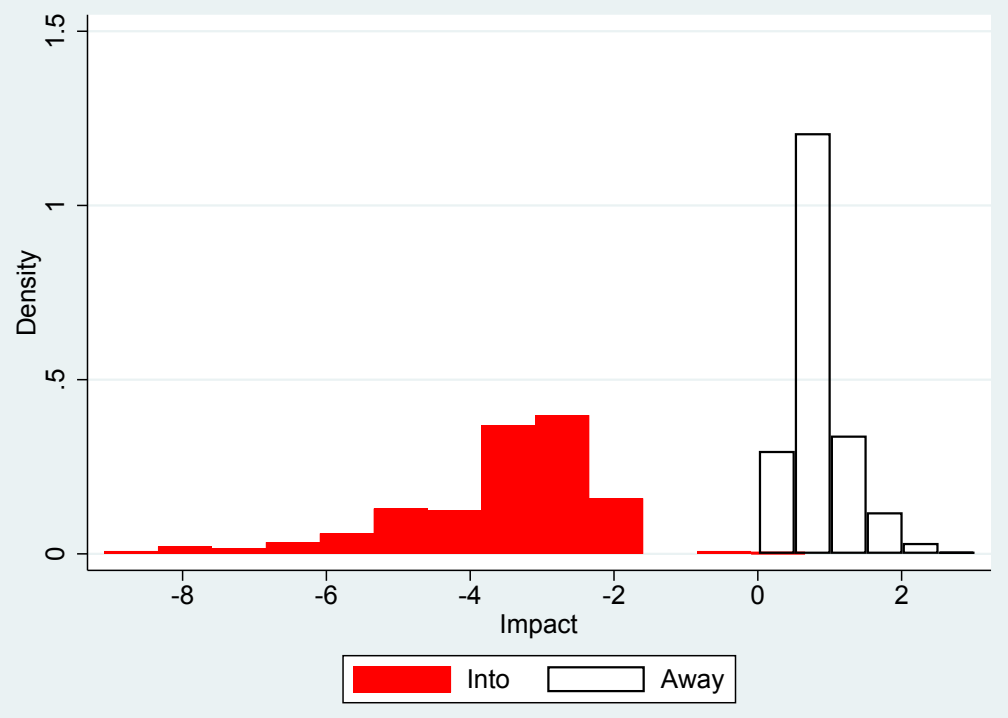

Figure 9: $\phi_{1}$ and $\psi_{1}$ using Coefficients from Table 3 (with censored selection) and a 20\% rebate

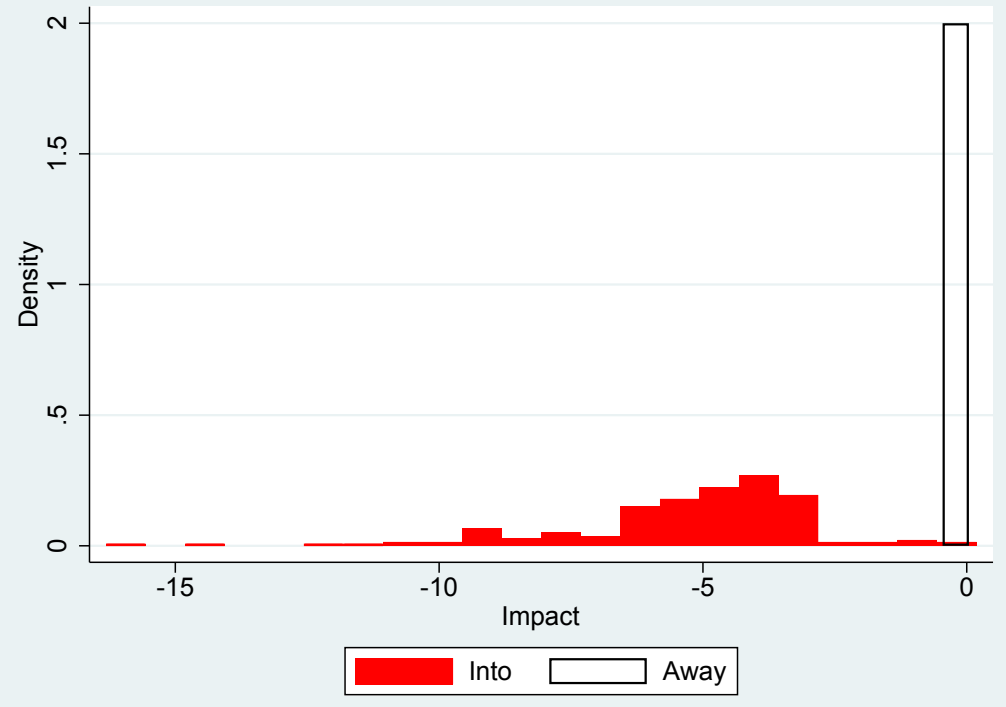


Figure 10: $\phi_{1}$ and $\psi_{1}$ using Coefficients from Table 3 (with censored selection) and a 50\% rebate

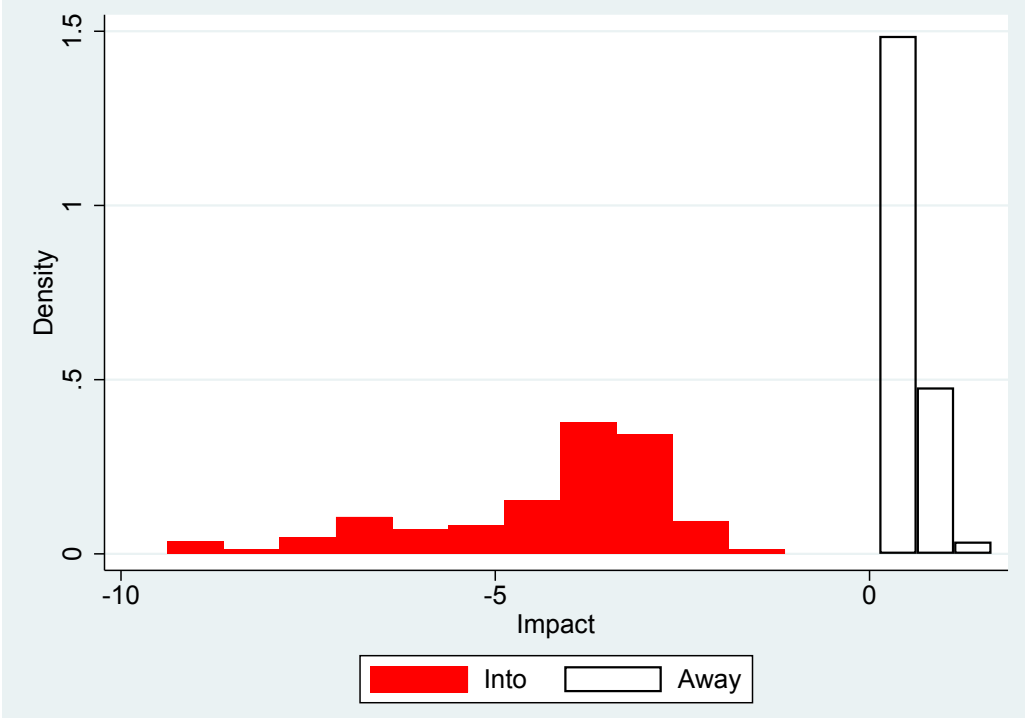

Figure 11: $\phi_{2}$ and $\psi_{2}$ using Coefficients from Table 3 (with censored selection) and a 5\% rebate

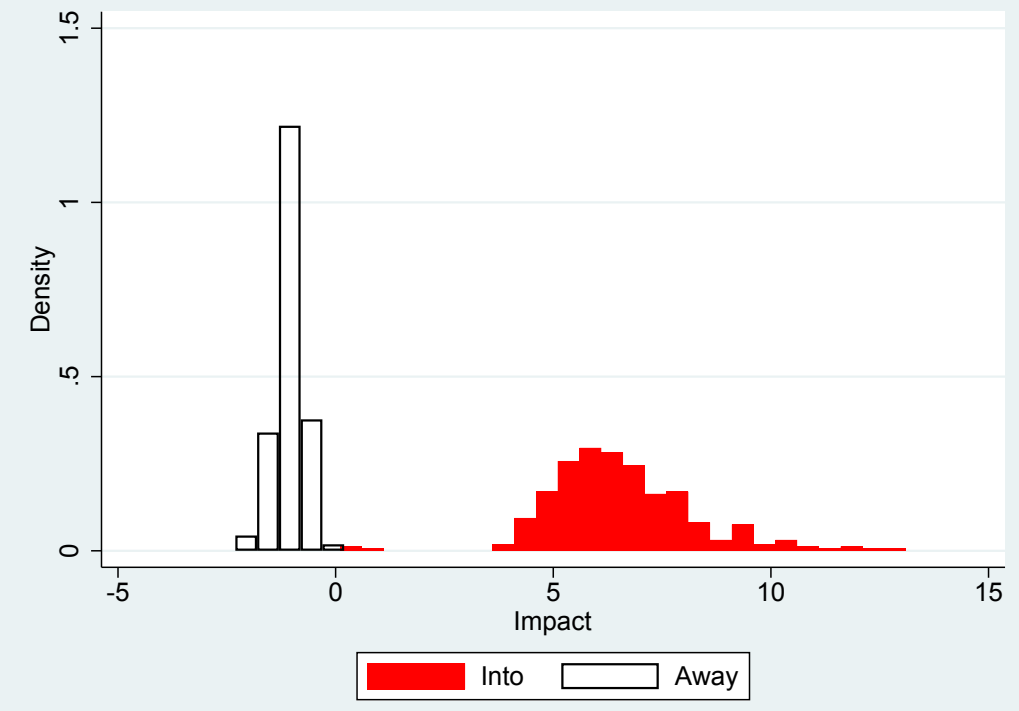


Figure 12: $\phi_{2}$ and $\psi_{2}$ using Coefficients from Table 3 (with censored selection) and a $20 \%$ rebate

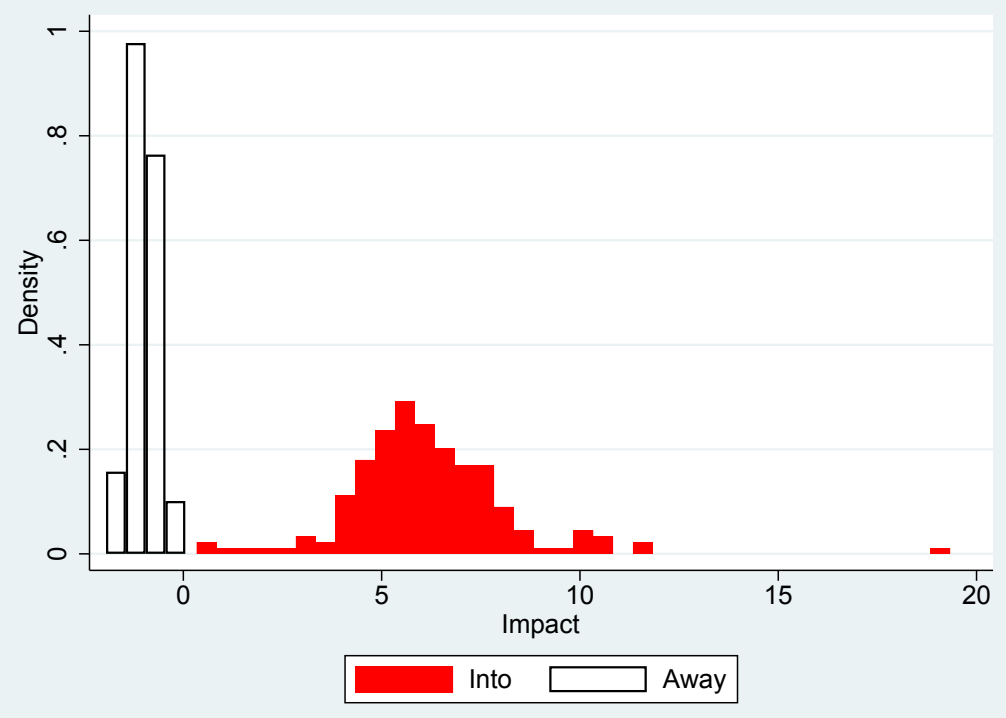

Figure 13: $\phi_{2}$ and $\psi_{2}$ using Coefficients from Table 3 (with censored selection) and a 50\% rebate

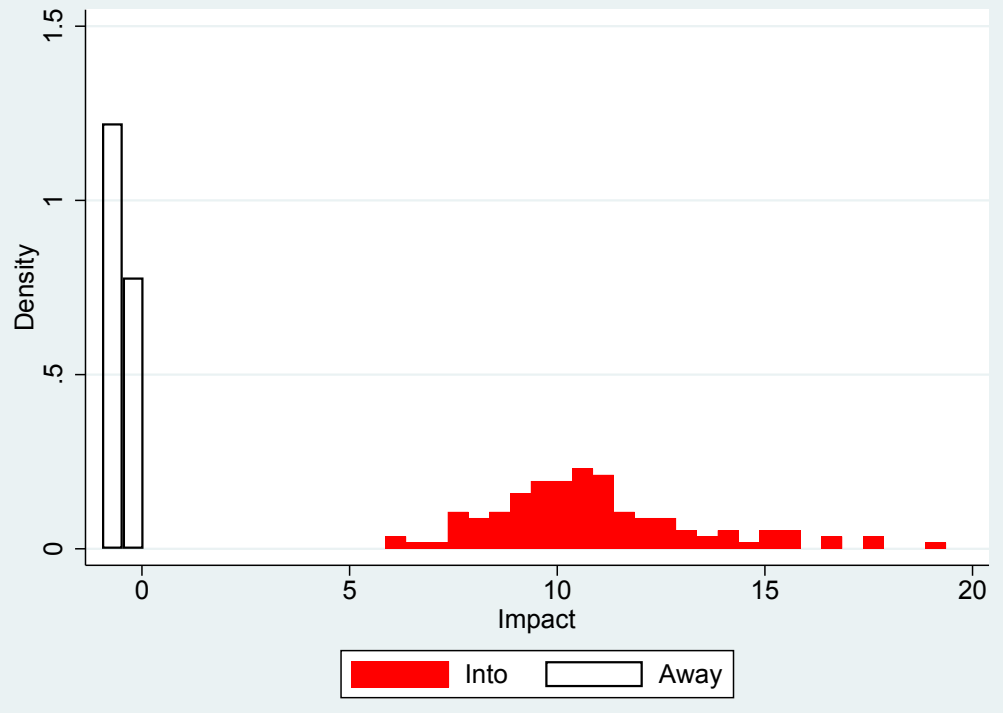


Figure 14: $\phi_{3}$ and $\psi_{3}$ using Coefficients from Table 3 (with censored selection) and a $5 \%$ rebate

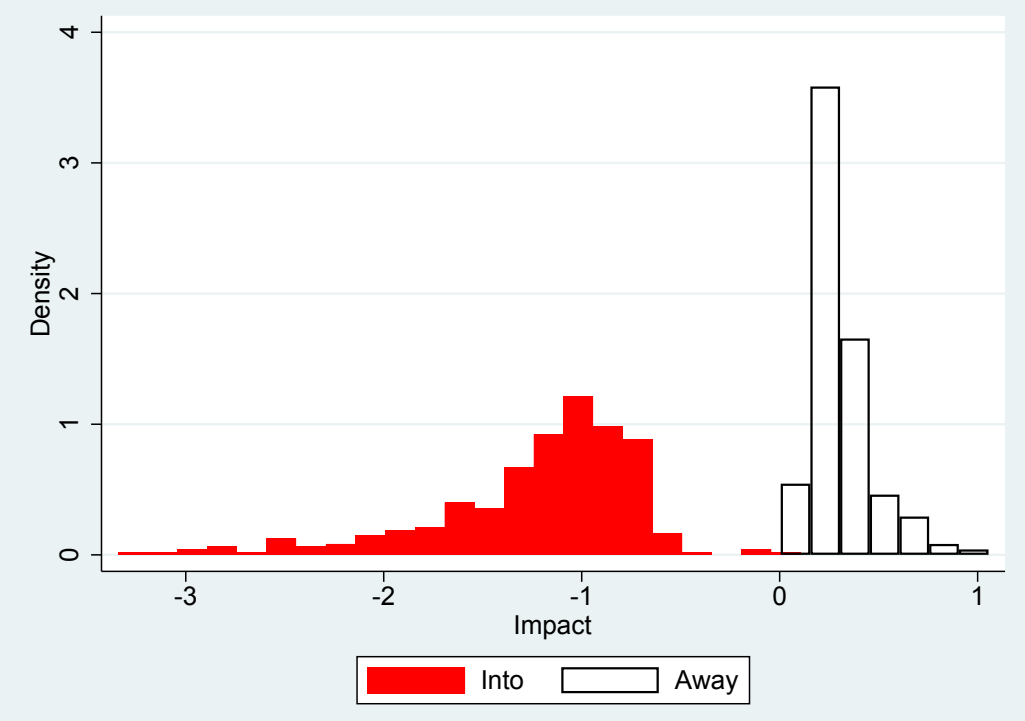

Figure 15: $\phi_{3}$ and $\psi_{3}$ using Coefficients from Table 3 (with censored selection) and a 20\% rebate

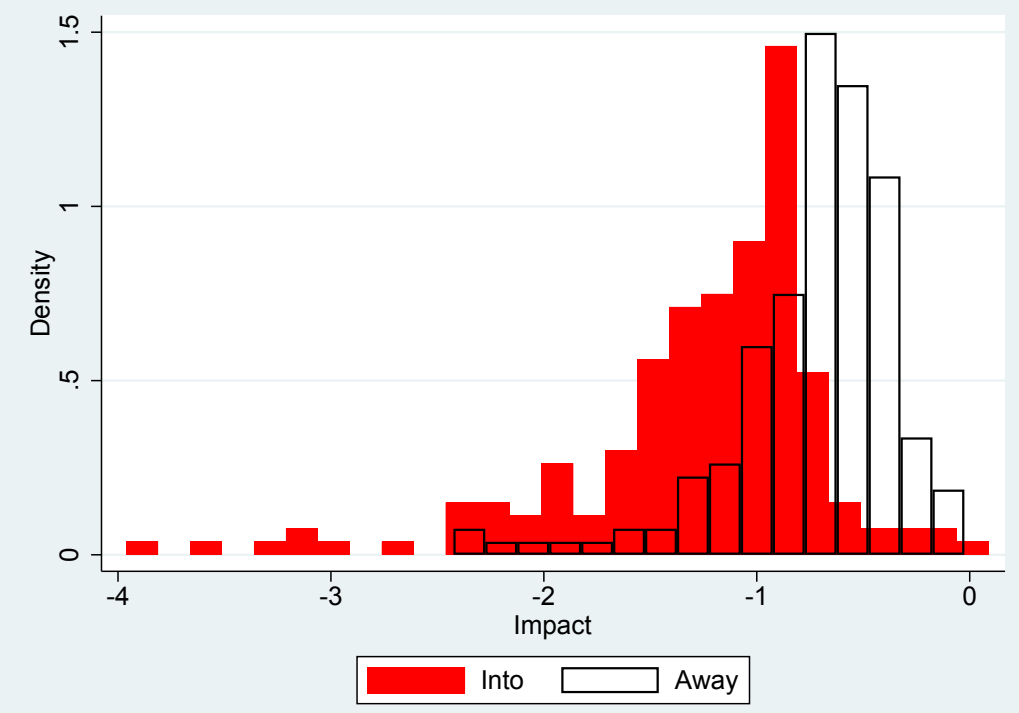


Figure 16: $\phi_{3}$ and $\psi_{3}$ using Coefficients from Table 3 (with censored selection) and a 50\% rebate

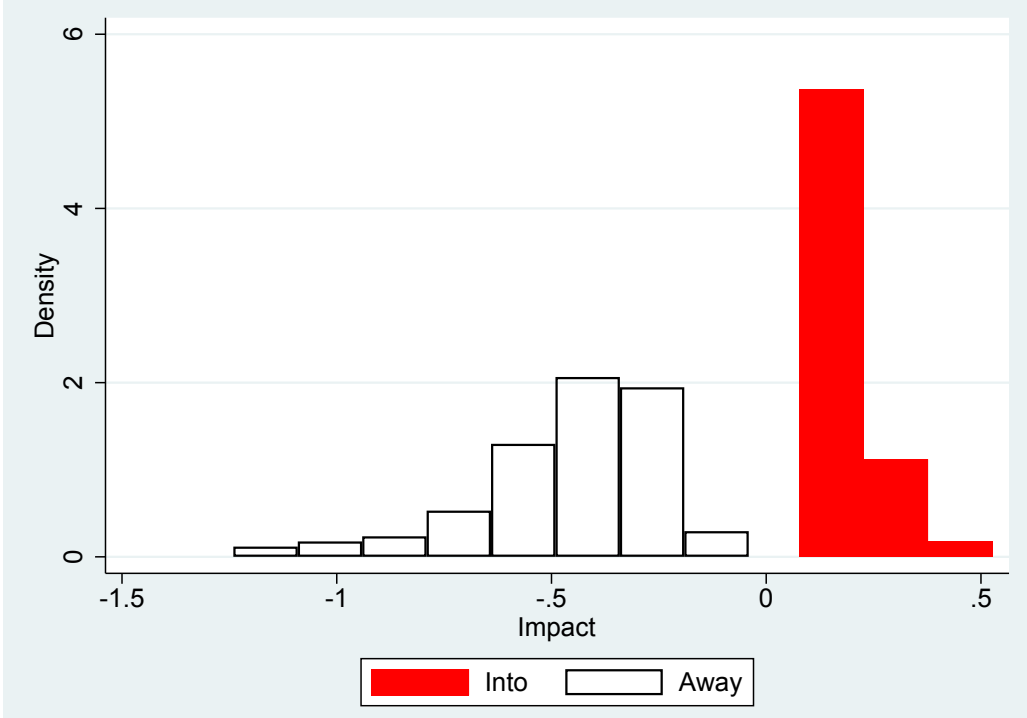

Figure 17: Daily Average Hourly Wholesale Energy Prices in SE's Zone in Nordpool in 2014 in Euros/MWh

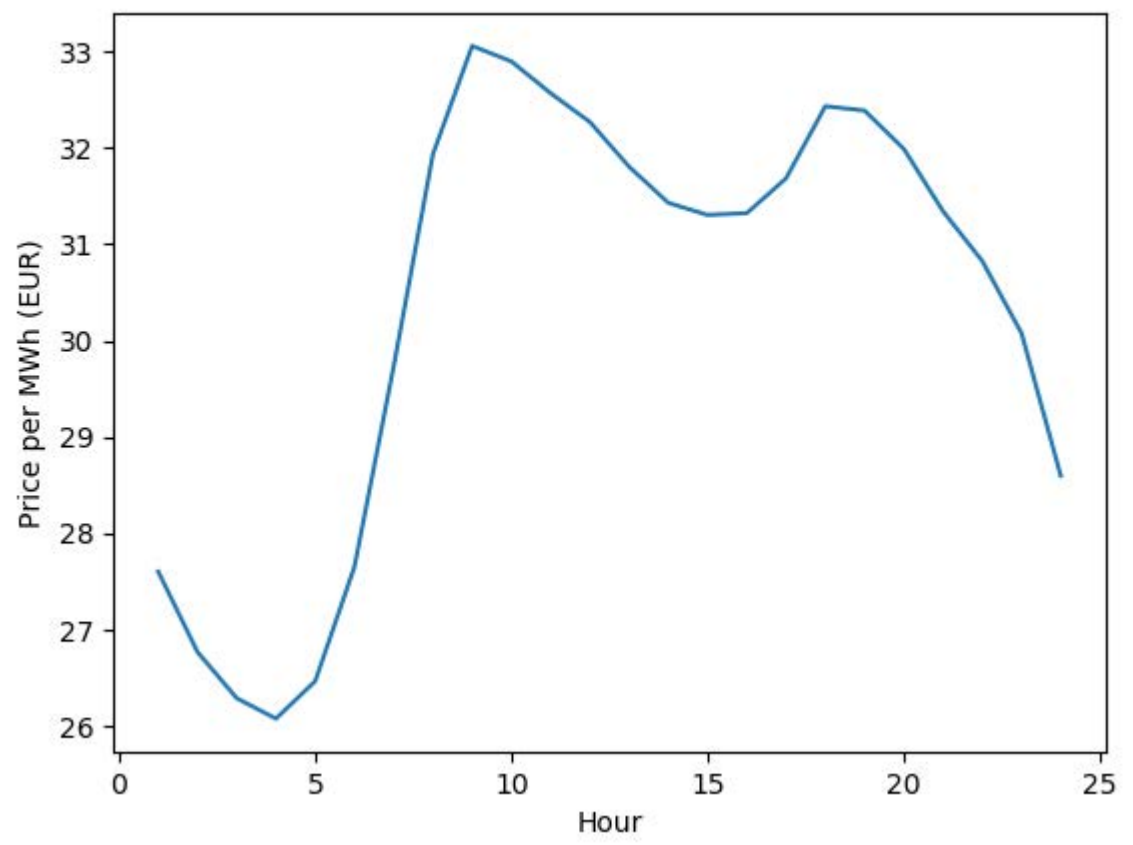


Figure 18(a): Into Rebate Pricing with Uncertain Demand

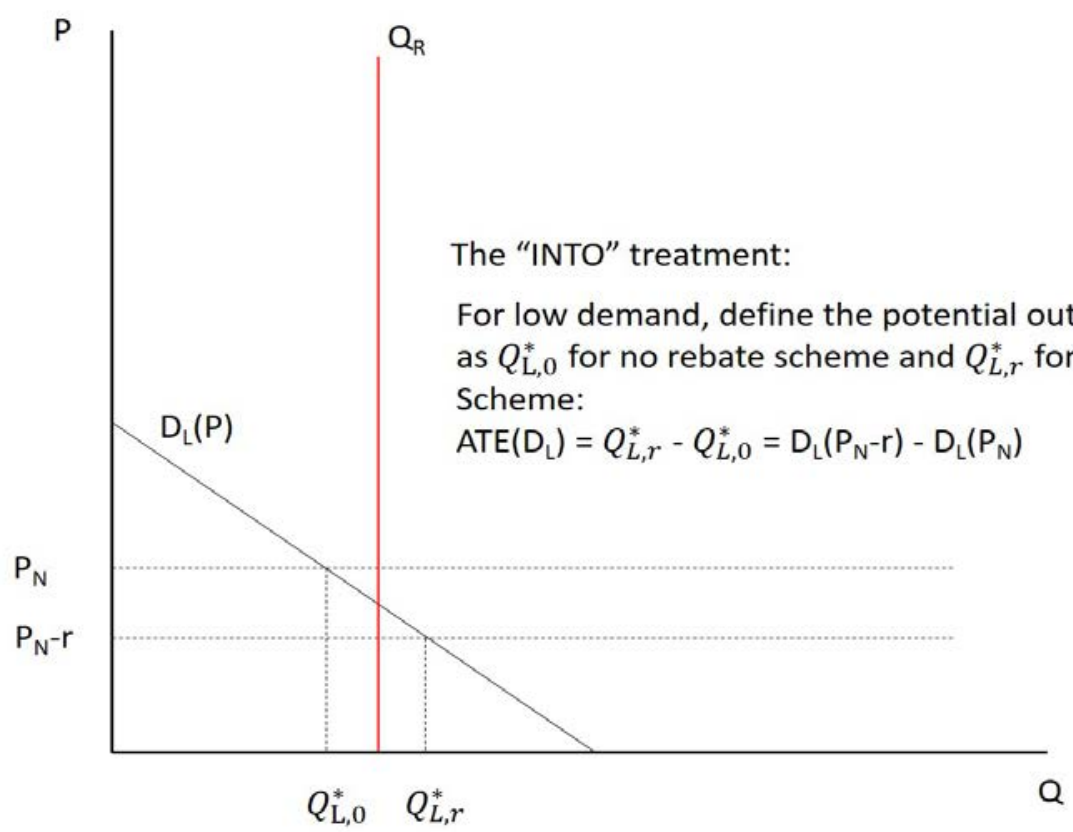

Figure 18(b): Into Rebate Pricing with Uncertain Demand

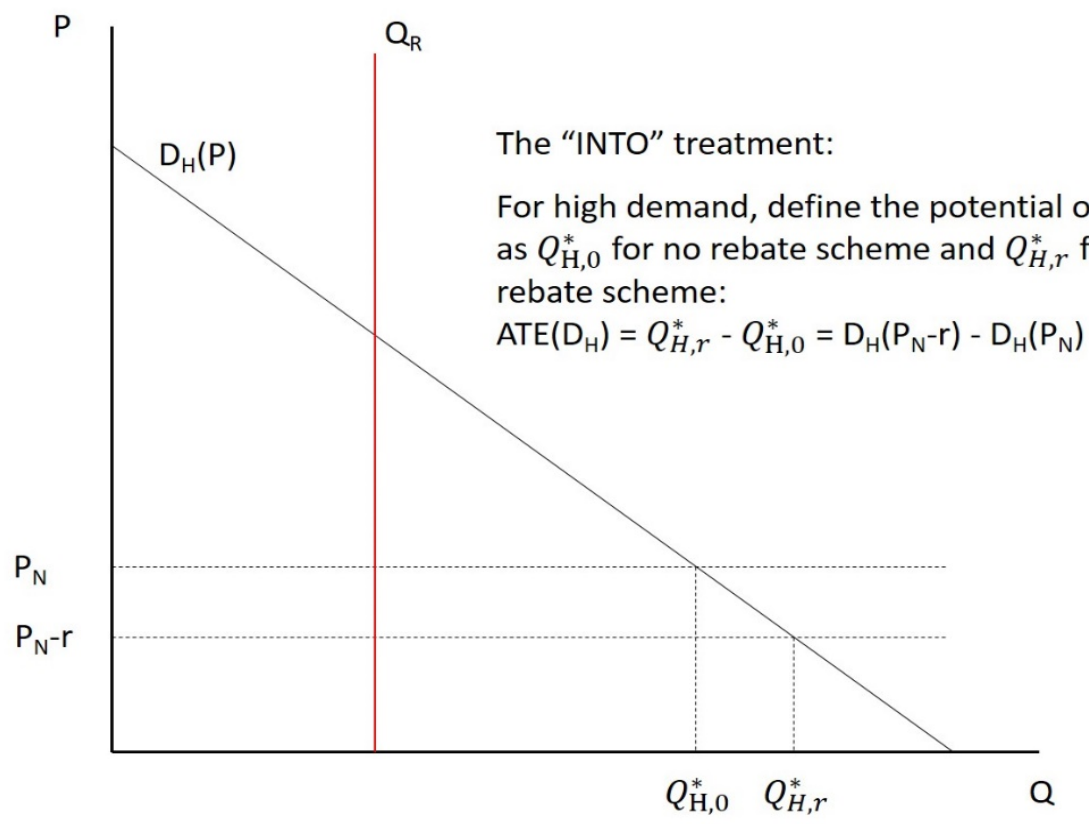


Figure 18(c): Into Rebate Pricing with Uncertain Demand

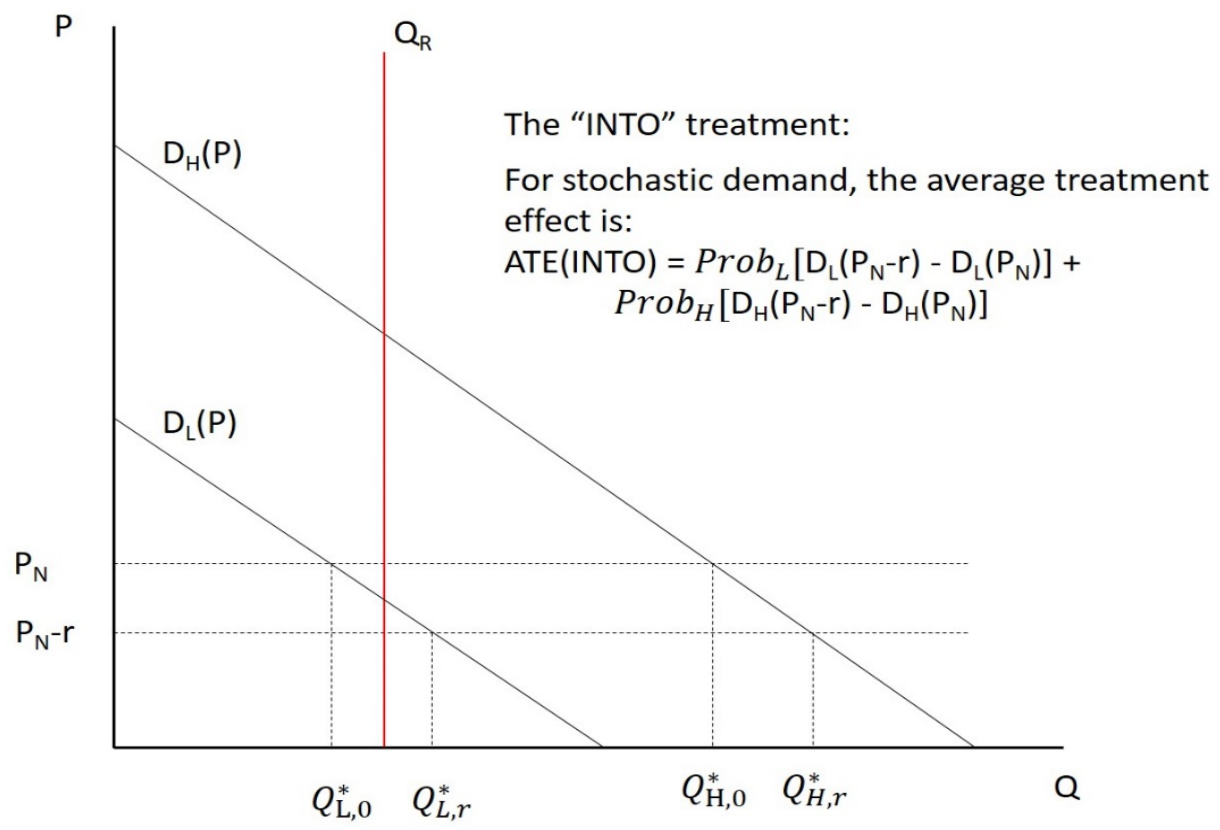

Figure 19(a): Away Rebate Pricing with Uncertain Demand

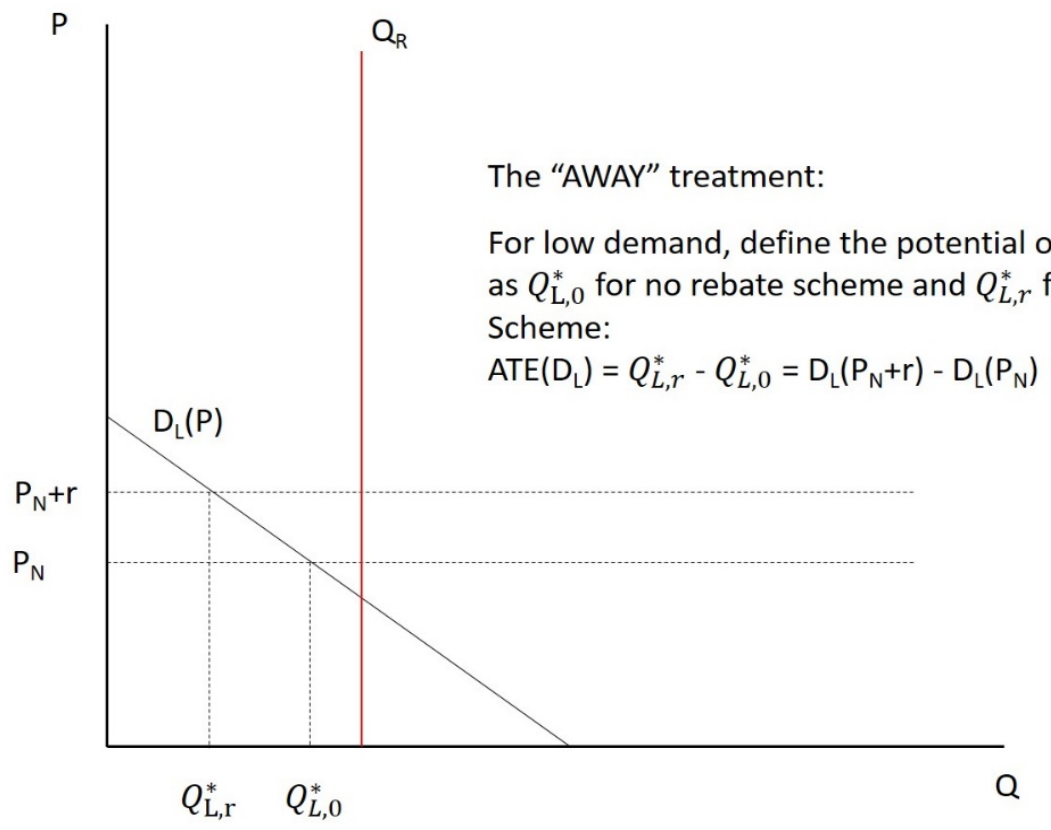


Figure 19(b): Into Rebate Pricing with Uncertain Demand

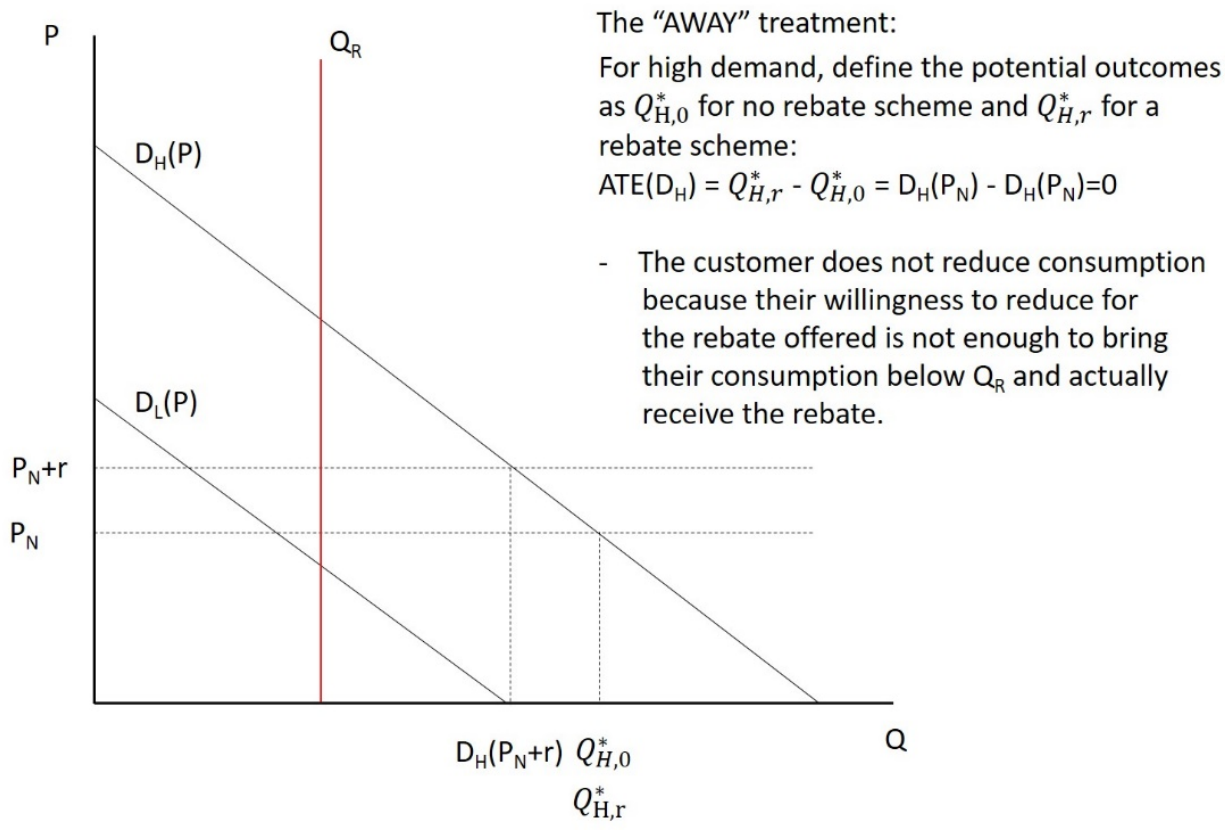

Figure 19(c): Into Rebate Pricing with Uncertain Demand

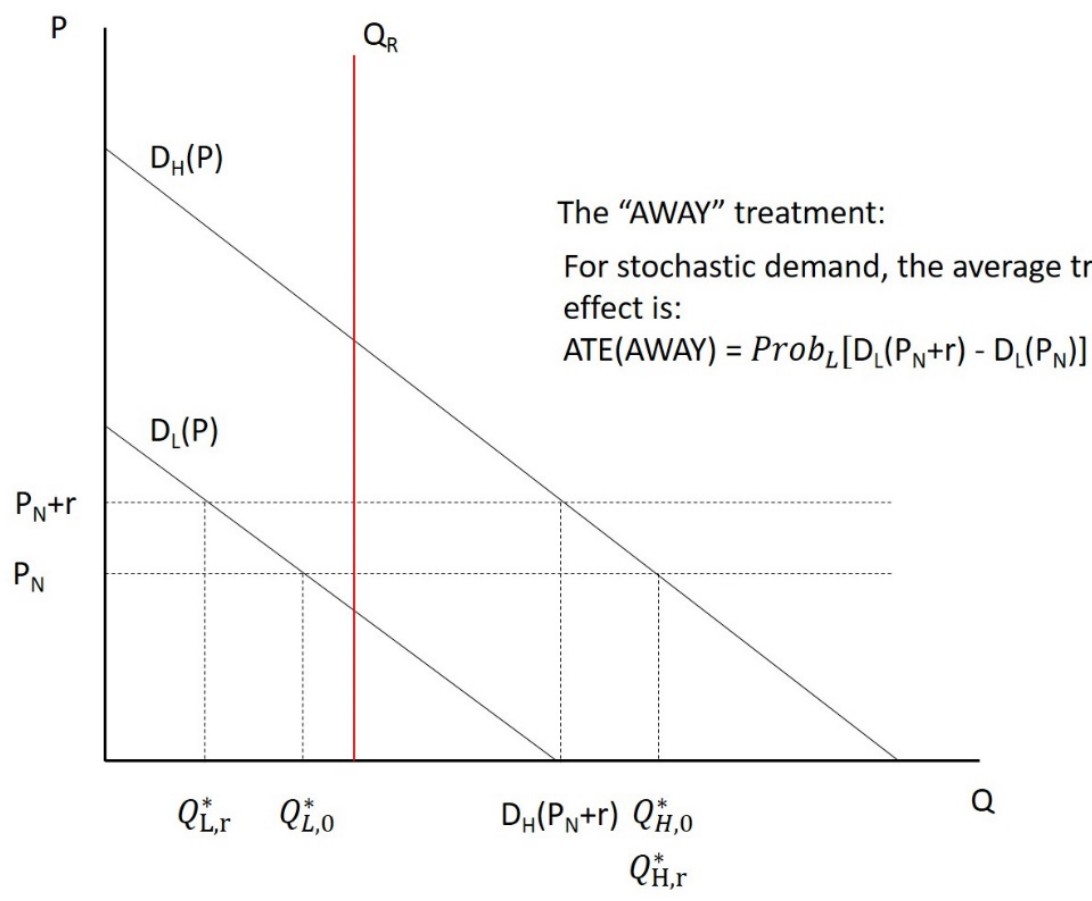


Figure 20(a): Comparison of Rebate Pricing with Uncertain Demand

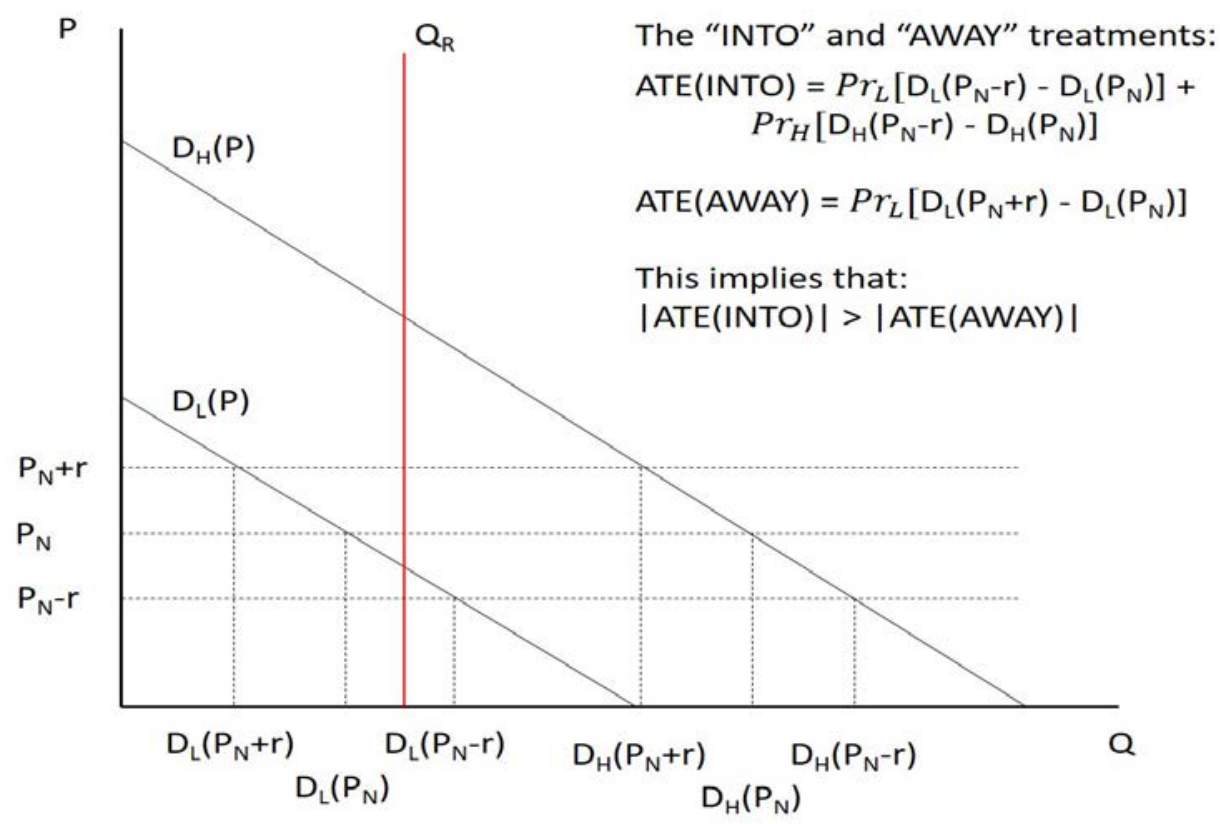

Figure 20(b): Comparison of Rebate Pricing with Uncertain Demand

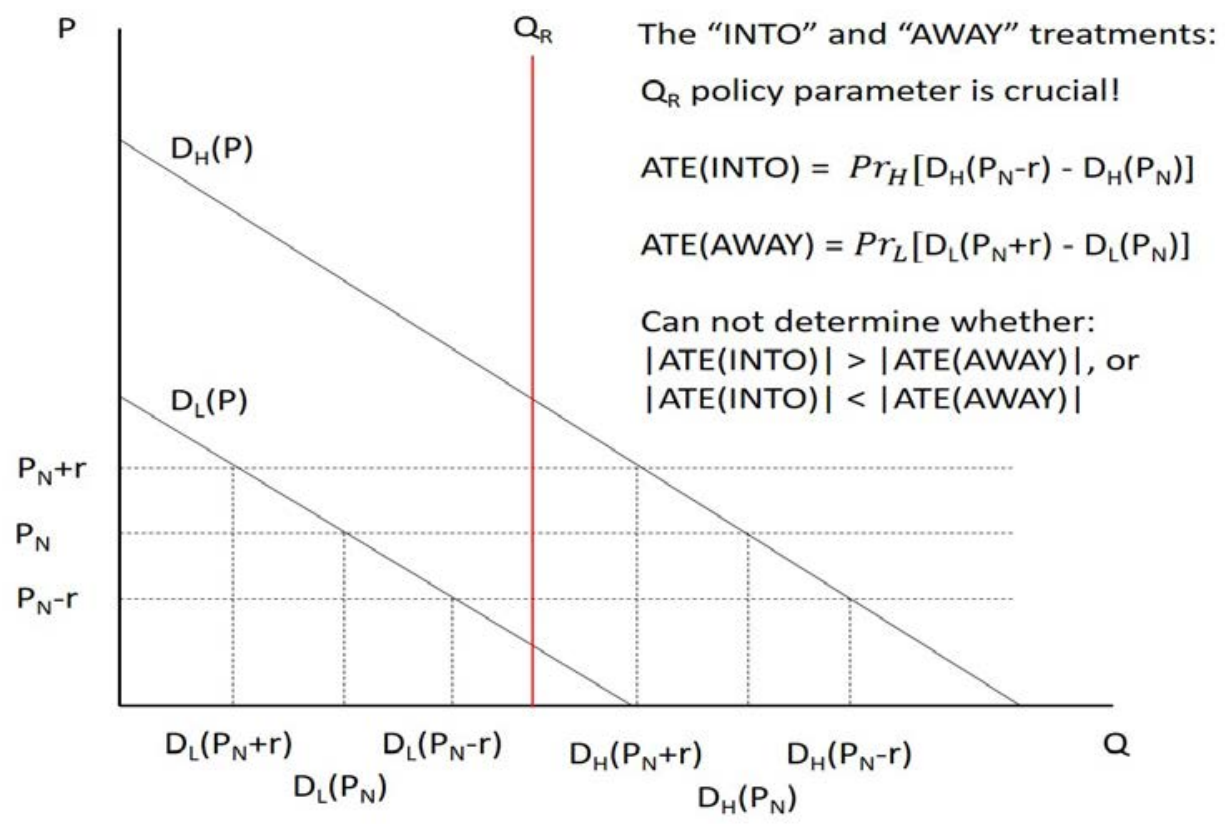




\section{Appendix A: Standard Errors}

We have the following asymptotically normal distribution for our selection-corrected estimates of $\Gamma$ :

$$
\sqrt{n}(\hat{\Gamma}-\Gamma) \stackrel{d}{\rightarrow} N\left(0, \Sigma_{x x}^{-1} \Omega_{x x}\left[\Sigma_{x x}^{-1}\right]^{\prime}\right)
$$

$\frac{1}{2} \hat{S}_{x x}$ consistently estimates $\Sigma_{x x}$, where $\hat{S}_{x x}=\frac{1}{9 D} \sum_{d=1}^{D} \sum_{t=1}^{9} \hat{S}_{x x}(t, d)$ and

$$
\hat{S}_{x x}(t, d)=\left(\begin{array}{c}
n_{t d} \\
2
\end{array}\right)^{-1} \sum_{i=1}^{n_{t}-1} \sum_{j=i+1}^{n_{t}} \hat{\omega}_{i j}\left(X_{i}(t, d)^{*}-X_{j}(t, d)^{*}\right)\left(X_{i}(t, d)^{*}-X_{j}(t, d)^{*}\right)^{\prime}
$$

where $n$ is the number of observations in the data, $n_{t d}$ is the number of observations in time period $t$ of day $d, X_{i}(t, d)^{*}$ is a vector of mean-differenced regressors for customer $i$ during time period $t$ of day $d$. We define $\hat{\omega}_{i j}$ as

$$
\hat{\omega}_{i j}=\frac{1}{h} k\left(\frac{\hat{g}_{i}-\hat{g}_{j}}{h}\right)
$$

where $k()$ is the Epanechnikov kernel defined earlier, $h$ is the bandwidth chosen as described earlier, and $\hat{g}_{i}$ the propensity score of individual $i$ (which does not vary with $t$ ).

An estimator of $\Omega_{x x}$ is $\hat{W}_{x x}=\frac{1}{9 D} \sum_{d=1}^{D} \sum_{t=1}^{9} \hat{W}_{x x}(t, d)$ :

$$
\hat{W}_{x x}(t, d)=\frac{1}{n_{t d}} \sum_{i=1}^{n_{t}}\left[\hat{\psi}_{i}(t, d)+\hat{\xi}_{i}(t, d) \hat{e}_{i}\right]\left[\hat{\psi}_{i}(t, d)+\hat{\xi}_{i}(t, d) \hat{e}_{i}\right]^{\prime}
$$

where

$$
\begin{gathered}
\hat{\psi}_{i}(t, d)=\frac{1}{n_{t}-1} \sum_{j=1}^{n_{t}} \hat{\omega}_{i j}\left(\hat{v}_{i}(t, d)-\hat{v}_{j}(t, d)\right)\left(X_{i}(t, d)^{*}-X_{j}(t, d)^{*}\right) \\
\hat{v}_{i}(t, d)=y_{i}(t, d)^{*}-X_{i}(t, d)^{* \prime} \hat{\Gamma} \\
\hat{e}_{i}=1-\hat{g}_{i} \\
\hat{\xi}_{i}(t, d)=\frac{1}{n_{t d}} \frac{1}{n_{t d}-1} \sum_{j=1}^{n_{t d}} \sum_{l=1}^{n_{t d}}\left[\left(\frac{1}{h}\right)^{2} k^{\prime}\left(\frac{\hat{g}_{i}-\hat{g}_{j}}{h}\right)\left(\hat{v}_{j}(t, d)-\hat{v}_{l}(t, d)\right)\left(X_{j}(t, d)^{*}-X_{l}(t, d)^{*}\right)\right]
\end{gathered}
$$

and $k^{\prime}(s)$ is the derivative of $k(s)$.

The matrix $\hat{W}_{x x}$ takes the following form if we are willing to allow arbitrary autocorrelation in the $v_{i}(t, d)$ over time periods and days and differences in this autocorrelation across customers. 


$$
\hat{W}_{x x}=\frac{1}{9 D} \frac{1}{n_{C}} \sum_{i=1}^{n_{C}}\left[\sum_{d=1}^{D} \sum_{t=1}^{9} \hat{\psi}_{i}(t)+\hat{\xi}_{i}(t) \hat{e}_{i}\right]\left[\sum_{d=1}^{d} \sum_{t=1}^{9} \hat{\psi}_{i}(t)+\hat{\xi}_{i}(t) \hat{e}_{i}\right]^{\prime}
$$

Where $n_{C}$ is the number of distinct individuals. These results imply that the approximately normal distribution of $\hat{\beta}$ is $N\left(\beta, \frac{\Sigma_{z x}^{-1} \Omega_{z z}\left[\Sigma_{z x}^{-1}\right]^{\prime}}{n}\right)$. 
Appendix B-1. Definitions of Invitation and Customers and Home Demographic Variables

\begin{tabular}{ll}
\hline $\begin{array}{l}\text { Invitation variables, see } \\
\text { Summary Stats in Table 9 } \\
\text { Second wave }\end{array}$ & $\begin{array}{l}\text { Description } \\
\text { The invitations were issued in two waves, one on } 14 \\
\text { April 2015, and one on 23 April } \\
\text { The consumer is only offered GHG-free energy } \\
\text { investments, corresponding to the amount of energy } \\
\text { moved in accordance with the text messages } \\
\text { The consumer is offered a 5\% rebate on the amount of } \\
\text { energy moved in accordance with the text messages } \\
\text { The consumer is offered a 20\% rebate on the amount } \\
\text { of energy moved in accordance with the text messages } \\
\text { The consumer is offered a 50\% rebate on the amount } \\
\text { of energy moved in accordance with the text messages } \\
\text { Before the actual invitation, the consumer received a }\end{array}$ \\
Foot In The Door with price motivation \\
50\% rebate & $\begin{array}{l}\text { Fefore the actual invitation, the consumer received a } \\
\text { Foot in the Door with Price }\end{array}$ \\
Motive & $\begin{array}{l}\text { In the invitation, the consumer is offered a device } \\
\text { Fhich can switch the consumers refrigerator off - and } \\
\text { Motive }\end{array}$ \\
Offered device & $\begin{array}{l}\text { back on - so that it automatically follows the text } \\
\text { messages }\end{array}$
\end{tabular}

Demographics and Home
Variables, see Summary
Stats in Table 10
\# of men $21+$ in house
\# of women $21+$ in house
\# of kids 15-20
\# of kids 7-14
\# of kids 0-6

Household disposable income $^{a)}$

Income $<0$

Income $\in[\mathrm{X}, \mathrm{Y})$

Income $\in[550,000, \max ]$

\# of Retired in $\mathrm{HH}$
The invitations were issued in two waves, one on 14 April 2015, and one on 23 April investments, corresponding to the amount of energy moved in accordance with the text messages energy moved in accordance with the text messages The consumer is offered a 20\% rebate on the amount of energy moved in accordance with the text messages The consumer is offered a 50\% rebate on the amount of energy moved in accordance with the text messages Foot In The Door with price motivation

Before the actual invitation, the consumer received a Foot In The Door with environmental motivation In the invitation, the consumer is offered a device which can switch the consumers refrigerator off - and messages

Number of men 21 years or older in the household Number of women 21 years or older in the household Number of children 15-20 years old in the household Number of children 7-14 years old in the household Number of children 6 years or younger in the household

Sum of all persons disposable income in the house, DKK/50,000 using 50,000 DKK as unit

Disposable income less than 0

Disposable income greater than or equal to X DKK, Dummy 0/1 and lower than Y DKK

Greater than or equal to $550,000 \mathrm{DKK}$, and lower than or equal to the highest amount which is $7,892,076$ DKK

Number of Early retirees or National pensioners in the Integer household
Dummy 0/1

Dummy 0/1

Unit

$0=14$ April

$1=23$ April

Dummy 0/1

Dummy 0/1

Dummy 0/1

Dummy 0/1

Dummy 0/1

Dummy 0/1

Dummy 0/1

integer

Integer

Integer

Integer

Integer 


\begin{tabular}{|c|c|c|}
\hline & Description & Unit \\
\hline \# of High-skill employees & $\begin{array}{l}\text { Number of Top Leaders in Companies, Organizations } \\
\text { and the Public Sector or Employees in work requiring } \\
\text { skills at the highest level }\end{array}$ & Integer \\
\hline \# of Mid-skill employees & Employee in work requiring intermediate level skills & Integer \\
\hline \# of low-skill employees & Employee in work requiring basic level skills & Integer \\
\hline HH state scholarship funds & $\begin{array}{l}\text { Total amount of state scholarships within the } \\
\text { household using } 50,000 \text { DKK as unit }\end{array}$ & $\mathrm{DKK} / 50,000$ \\
\hline $\mathrm{HH}$ pension income & $\begin{array}{l}\text { Sum of all National and early retirement pension, } \\
\text { and other pensions in the using } 50,000 \text { DKK as unit } \\
\text { household }\end{array}$ & $\mathrm{DKK} / 50,000$ \\
\hline Married couple in $\mathrm{HH}$ & At least one married couple in the household & Dummy 0/1 \\
\hline \# of immigrants in $\mathrm{HH}$ & $\begin{array}{l}\text { Number of persons in household with reported origin } \\
\text { outside Denmark }\end{array}$ & Integer \\
\hline HH unemployed & $\begin{array}{l}\text { Dummy indicating if ALL members of the household } \\
\text { are either unemployed at least half of the year, } \\
\text { retired or beneficiaries of sickness benefits, education } \\
\text { allowances, etc. }\end{array}$ & \\
\hline * Single Family Home & House on single plot of land & Dummy 0/1 \\
\hline Farmhouse & House for living, related to agricultural property & Dummy 0/1 \\
\hline Terraced or double house & $\begin{array}{l}\text { Terraced or Double house, single family houses } \\
\text { sharing a wall }\end{array}$ & Dummy 0/1 \\
\hline Storey building & Storey building, combination of flats & Dummy 0/1 \\
\hline other type of building & None of the above types of buildings & Dummy 0/1 \\
\hline \# of rooms & Number of rooms in the home & Integer \\
\hline Total area of home & & Square meter \\
\hline Construction Year & & Integer \\
\hline District heating & & Dummy 0/1 \\
\hline Central heating & & Dummy 0/1 \\
\hline Electric oven & & Dummy 0/1 \\
\hline Heating pump & & Dummy 0/1 \\
\hline Other heating & & Dummy 0/1 \\
\hline Individual Owns Home & Home owner, as opposed to renting the home & Dummy 0/1 \\
\hline
\end{tabular}

a) Not part of the estimation, only descriptive table. 
Appendix B-2. E-mail invitation offering rebates of either 5\%, $20 \%$ or $50 \%$ to customers Read the newsletter on the Internet

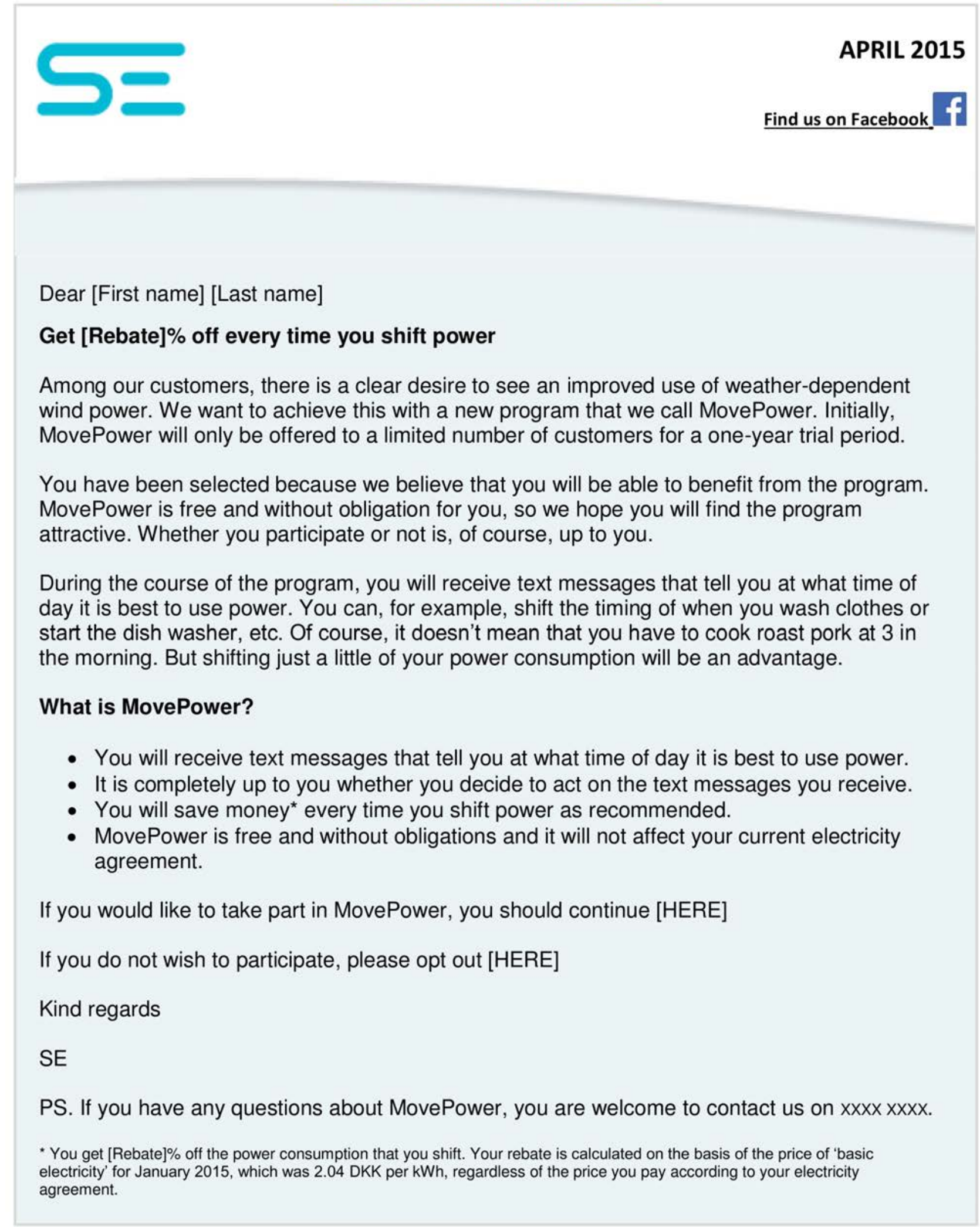




\title{
Appendix B-3. E-mail invitation offering GHG-free production to costumers in group
}

\author{
$31,34,35$ and 36
}

\section{Read the newsletter on the Internet}

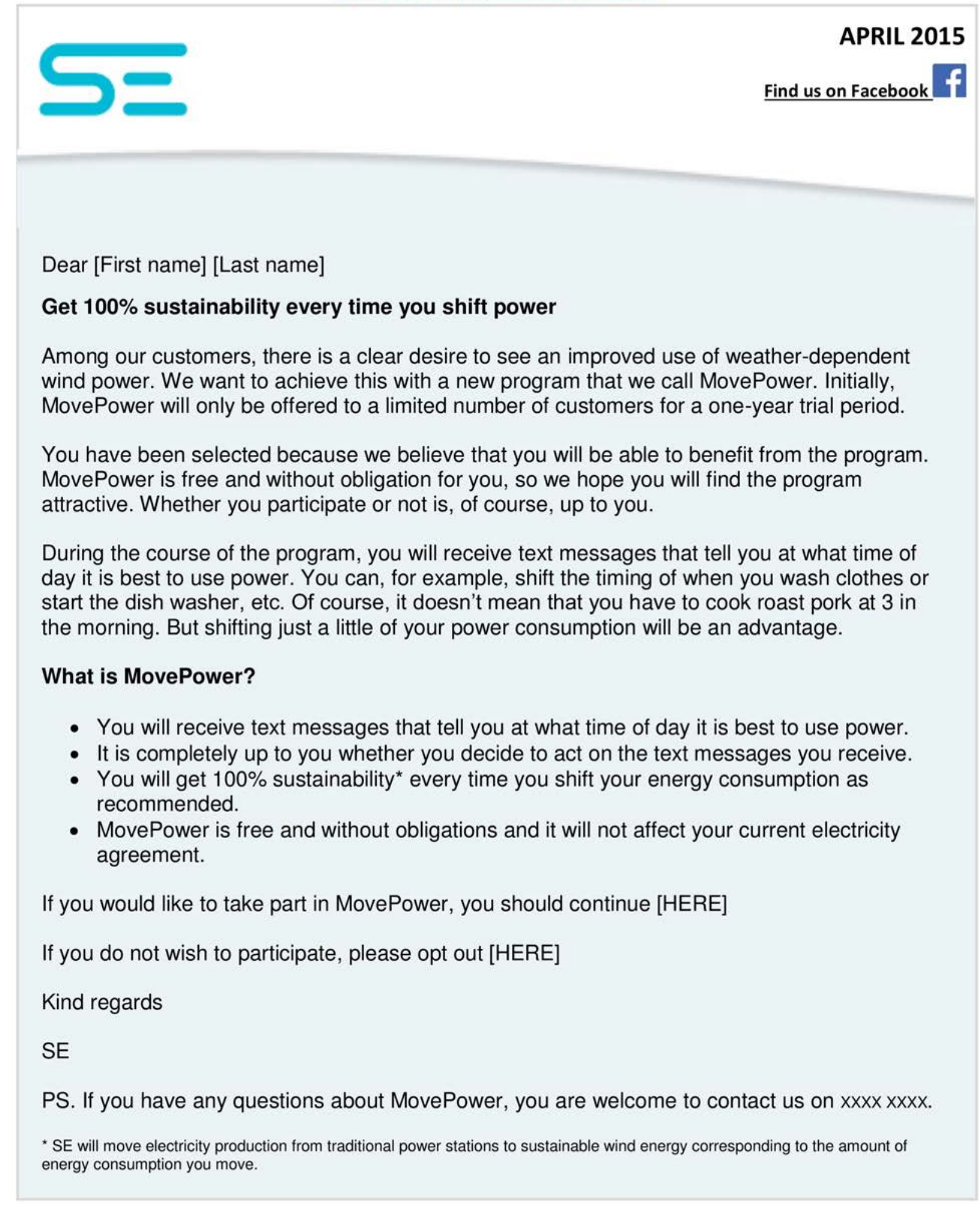




\title{
Appendix B-4. Supplementary information provided after accepting rebate invitations:
}

Terms of conditions to customers offered rebate (identical for all rebate levels.)

\author{
https://www.se.dk/vilkaar1501
}

\section{MovePower terms and conditions}

\author{
These are the terms and conditions of MovePower:
}

- During the course of the week, you will receive text messages that specify at what time of the day it is best to use electricity.

- If you decide to shift some of your electricity consumption in line with the recommendations in the text messages, you will earn the percentage rebate stated in the text message for every $\mathrm{kWh}$ you shift. The rebate will be at least the rate you were promised in the MovePower offer. The rebate is calculated as a percentage of the list price for 'Base electricity' from January 2015 (2.04 DKK per $\mathrm{kWh}$ ) regardless of the rate you pay based on your electricity contract. In this way, you'll save money.

- Whether you decide to shift some of your electricity consumption as recommended in the text messages is up to you.

- In order to give you an overview, every month, you will receive a message with details of how much electricity consumption you have shifted in line with the suggestions in the text messages.

- Initially, MovePower will involve a limited number of customers for a one-year trial period. You will receive a message when the scheme starts and when the trial period is over.

- If you have earned a rebate, you will receive the money once the one-year trial period has ended.

- The MovePower program only applies to one address (where you live on a daily basis). If you move address during the one-year trial period, you will automatically leave MovePower and the rebate you have earned will be null and void.

- MovePower is conducted in collaboration with Copenhagen University. Carsten Jensen is responsible for the data. The aim is to investigate whether private households can play a role in the utilisation of weather-dependent wind energy. The project has been reported to the Danish Data Protection Agency in line with the Personal Data Protection Act. The Danish Data Protection Agency has established terms and conditions for the project in order to protect the participants' privacy. Participation in MovePower is voluntary. Consent to participate in MovePower can be withdrawn at any time.

If you would like to know more about how you can shift your electricity consumption, you can visit: www.se.dk/FlytStroem 


\title{
Appendix B-5. Supplementary information provided after accepting GHG-free invitations: \\ Terms of conditions for costumers offered GHG-free production (group 35 and 36). *)
}

\author{
https://www.se.dk/vilkaar1503
}

\section{MovePower terms and conditions}

\author{
These are the terms and conditions of MovePower:
}

- During the course of the week, you will receive text messages that specify at what time of the day it is best to use electricity.

- If you decide to shift some of your electricity consumption in line with the recommendations in the text messages, the power you move will become $100 \%$ sustainable as specified in the text messages. Therefore, you will ensure $100 \%$ sustainability for every kWh you shift is. Sustainability will be ensured by SE shifting the electricity production from traditional power stations to sustainable wind turbines corresponding to the amount of electricity you shift. In this way you will help reduce the environmental impact.

- Whether you decide to shift some of your electricity consumption as recommended in the text messages is up to you.

- In order to give you an overview, every month, you will receive a message with details of how much electricity consumption you have shifted in line with the suggestions in the text messages.

- Initially, MovePower will involve a limited number of customers for a one-year trial period. You will receive a message when the scheme starts and when the trial period is over.

- If you help to shift power, SE will increase the wind turbine capacity corresponding to the total amount of power you have shifted during the one-year trial period.

- The MovePower program only applies to one address (where you live on a daily basis). If you move address during the one-year trial period, you will automatically leave MovePower and the rebate you have earned will be null and void.

- MovePower is conducted in collaboration with Copenhagen University. Carsten Jensen is responsible for the data. The aim is to investigate whether private households can play a role in the utilisation of weather-dependent wind energy. The project has been reported to the Danish Data Protection Agency in line with the Personal Data Protection Act. The Danish Data Protection Agency has established terms and conditions for the project in order to protect the participants' privacy. Participation in MovePower is voluntary. Consent to participate in MovePower can be withdrawn at any time.

If you would like to know more about how you can shift your electricity consumption, you can visit: www.se.dk/FlytStroem

*) In the terms of conditions for the group 35 and 36, it was not implied that the costumers were part of a team effort, which is in contrast to group 31 and 34 where this was implied. 


\title{
Appendix B-6. Supplementary information provided after accepting GHG-free invitations: Terms of conditions for costumers offered GHG free production (group 31 and 34*)
}

\author{
https://www.se.dk/vilkaar1504
}

\section{MovePower terms and conditions}

\author{
These are the terms and conditions of MovePower:
}

- You are a member of a MovePower team with others who are like you. You and the others on your team will receive text messages that specify at what time of the day it is best to use electricity.

- If you and your team decide to shift some of your electricity consumption in line with the recommendations in the text messages, the power you shift will be $100 \%$ sustainable as specified in the text messages. Therefore, you and your team will ensure that every kWh you shift will be $100 \%$ sustainable. Sustainability will be ensured as SE will shift electricity production from traditional power stations to sustainable wind turbines corresponding to the amount of electricity you shift. In this way, you will help to reduce the environmental impact.

- Whether you decide to shift some of your electricity consumption as recommended in the text messages is up to you.

- In order to give you an overview, every month, you and your team will receive a message with details of how much electricity consumption you have shifted in line with the suggestions in the text messages.

- Initially, MovePower will involve a limited number of customers for a one-year trial period. You will receive a message when the scheme starts and when the trial period is over.

- If you and your team help to shift power, SE will increase the wind turbine capacity corresponding to the total amount of power you have shifted during the one-year trial period.

- The MovePower program only applies to one address (where you live on a daily basis). If you move address during the one-year trial period, you will automatically leave MovePower and the rebate you have earned will be null and void.

- MovePower is conducted in collaboration with Copenhagen University. Carsten Jensen is responsible for the data. The aim is to investigate whether private households can play a role in the utilisation of weather-dependent wind energy. The project has been reported to the Danish Data Protection Agency in line with the Personal Data Protection Act. The Danish Data Protection Agency has established terms and conditions for the project in order to protect the participants' privacy. Participation in MovePower is voluntary. Consent to participate in MovePower can be withdrawn at any time.

If you would like to know more about how you can shift your electricity consumption, you can visit: www.se.dk/FlytStroem

*) It the terms of conditions for the group 31 and 34 it was implied that the costumers were part of a team effort, which is in contrast to group 35 and 36 where this was not implied. 


\section{Appendix C. Text Message Variations.}

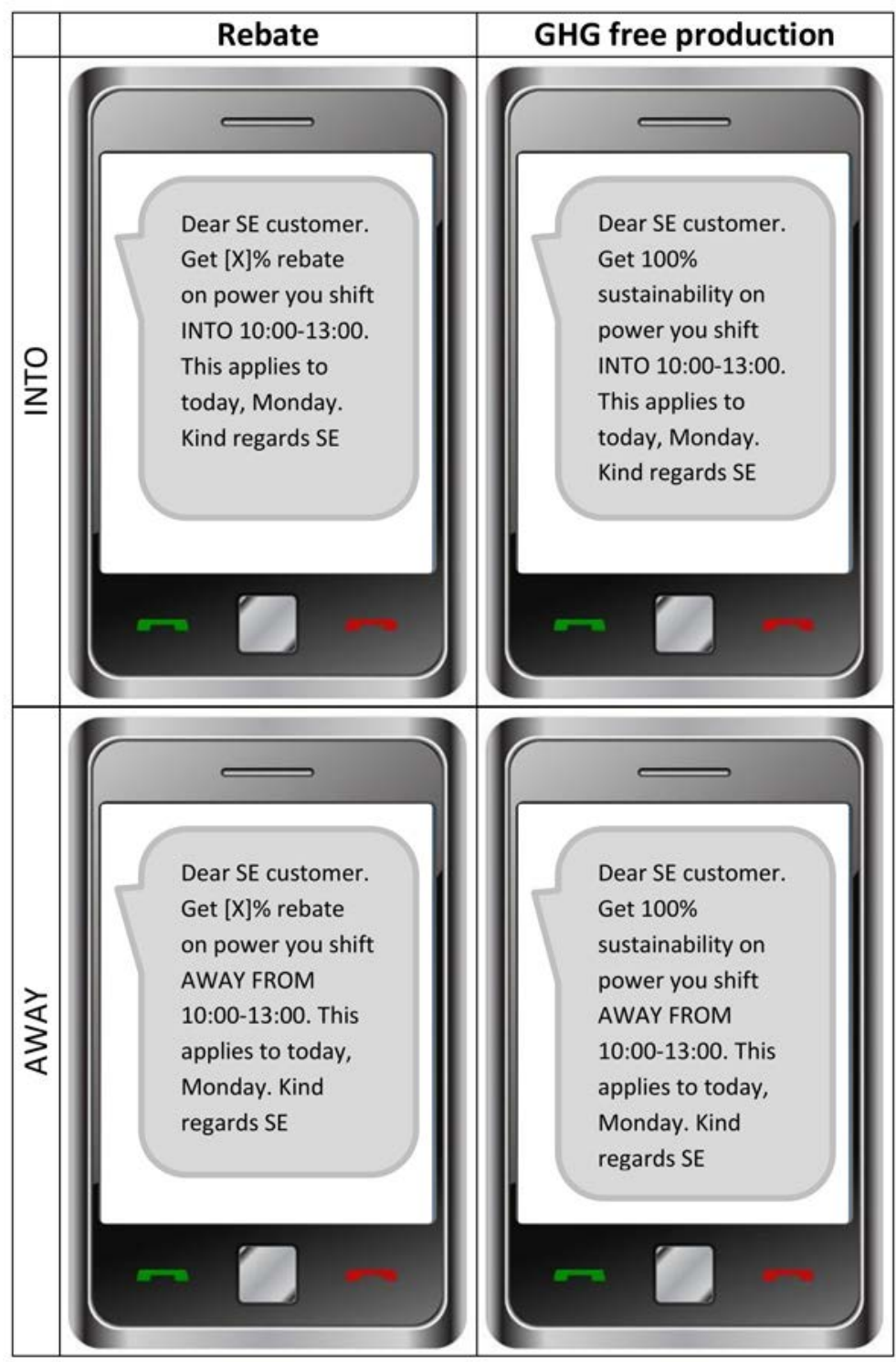

[X]: Treatment rebate groups 5\%, $20 \%$ and $50 \%$.

Treatment hours varied across time slots ( 10 am to $1 \mathrm{pm} ; 3 \mathrm{pm}$ to $6 \mathrm{pm} ; 6 \mathrm{pm}$ to $9 \mathrm{pm} ; 9 \mathrm{pm}$ to $24 \mathrm{pm}$, and 12 am to $3 \mathrm{pm})$.

Treatment day variations (Monday, Tuesday, Wednesday Thursday Friday, Saturday and Sunday)

The text messages to the GHG groups $(31,34,35$ and 36$)$ are identical. 


\section{Appendix D. An example of the monthly e-mail feedback}

\section{Page 1:}

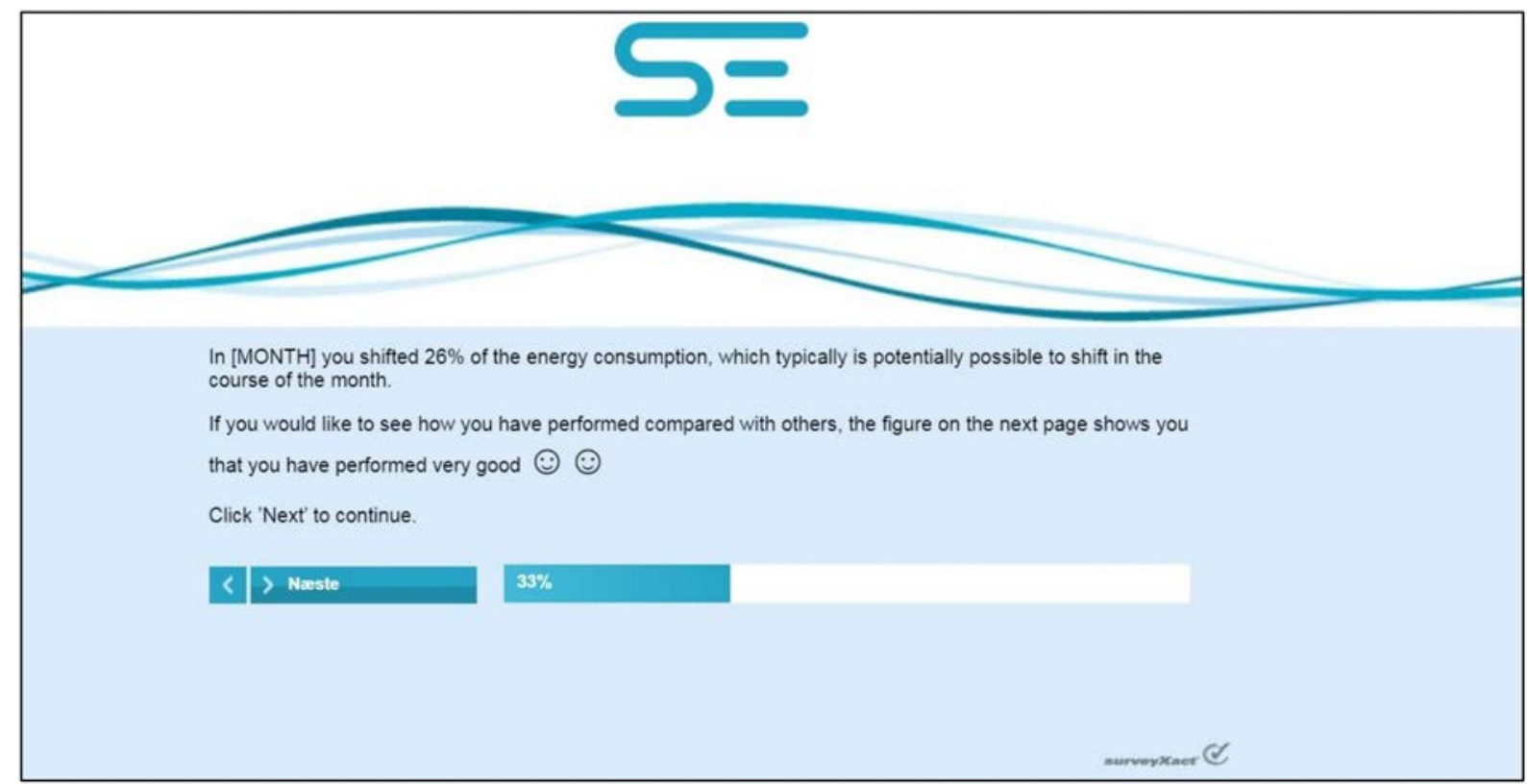

Page 2:

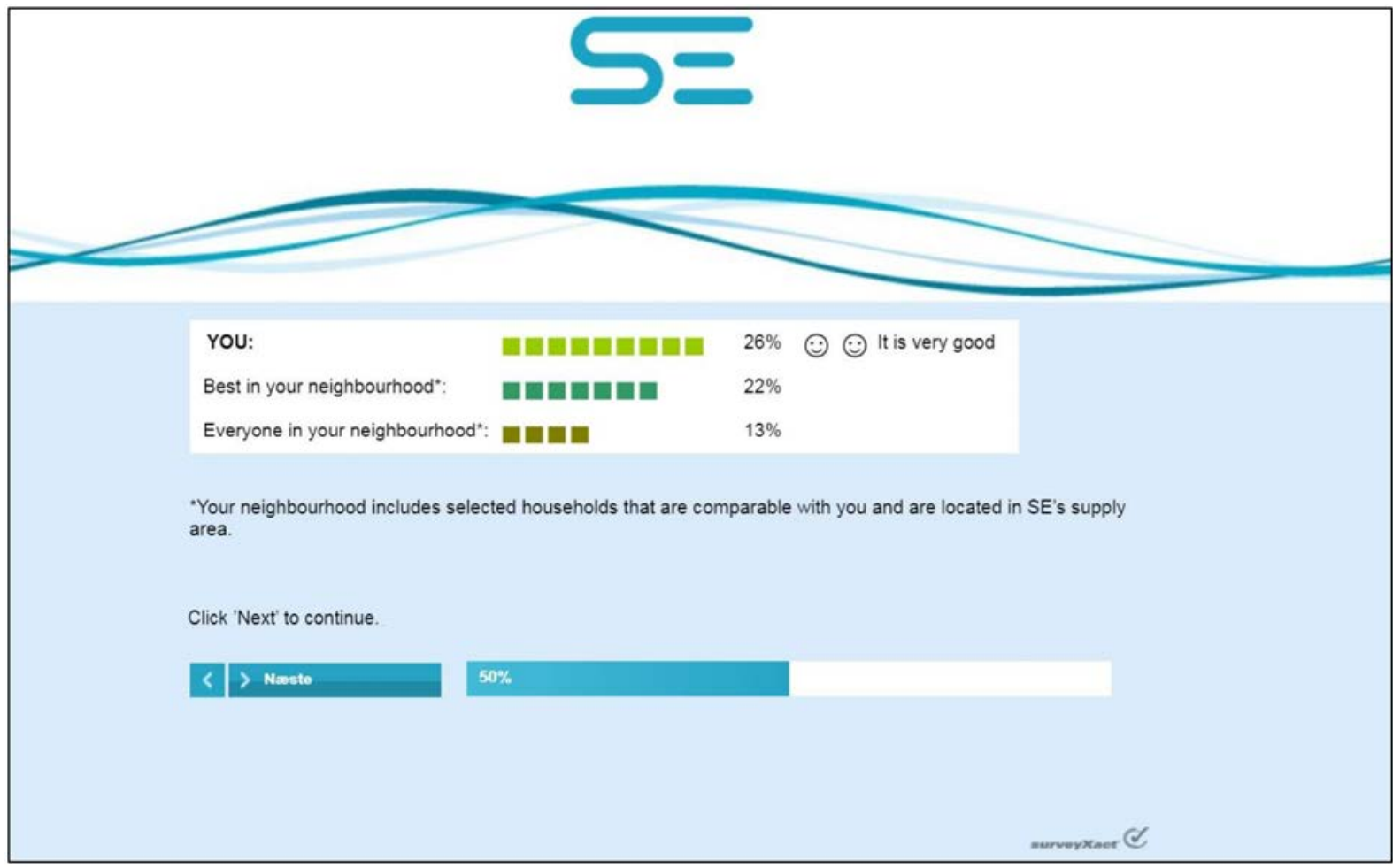

